\title{
¿CATÁSTROFES ECOLÓGICAS EN LA ESTEPA? ARQUEOLOGÍA DEL PAISAJE EN EL COMPLEJO MINERO- METALÚRGICO DE KARGALY (REGIÓN DE ORENBURG, RUSIA)
}

\author{
ECOLOGICAL CATASTROPHES IN THE STEPPE? LANDSCAPE ARCHAEOLOGY AT THE \\ MINING AND METALLURGICAL COMPLEX OF KARGALY (REGION OF ORENBURG, \\ RUSSIA)
}

\author{
JUAN M. VICENT GARCÍA (*) \\ ÁNGEL L. RODRÍGUEZ ALCALDE (**) \\ JOSÉ ANTONIO LÓPEZ SÁEZ $(* * *)$ \\ IGNACIO DE ZAVALA MORENCOS $(* * * *)$ \\ PILAR LÓPEZ GARCÍA $(* * *)$ \\ M. ${ }^{a}$ ISABEL MARTÍNEZ NAVARRETE $(*)$
}

\section{RESUMEN}

Kargaly es uno de los centros de minería y metalurgia del cobre mas significativos de la Gran Estepa Euroasiática. El Dr. E.N. Chernyj y su equipo (Instituto de Arqueología, Academia Rusa de Ciencias, Moscú) y varios investigadores del CSIC y de otras instituciones españolas desarrollan allí un proyecto conjunto para el estudio integral de sus dos fases de explotación: la Edad del Bronce (II milenio AC) y la primera industrialización rusa (1745-1900 AD). Los miembros rusos del equipo están a cargo de la investigación arqueológica de este proyecto coordinado y los miembros españoles del estudio de los aspectos tecnológicos y productivos de la minería y la metalurgia, por un lado, y del contexto ambiental de ambas actividades, así como de su impacto sobre el territorio por otro.

El propósito de este artículo es presentar los planteamientos y primeros resultados del programa de estudios paleoambientales, que consta de dos fases. La primera dio lugar a uno de los registros paleoambientales más comple-

(*) Dpto. de Prehistoria. Instituto de Historia. CSIC. Serrano, 13. 28001 Madrid.

(**) Centro de Humanidades. CSIC. Duque de Medinaceli, 4. 28014 Madrid.

(***) Laboratorio de Arqueobotánica. Dpto. de Prehistoria. Instituto de Historia. CSIC. Duque de Medinaceli, 6. 28014 Madrid.

$(* * * *)$ Dpto. de Ingeniería Cartográfica, Geodesia y Fotogrametría. Escuela Universitaria de Ingeniería Técnica Agrícola. Universidad Politécnica de Madrid. Ciudad Universitaria s/n. 28040 Madrid.

El artículo fue remitido en su versión final el 2-VI-2000.

tos de esta región mediante muestreo sistemático antracológico, paleocarpológico y palinológico en varios yacimientos arqueológicos, y sondeos palinológicos en depósitos naturales. En ambos casos se contó con el apoyo de dataciones radiocarbónicas.

La segunda fase, a la que se dedica la mayor parte del artículo, se orientó a la contextualización de ese registro mediante una investigación sobre el paisaje actual, con especial énfasis en la comprensión de los procesos de formación de la lluvia polínica. Su finalidad es obtener criterios explícitos y controlables de calibración para la interpretación de las cuestiones paleoambientales demandadas por la investigación arqueológica y arqueometalúrgica. Destaca entre ellas la evaluación de los recursos forestales durante la Edad del Bronce, base energética del complejo minero metalúrgico, y el problema del reconocimiento de las prácticas subsistenciales, en relación con la discusión sobre el comienzo de la economía productora en la Gran Estepa Euroasiática. Ambas rebasan el marco de la práctica paleoambiental convencional, al requerir información muy específica sobre la distribución espacial en el pasado de la vegetación a escala local y regional.

Se propone un enfoque metodológico que enmarca la práctica de la palinología arqueológica en los objetivos, planteamientos teóricos y métodos de la Arqueología del Paisaje. Desde este marco se evalúan y diagnostican las limitaciones de la práctica convencional de la Arqueología paleoambiental (particularmente la palinología arqueológica) y se ofrece una aplicación intensiva del "enfoque modelizador" en paleopalinología basada en la combinación 
de métodos de modelización matemática del paisaje y de la lluvia polínica. Para su puesta en práctica se aplican métodos avanzados de observación de la Tierra, como la Teledetección espacial, apoyados en el uso intensivo de la tecnología de los Sistemas de Información Geográfica (GIS) y las técnicas de posicionamiento global (GPS).

\begin{abstract}
Kargaly is one of the most important centers of mining and metallurgy in the great Eurasian steppe. Dr. E.N. Chernykh and his team (Institute of Archaeology, Russian Academy of Sciences, Moscow) and various researchers at the CSIC and other Spanish institutions have developed a joint project to undertake a comprehensive study of the site's two main phases of occupation, the Bronze Age $\left(2^{\text {nd }}\right.$ millenium $B C$ ) and the first Russian industrialization (17451900 AD). The Russian members of the joint team are in charge of the archaeological investigations, while the Spanish members are studying metallurgical and mining technology and production, on the one hand, and the environmental context and impact of these activities, on the other.
\end{abstract}

This article presents the research design and first results of the Palaeoenvironmental research at Kargaly. This work has two aspects. The first consisted of obtaining one of the most complete palaeoenvironmental data sets from the steppes through both the systematic sampling of archaeological sites to recover charcoal, seeds, fruits and pollen and the taking of palynological cores from natural deposits, on the other. Both sampling programs were supported by radiocarbon dates.

The second aspect, to which the greater part of this article is devoted, was dedicated to contextualizing the palaeobotanical evidence by studying the present-day landscape, with particular attention to understanding the processes which shape the variability of the pollen rain. Our purpose was to obtain explicit and measurable calibrative criteria which would enable us to answer the palaeoenvironmental questions raised by our archaeological and archaeometallurgical research. These questions include, most importantly, the following: what was the extent of forest (the energy base for the mining/metallurgical complex) during the Bronze Age? and how do we evaluate subsistence practices? (an issue related to the origins of agriculture on the steppe). Answering both questions require us to go beyond conventional palaeoenvironmental practice, since they require very specific information about the past spatial distribution of vegetation on both local and regional scales.

We propose a methodological perspective that places the practice of palynology in archaeology within the goa$l s$, theoretical premisses, and methods of Landscape Archaeology. Using this framework we evaluate and identify the limitation of conventional palaeoenvironmental practice (particularly the use of pollen analysis in archaeology) and we develop an intensive application of model-based approach to palynology, one that combines study of the pollen rain with mathematical modelling of the landscape. To put it into practice we used modern methods of terrestrial observation, such as satellite imagery, grounded in the use of Geographical Information Systems (GIS) and global positioning (GPS) technology.

Palabras clave: Arqueología medioambiental. Arqueología del Paisaje. Edad del Bronce. Eurasia. Minería. Metalurgia. Agricultura. Teledetección espacial.

Key words: Environmental Archaeology. Landscape Archaeology. Bronze Age. Eurasia. Mining. Metallurgy. Agriculture. Remote sensing.

\section{PRESENTACIÓN DEL PROYECTO}

\subsection{Marco institucional, trayectoria de la investigación}

En este proyecto convergen tres de las líneas de investigación practicadas en el Dpto. de Prehistoria del Instituto de Historia (CSIC): la Arqueometalurgia, la Arqueología medio-ambiental y una Arqueología del paisaje que desarrolla técnicas avanzadas de investigación como el Sistema de Posicionamiento Global (1), los Sistema de Información Geográfica y la Teledetección espacial (Vicent, 1993a: 31-34; Chapa et alii, 1998). A estas tres habría que añadir una cuarta línea importante: las relaciones con el Instituto de Arqueología de Moscú (Academia Rusa de Ciencias)(Martínez Navarrete (coord.),1993; VV.AA, 1994) sostenidas, fundamentalmente, por las becas de intercambio entre dicha Academia y el CSIC.

En 1992, varios miembros de dicho Departamento se unen al equipo interdisciplinar dirigido por el Dr. Chernykh (1994) (2) en Kargaly. En 1996

(1) Se identificará por convención en el texto con las iniciales en inglés GPS.

(2) La diferente trasliteración del alfabeto cirílico al francés, inglés (Chernykh), aleman (Černych) y español puede dificultar la identificación de sus publicaciones y dar lugar a errores como, en nuestro caso, optar por Chernij en vez de Chernyj (Presa (coord.), 1997). En el artículo manejamos la segunda trasliteración salvo en las citas bibliográficas.

T. P., 57, n. $^{\circ} 1,2000$ 
la consecución por el equipo ruso (3) y español (4) de sendos proyectos nacionales de investigación potencia esta colaboración facilitando, por primera vez, financiación específica para el desarrollo de las líneas de investigación asumidas por los miembros españoles del equipo. Dichas líneas se establecieron sobre el principio de su coordinación y complementariedad con las ya en marcha (5).

\subsection{Escenario geográfico y encuadre cronológico y cultural}

Kargaly es un extenso coto de mineral de cobre (Fig. 1), encuadrado biogeográficamente dentro del contexto paisajístico de las estepas euroasiáticas. Consideradas tradicionalmente como la más amplia de las formaciones herbáceas del planeta, se extienden como una franja relativamente estrecha, a lo largo de casi cuatro mil kilómetros de longitud, desde los Cárpatos, a través de Rusia meridional, hasta los confines de Manchuria en el nordeste de China (Cardelús, 1988). Con tan dilatada superficie, resulta lógico concebir que, aunque parezcan uniformes, las estepas no son del todo homogéneas. El ejemplo de Kargaly es bastante representativo (Chibilyov, 1996). Está situado en la zona correspondiente a la estepa arbolada o bosque-estepa, conformada por pequeños y aislados retazos de bosque ripario en el seno de la gran planicie, marcando el tránsito desde las regiones forestales situadas en el

(3) N. 96-06-80135 (1996-98) Russian Foundation of Fundamental Investigation RFFI. "Ancient Mining and Metallurgy in the East European Steppe: Kargaly complex". Investigador principal Dr. E.N. Chernyj.

(4) PS95-0031 (1996-99) "El inicio de la economía productiva en la gran estepa euroasiática y su impacto en el medio ambiente: ¿catástrofes ecológicas en la estepa?”. La investigadora principal es $\mathrm{M}^{\mathrm{a}}$ Isabel Martínez Navarrete y sus miembros son Pilar López García, Jose Antonio López Sáez y Salvador Rovira Lloréns. El equipo, coordinado con el del Dr. Chernyj, es mucho mas amplio. Son integrantes del mismo los autores de este artículo y del cartel (cf. nota 5) y Carmen Gómez Ferreras (Facultad de Biología, Universidad Complutense)

(5) La participación española se dió a conocer en un cartel presentado al First Meeting of the European Association of Archaeologists (Santiago de Compostela, 1995): E.N. Chernykh, J.M. Vicent, A. Rodríguez Alcalde, S. Rovira (Museo Arqueológico Nacional. Madrid), S.A. Agapov (Asociación Histórico-ecológica y cultural, "Powolzhje". Samara, Rusia), E.E. Antipina, T.B. Bartseva, S.V. Kuzminykh, H.Y. Levedeva, P. López, V.Y. Lunkov, I. Martínez Navarrete, L.B. Orlovskaia, T.O. Teneishvili and P. Uzquiano (Laboratorio de Arqueobotánica, CEH, CSIC, Madrid): "Kargaly: the earliest mining and metallurgical center in Northern Eurasia. A Russian-Spanish Project". Diseño: Julia Sánchez (CEH, CSIC, Madrid). Los colegas rusos -salvo S.A. Agapov-son miembros del Instituto de Arqueología de la Academia Rusa de Ciencias. sur de los Urales, hasta las zonas desérticas de Kazastán. El bosque ripario más típico es el formado por Betula pendula y Populus tremula, donde esporádicamente pueden aparecer ciertos sauces (Salix sp.), robles (Quercus robur) y alisos (Alnus glutinosa, Alnus incana). El dosel arbustivo es copioso y está dominado por rosáceas arbustivas (Prunus avium, Sorbus aucuparia, Rubus idaeus, Rosa cinnamomea, Spiraea crenata y Padus racemosa) y la vegetación esteparia por gramíneas de gran talla (Stipa zalesski-wilensky, S. dasyphylla, S. pennata, S. capillata) y Artemisia sp. (Lám. I).

El Dr. Chernykh (1992; Vicent, 1993b) ha dedicado mas de veinte años al estudio de las sociedades de Europa oriental y del Asia noroccidental durante el Calcolítico y las Edades del Bronce y del Hierro. Para abordar el tema a una escala espacial y temporal de tanta magnitud se ha centrado en los metales cuyo papel es fundamental en las interacciones a larga distancia por la práctica ausencia de mineral de cobre en extensos territorios del continente euroasiático. Chernykh (1996: 86-87) considera Kargaly el centro minero y metalúrgico mas antiguo y significativo de la Gran Estepa Euroasiática. La primera explotación de los depósitos cupríferos se produce en la Edad del BronceAntiguo (3300-2500/ 2400AC)(Chernyj et alii, 2000: 26) y se asocia con pastores nómadas, de los que sólo se conocen sus cementerios de kurganes, algunos distantes de Kargaly hasta $500 \mathrm{~km}$. Los principales indicadores de la actividad minera son los resultados del análisis espectral que relacionan la composición de los objetos metálicos descubiertos en las tumbas mas ricas con la de los minerales de ese coto.

Las características técnicas y tipológicas de esta producción, integrada en la Provincia Metalúrgica Circumpóntica (Chernij et alii, 1990), se mantie-nen durante el Bronce Medio (2800-2000/1900 AC)(Chernyj et alii, 2000: 26) pero cambian en la Edad del Bronce Final (2000-1250AC) (Chernykh, 1996: 88). Kargaly se convierte en uno de los centros mas relevantes de la nueva y amplísima Provincia Metalúrgica Euroasiática, coincidiendo con la aparición de mas de una veintena de poblados minero-metalúrgicos de la cultura Srubnaia-Andronovska que sugieren el asentamiento de los grupos de pastores nómadas. La ausencia de elementos de prestigio en los ajuares domésticos y funerarios del área reforzaría la tesis del carácter especializado de su ocupación.

Esa fase de asentamientos permanentes con actividad metalúrgica concluye abruptamente, sin que 

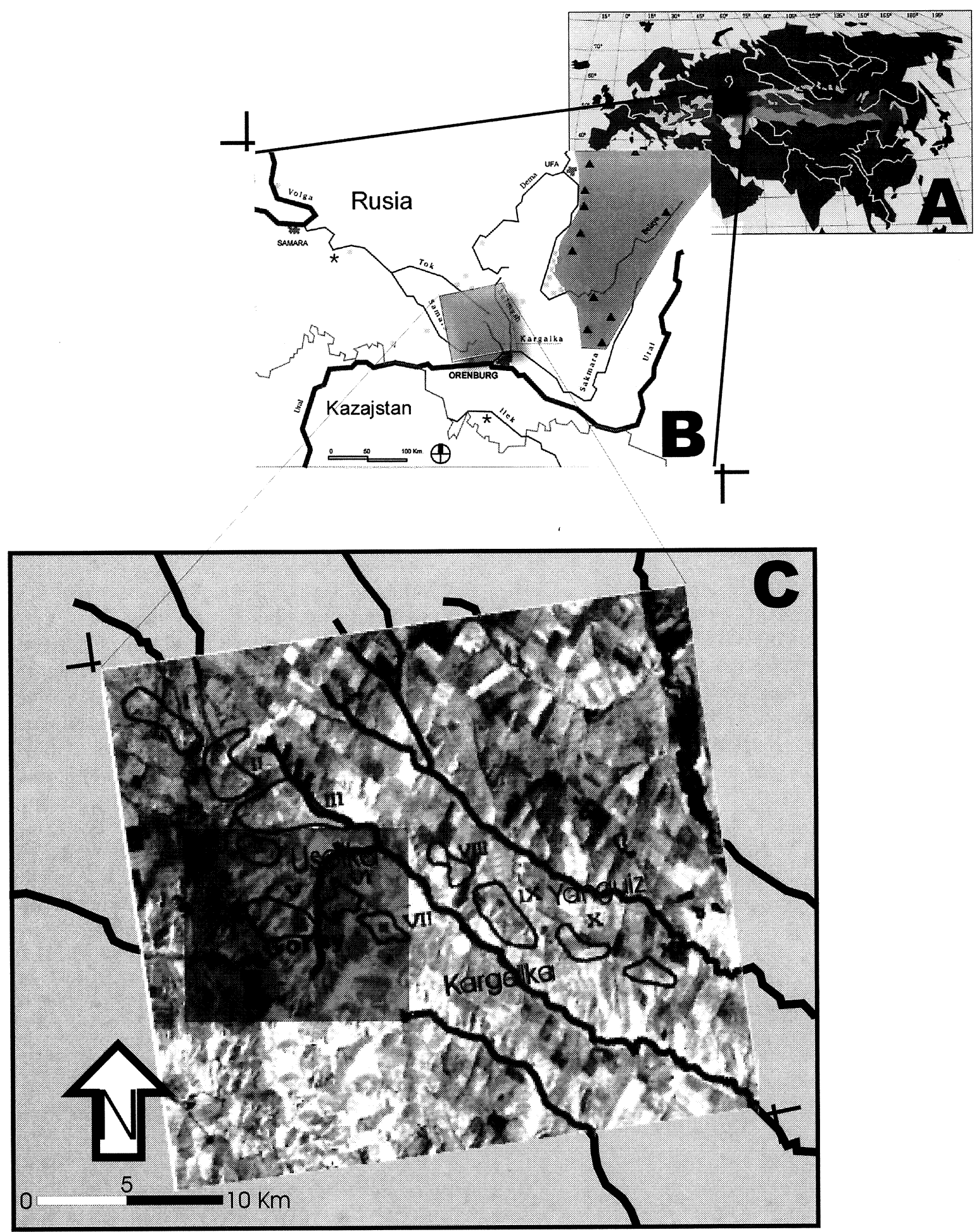

Fig. 1. A. Posición del área del proyecto de Kargaly en relación con la Gran Estepa Euroasiática. B. Localización del Área general $\left(774 \mathrm{~km}^{2}\right.$ ) del modelo experimental del paisaje en la Región de Orenburg (Rusia). La zona tramada al noreste representa los Urales. Los triángulos corresponden a las fábricas metalúrgicas modernas. C. Situación del Área de trabajo analítico $\left(45 \mathrm{~km}^{2}\right)$ en el Área general sobre una composición TM 543. Se representa la red hidrográfica y los contornos de los 11 distritos mineros de Kargaly.

T. P., 57, n. $^{\circ} 1,2000$ 
se registre actividad minero-metalúrgica a escala arqueológicamente perceptible hasta la primera industrialización rusa. El final de la ocupación prehistórica supone también la desaparición de indicios de asentamiento permanente en la región, ocupada por poblaciones nómadas hasta una segunda fase de explotación, muy intensiva, correspondiente a la primera industrialización rusa (entre 1745 y 1900 AD). Significativamente, según los documentos escritos, los mineros rusos se guiaron por los vestigios de unas obras mineras todavía reconocibles casi tres mil años después (Chernyj, 1997). Esta superposición configura el paisaje actualmente visible (Láms. I y II).

El Dr. Chernyj ha sugerido que el final de la metalurgia prehistórica en Kargaly puede estar conectado, entre otros factores, con episodios de degradación ecológica extrema provocada por la sobreexplotación de los escasos y frágiles recursos forestales debida al efecto acumulado de una intensa actividad metalúrgica. La destrucción de dichos recursos afecta la posibilidad de mantener no sólo la escala de producción metalúrgica, sino también un patrón sostenible de asentamiento permanente en la región. Por un lado, el extremo rigor de los inviernos de la estepa plantea altos costes energéticos. Por otro, las formaciones forestales parecen tener un importante papel en la regulación de otros aspectos relevantes del equilibrio ecológico, como la disponibilidad de agua.

Esa hipótesis de "las catástrofes ecológicas" es de gran alcance en cuanto el Dr. Chernykh (1994: 57; 1996: 88) reúne la fase prehistórica y la fase rusa en un estadio pre-industrial de la metalurgia por la utilización del carbón vegetal como energía para la reducción. Esta secuencia de explotación dota al coto minero de gran interés arqueometalúrgico e histórico al facilitar un conocimiento global de las actividades extractivas y metalúrgicas en condiciones primitivas y permitir evaluar su impacto ambiental.

El proyecto se propone el estudio integral de la metalurgia temprana en Kargaly, su impacto en el medio y su contexto económico y social. Se interesa por la relación de la metalurgia con las prácticas subsistenciales ganaderas y agrícolas, por el patrón de asentamiento, la división social del trabajo, etc. Para alcanzar estos objetivos se plantean dos subprogramas de investigación coordinados: uno centrado en los aspectos tecnológicos y productivos de la metalurgia (Rovira, 1999) y otro destinado a aportar datos sobre el contexto ambiental de la mi-

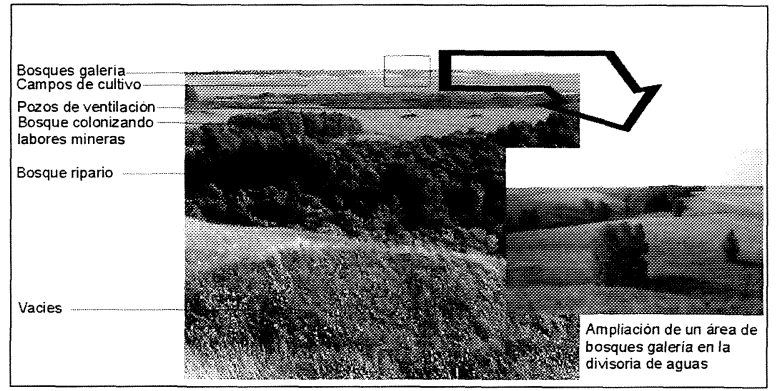

Lám. I. Paisaje en el coto cuprífero de Kargaly (Urales del Sur, Región de Orenburg. Rusia).

nería y la producción metalúrgica de Kargaly y sobre su impacto en el territorio (Lopez García et alii, 1996). Estos programas se desarrollan paralela y complementariamente con el programa de investigación arqueológica de nuestros colegas rusos (Chernyj et alii, 1999; Antipina, 1999).

El propósito de este artículo es presentar los planteamientos y primeros resultados del programa de estudios paleoambientales, con énfasis especial en los aspectos metodológicos: el diagnóstico de los problemas, la modelización teórica de los mismos, los métodos y técnicas y las principales conclusiones que cabe extraer de la experiencia. Con respecto a estas últimas, y más allá del problema específico planteado por la investigación, consideramos que tienen un valor general en dos sentidos:

1) Como crítica positiva a las limitaciones del "enfoque convencional" en el uso histórico de los datos arqueo-botánicos, basado con frecuencia en una lectura directa y descontextualizada de la evidencia palinológica.

2) Como ejemplo práctico de la aplicación de varias tecnologías avanzadas a la modelización del paisaje en relación con problemas arqueológicos.

\subsection{Planteamiento y objetivos de la investigación}

El programa de estudios paleoambientales del proyecto Kargaly combina los métodos y técnicas habituales en laArqueología Medioambiental con técnicas y métodos propios de la Arqueología del Paisaje para resolver problemas históricos de dimensión geográfica. Su base es la concepción integral del paisaje (con sus aspectos ecológicos, pero también sociales e históricos) como registro arqueológico.

Kargaly ofrece un excepcional laboratorio para 


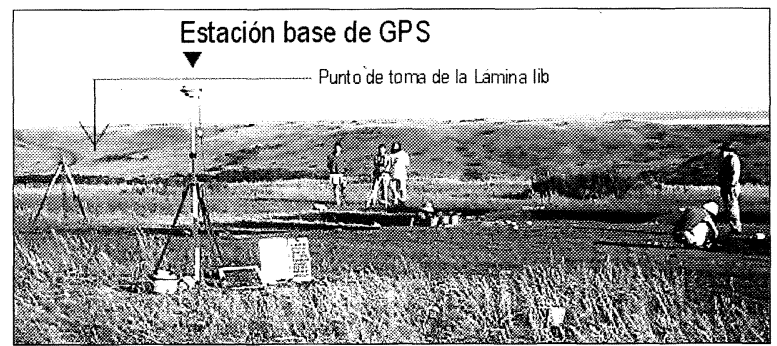

A

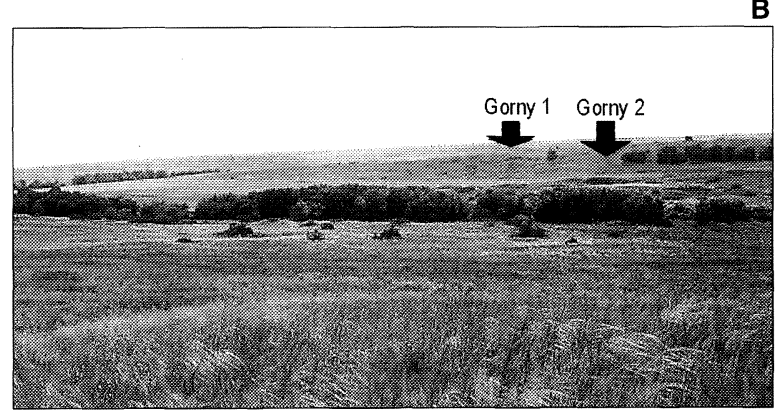

Lám. II. A. Situación de la estación GPS en Gorny 1. Se aprecian en la parte inferior los paneles de alimentación fotovoltaica. B. Vista general de los yacimientos arqueológicos de la Edad del Bronce sobre la colina Gorny (Kargaly, Urales del Sur, Región de Orenburg. Rusia). En primer término pozos mineros colonizados por arbustos.

ensayar un enfoque de este tipo. La escasa densidad de su ocupación humana a lo largo de la historia y su relativa poca complejidad morfológica facilitan extraordinariamente el planteamiento de un enfoque experimental. El paisaje, en su aspecto actual, ha sido modelado por tres episodios históricos de gran impacto: la minería prehistórica, la minería moderna y la colonización agraria soviética (Láms. I y II). Entre estos periodos de máxima antropización, Kargaly estuvo ocupado por poblaciones nómadas que interactuaban con su entorno de una manera aún por determinar, pero en cualquier caso poco intensa. Esta alternancia de periodos de máxima y mínima antropización del entorno actuando sobre un medio natural relativamente homogéneo permiten considerar la hipótesis general de que es posible identificar arqueológicamente los principales procesos de la historia del paisaje, en cuanto son una instancia decisiva en la propia historia de la ocupación humana.

Los principales problemas interpretativos que suscita el registro arqueológico kargaliense nos remiten a aspectos cruciales de la historia del paisaje que no suelen ser abordados desde la práctica convencional (puramente paleoecológica) de la arqueología medioambiental. El primero de estos proble- mas hace referencia al funcionamiento mismo de un sistema de producción minera y metalúrgica a gran escala en un entorno paisajístico extremadamente pobre (en un primer análisis) en recursos energéticos, como la estepa al sur de los Urales. El segundo es un problema general de la Arqueología de la Edad del Bronce en la Gran Estepa Euroasiática, que en el caso de Kargaly toma gran relevancia por su conexión precisamente con la escala e intensidad de la explotación minera y la producción metalúrgica. Se refiere a la ausencia de evidencia de prácticas agrícolas en los contextos de asentamientos permanentes de las culturas Srubnaia y Andronovska y a la correlativa valoración en la literatura de la crucialidad de la economía pastoril.

La cuestión acerca de las bases energéticas del complejo minero-metalúrgico de Kargaly centra el presente trabajo y nos remite directamente a un problema de historia del paisaje: la distribución, densidad, composición y evolución en el tiempo de las masas forestales de la región.

Los trabajos analíticos del Dr. Chernyj indican la amplia presencia del cobre kargaliense en los contextos arqueológicos de la extensa área cultural Srubnaia-Andronovska. Esto sugiere una gran escala e intensidad en la actividad extractiva, y tal vez metalúrgica, en la región durante este periodo. El modelo interpretativo propuesto por Chernyj contempla que el ciclo completo de extracción y reducción del mineral se practicó intensivamente y a gran escala en Kargaly durante la vida de los asentamientos permanentes de la cultura Srubnaia, exportándose de la región una gran parte. Chernykh (1998: 72) ha calculado en $150000 \mathrm{Tm}$ el cobre metálico producido en Kargaly durante la Edad del Bronce, correspondiendo al menos unas $100000 \mathrm{Tm}$ al periodo de vigencia de la cultura Srubnaia. Según los datos de S. Rovira (1999: 111) acerca del alto consumo energético de la tecnología aplicada en la reducción del mineral, los cálculos preliminares para el volumen de producción estimado arrojan la cifra de $75000000 \mathrm{Tm}$ de madera para toda la Edad del Bronce. Ello equivaldría en el modelo más simple posible (producción constante a lo largo del tiempo) a unas $37500 \mathrm{Tm}$ al año. Si aceptamos los datos de Chernykh (1994: 60) sobre la productividad forestal en la región de Orenburg, esto implica la tala anual de un promedio mínimo de $150 \mathrm{Ha}$ de bosque al año.

Estas cifras son aparentemente incompatibles con la capacidad forestal actual. Considerando un modelo sostenible de explotación con un ciclo de 60 
años para la recuperación de la capacidad productiva inicial, la masa total de recursos potenciales exigida por el modelo de Chernyj sería de unas $9000 \mathrm{Ha}$ de bosque. Como en la actualidad podemos estimar la cobertura arbórea de la región de Kargaly en un $2.6 \%$, estos recursos requieren un territorio de unos $3500 \mathrm{Km}^{2}$, casi el triple de la superficie aproximada del coto minero. De ello sólo cabe deducir que o bien la extensión del bosque fue mucho mayor durante la Edad del Bronce que en los tiempos históricos (del orden de tres veces más) o bien la intensidad del uso de recursos energéticos fue menor de lo supuesto por el modelo. En tal caso, se requiere otro alternativo que de cuenta de la amplia distribución del cobre kargaliense. El propio Chernykh (1994: 65) y Rovira (1999: 112) han propuesto en este sentido la posibilidad de que las exportaciones se realizaran en forma de mineral, no de cobre metálico. Eventualmente se podría considerar como tercer modelo la importación de combustible, aunque un sencillo cálculo de costes mínimos permite descartarla a priori: la reducción de un tonelada de cobre requiere el transporte de 500 Tm de madera. La minería de tiempos históricos resolvió estos problemas trasladando el mineral a fundiciones situadas a más de $300 \mathrm{Km}$, en el actual territorio de la República Autónoma de Bashkiria, para aprovechar los recursos forestales de las estribaciones sudoccidentales de los Urales (Chernykh, 1994: 65; Rovira, 1999: 103) (Fig. 1B).

La decisión entre estos modelos tiene amplias implicaciones en todos los órdenes de la interpretación histórica de la metalurgia de Kargaly, al remitirnos a modelos opuestos de producción-circulación y división social del trabajo. Esa decisión plantea una pregunta muy clara al registro paleoambiental, acerca de las variaciones en la extensión, composición y distribución de las masas forestales de Kargaly a lo largo del tiempo. Podemos decir que esta cuestión es la principal implicación contrastadora del modelo de funcionamiento de la metalurgia prehistórica de Kargaly.

En cuanto al segundo problema relativo a las prácticas subsistenciales durante la Temprana Edad de los Metales, las investigaciones arqueológicas sobre las ocupaciones metalúrgicas de la cultura Srubnaia-Andronovska en Kargaly plantean importantes problemas en relación con los inicios de la economía productora en la Gran Estepa Euroasiática.A ese respecto el debate en laArqueología rusa sobre el papel de la agricultura y la ganadería está limitado por la todavía escasa implanta- ción de criterios técnicos actualizados para la recuperación de datos paleo-ambientales (Černych et alii, 1998; Morales-Muñiz y Antipina, e.p.).

Las excavaciones realizadas por el Proyecto Kargaly son, de hecho, las primeras en la región en las que se ha aplicado este tipo de criterios (Chernyj et alii, 1999: notas 6,11), y han generado un detallado registro arqueozoológico y arqueobotánico. La flotación de sedimentos y los análisis palinológicos en el poblado Gorny 1 (Lám. II) (López García et alii, 1996) (6), no han detectado la presencia de polen de cereal aunque sí de ciertos palinomorfos usualmente acompañantes de cultivos.

El registro arqueozoológico apunta un uso intensivo de los animales domésticos como fuente de alimentación (Antipina, 1999: 106-108). Sin embargo ciertas particularidades de ese registro y las exigencias en pastos y en mano de obra de las especies representadas dificultan una interpretación de la subsistencia basada en una ganadería extensiva al estilo del de las poblaciones nómadas posteriores pero compatible con un patrón de asentamiento sedentario. Estas anomalías sugieren un patrón de subsistencia más complejo que el supuesto por la versión tradicional, posiblemente basado en principios de división técnica y social del trabajo a gran escala.

La problemática esbozada requiere una sólida base de información sobre el paisaje de Kargaly a lo largo del tiempo y plantea demandas que rebasan el marco normal de interpretación. El diseño teórico y metodológico del subprograma de investigación paleo-ambiental parte de la constatación y diagnóstico de estas limitaciones del enfoque convencional que no sirve para una aproximación fisiográfica. Los métodos habituales de interpretación comparativa movilizan secuencias palinológicas, datos antracológicos, paleo-carpológicos y arqueozoológicos procedentes de un número limitado de contextos arqueológicos. Permiten, por una parte, reconocer elementos específicos del entorno inmediato y las prácticas subsistenciales de los sitios arqueológicos $\mathrm{y}$, por otra, identificar tendencias dinámicas de alcance regional y local. Sin embargo, esos mismos datos son insuficientes cuando tratamos de aproximarnos a la morfología regional de esos mismos elementos y procesos, en este caso,

(6) P. López, E.N. Chernykh, A. López Sáez y P. Uzquiano (e.p.): "Archaeobotanical analysis at Gorny site (Kargaly region): the earliest metallurgical center in Northern Eurasia (Russia)". Ninth International Palynological Congress (Houston, 1997). 
la distribución espacial de las distintas formaciones vegetales.

Por ejemplo, los datos antracológicos (7) procedentes del sitio metalúrgico de Gorny 1, excavado en el marco del proyecto, muestran que se usaron como combustible en los contextos metalúrgicos las mismas especies arbóreas implantadas actualmente en el entorno: Betula, Quercus, Salix, Alnus, etc. Pero, como ya hemos visto, esa información es insuficiente para acercarnos a la disponibilidad real de combustible para los metalúrgicos del poblado, ni al impacto de su actividad en la misma y en otros aspectos de la morfología del paisaje que resultan cruciales para explicar el conjunto de la trayectoria histórica del sitio.

Los datos paleopalinológicos son el recurso más usado para estudiar las tendencias en la distribución de recursos vegetales. Se asume, a menudo acríticamente, que las alteraciones en la proporción de determinados palinomorfos a lo largo de las secuencias paleopalinológicas informan sobre las alteraciones en la distribución de las especies productoras de los mismos. Desde este punto de vista, el examen de la evolución del polen de las especies arbóreas de interés energético (básicamente Betula y Quercus, en este caso) permitiría una aproximación positiva al problema. Sin embargo, en Kargaly, esta asunción es insostenible como veremos.

En el proyecto se obtuvieron secuencias paleopalinológicas en dos sitios de ocupación de la fase Srubnaia en la colina de Gorny. Dos de estas secuencias proceden del sitio metalúrgico Gorny 1 (en el interior y exterior del área ocupada), emplazado en la cima de la colina y una tercera en el asentamiento Gorny 2 , situado a unos $500 \mathrm{~m}$ del primero, sobre la falda de la colina. Si tomamos, por ejemplo, la evolución de las proporciones de polen del grupo "arbóreas autóctonas" en la secuencia procedente de Gorny 2 (Fig. 2A) observaremos un aumento espectacular en las muestras de las fases mas recientes. En la última supera el $60 \%$ del total de palinomorfos identificados, frente al máximo de $24 \%$ en las correspondientes a la ocupación Srubnaia (fase 3). Si careciéramos de otra referencia estaríamos tentados a interpretar estos datos en términos de una importante reforestación del entorno de Gorny en tiempos recientes (y quizá incluso de una fase climática más húmeda). Esa tentación quedaría reforzada cuando advirtiéramos que la

(7) P. Uzquiano (Laboratorio de Arqueobotánica. Dpto. de Prehistoria. Instituto de Historia. CSIC), miembro del proyecto, efectuó las identificaciones.
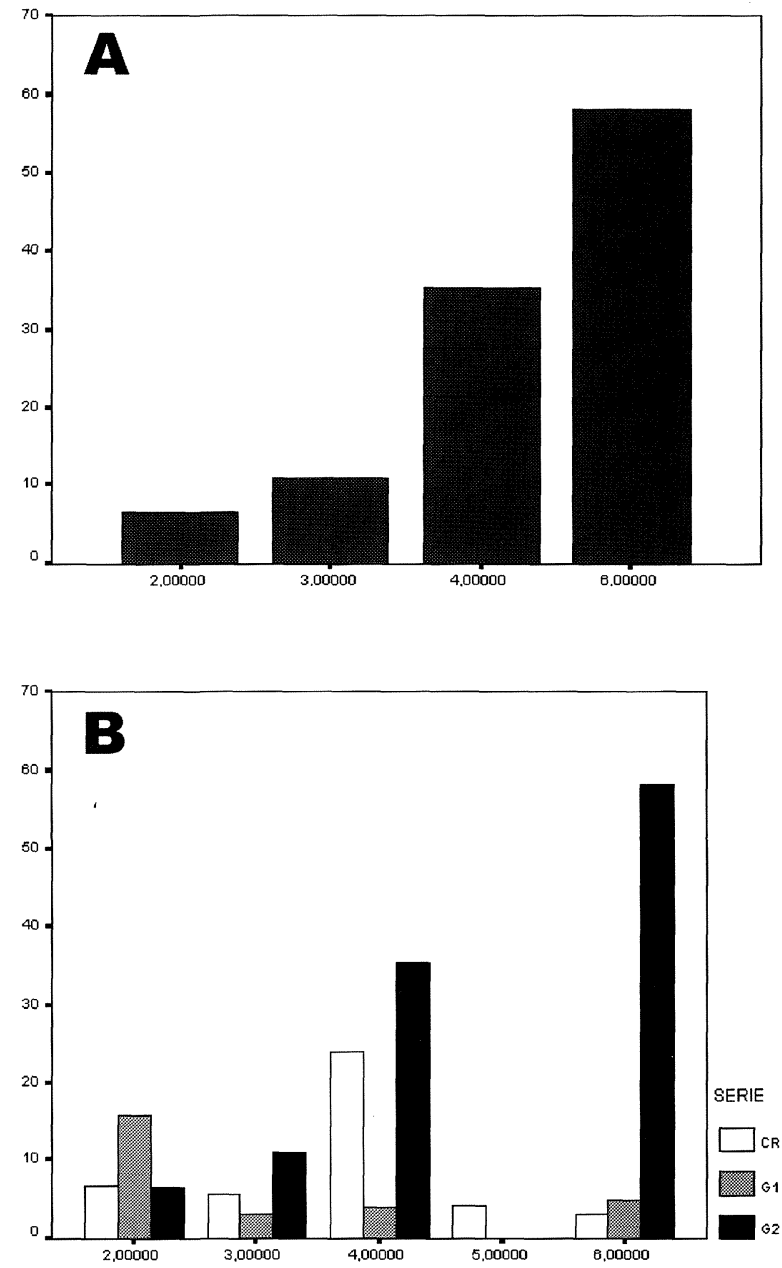

Fig. 2. A. Evolución de porcentaje de Betula por fases estratigráficas en el sitio Gorny 2. B. Comparación de la evolución de porcentaje de Betula en los sitios arqueológicos de la colina Gorny = Gorny 1 (G1), "Casa Rusa" (CR) y Gorny 2 (G2) por fases estratigráficas $=2$ pre-Srubnaia, 3 Srubnaia, 4 Srubnaia final, 5 Subactual, 6 Actual. La fase estratigráfica 5 sólo se ha identificado en CR.

tendencia ascendente de este grupo ecológico se inicia aparentemente en la Edad del Bronce y es continua a lo largo de la secuencia. Sin embargo, al comparar esta última con las otras dos disponibles en su entorno, observamos que esta tendencia no puede generalizarse. La figura 2B muestra los promedios del porcentaje de arbóreas autóctonas para cada fase estratigráfica en las series procedentes de la colina de Gorny. Las discrepancias observables en las fases 4 (Srubnaia final) y 6 (actual) contrastan con la coherencia en la fase 3 (Srubnaia). En tales condiciones lo más sensato es atribuirlas a factores tafonómicos o a fenómenos de alcance

T. P., 57, n. $^{\circ} 1,2000$ 


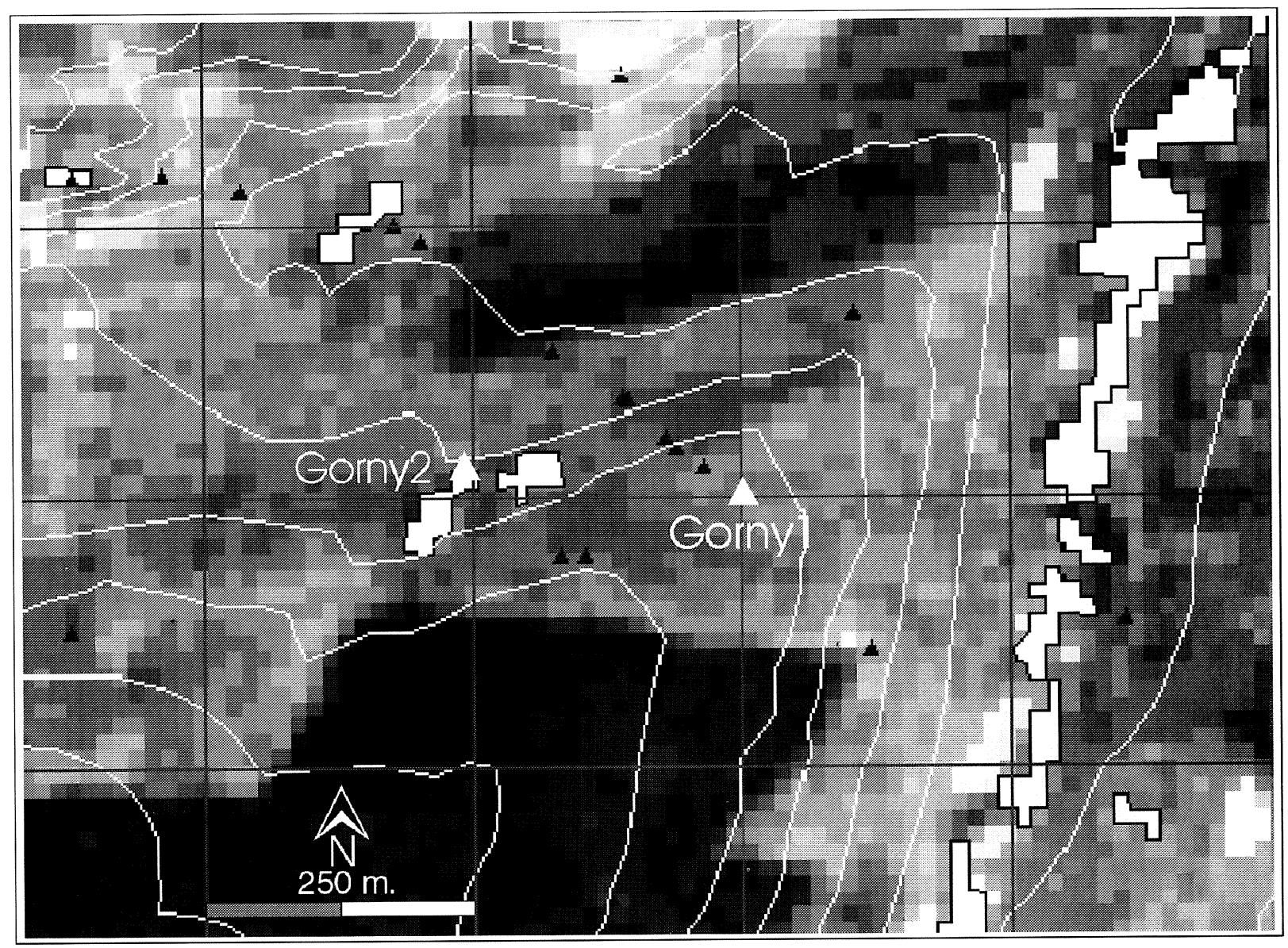

Fig. 3. Sector de la colina de Gorny sobre una composición TM 742. Las zonas más oscuras representan campos de cultivo. Los bosques aparecen en trama blanca. Los triángulos blancos identifican los yacimientos arqueológicos y los negros los puntos de muestreo palinológico.

extremadamente local ya que las series proceden de puntos circunscritos en un área de pocos centenares de metros. En efecto, el sitio Gorny 2 está en la actualidad situado al pie de un pequeño grupo de abedules que han colonizado varios pozos mineros de época moderna, que les ofrecían acceso fácil a la humedad de la capa freática (un fenómeno muy corriente en Kargaly) (Fig. 3 y Lám. IIB). La influencia de este factor extremadamente contingente genera pues alteraciones en el significado de los datos polínicos que no podrían ser correctamente interpretadas sin datos sobre la distribución actual de la vegetación a escala local, y que, en cualquier caso, ponen en cuestión cualquier generalización procedente del análisis de una sola secuencia.

Este tipo de fenómenos son muy frecuentes y, a veces, afectan a categorías cruciales de datos. Así, los arqueólogos suelen usar la falta de pólenes de cereal en sedimentos arqueológicos como argumen- to en favor de la ausencia de prácticas agrícolas (y no sólo en la Arqueología de la Gran Estepa Euroasiática). En ninguna de las secuencias de la colina de Gorny hay indicios de polen de cereal en las fases prehistóricas. Sin embargo tampoco existen en las fases recientes ni en los sedimentos superficiales, pese a que la colina está en gran parte cultivada y a su alrededor se extienden grandes campos de cereal, que se han venido cultivando al menos en los últimos 50 años. Gorny 2 está a algo más de 100 $\mathrm{m}$ del borde de uno de ellos, y Gorny 1 tiene cultivos al $\mathrm{N}$ y S, a unos $300 \mathrm{~m}$ de distancia en ambos casos (Fig. 3). Cabe suponer que este hecho se deba, al menos en parte, a la poca dispersión del polen de cereal.

Estos ejemplos no son casos aislados o extremos, sino la pauta normal de problemas que se suscitan cuando la interpretación de los datos palinológicos pasa del plano del análisis de tendencias 
generales al de la reconstrucción morfológica de contextos de paisaje. No existe ninguna forma de relacionar las variaciones cuantitativas en la composición de los espectros polínicos con la distribución real de la vegetación en su entorno. Esto se debe, por una parte, a la propia naturaleza del proceso de polinización, diferente en cada especie y afectado por numerosos factores que pueden alterar su intensidad y dispersión, y por otra, a los numerosos factores que intervienen en la formación del registro polínico, desde los referidos a la dispersión y transporte a los de sedimentación y fosilización del polen.

Estos problemas han sido extensamente considerados en el campo de la paleopalinología, aunque con escasa repercusión, por el momento, en la práctica arqueológica normal. Como respuesta se ha insistido reiteradamente desde aquel campo (Hicks y Birks, 1996: 269-271; Gaillard et alii, 1992: 3-4, 15-16, 1994: 47, 68-71) en la necesidad de calibrar los datos de procedencia arqueológica mediante la investigación de la formación del registro polínico en condiciones conocidas de distribución de la vegetación, clima e influencia antrópica.

A nivel local ciertos factores condicionan no sólo la productividad o capacidad de dispersión de cada taxón, sino su propia representatividad en el seno de los diagramas polínicos: la orografía del territorio, la orientación y ubicación de las fuentes productoras de polen, la climatología local que delimitará la productividad, la situación exacta del perfil estudiado en relación con la lluvia polínica, etc. A nivel paleoecológico, la evolución conjunta de todos estos factores es el vector más importante de comprensión paleoambiental, siendo el hombre uno de los posibles factores de alteración. $\mathrm{La}$ bibliografía al respecto es abundantísima.

Uno de los métodos más prometedores para aproximarse con detalle al paleopaisaje de un territorio es el estudio de muestras de superficie de la vegetación actual (Moore et alii, 1991; Janssen, 1966). La alternativa más usual de comparación mediante un análisis numérico de los resultados del estudio de la lluvia polínica en muestras superficiales con muestras fósiles es un análisis multivariante, similar al usado en los análisis de la vegetación (discusión en Birks y Birks, 1980; Birks y Gordon, 1985). Birks (1987) resume así sus aplicaciones: permite estudiar un amplio conjunto de muestras de superficie, presentarlas de forma simple y tratar los datos en diferentes grupos mediante métodos de taxonomía numérica. Determina ponderadamente el peso real de cada palinomorfo en relación con la distribución actual de la especie productora. Hace posible ordenar los datos fósiles de la misma manera que los actuales (lluvia polínica de muestras superficiales), observar la evolución temporal seguida por la vegetación en una secuencia particular $\mathrm{y}$, finalmente, interpretar las formaciones vegetales del pasado (representadas por su espectro polínico fósil) según los patrones actuales de la lluvia polínica en superficie.

La aplicación extensiva de este enfoque a la palinología arqueológica está muy limitada por factores externos como el alto coste de obtención de la información o la dificultad de una integración multidisciplinar en contextos de recursos de investigación muy limitados. Pero también influyen factores internos, atribuibles a la dificultad de los arqueólogos, y de sus propios colaboradores botánicos, para concebir el paisaje en su integridad como una fuente de información arqueológica de primer orden, susceptible, por lo tanto, de ser abordada con una metodología arqueológica que integre en su propia constitución epistemológica los métodos de la arqueobotánica.

El proyecto Kargaly ofreció la posibilidad de rebasar estas limitaciones. El subprograma de estudios paleoambientales se pudo diseñar como un ensayo de aplicación intensiva del enfoque modelizador de la paleopalinología integrado en el marco de una Arqueología del paisaje.

\subsection{Diseño de la investigación}

El planteamiento general del subprograma de estudios paleoambientales en Kargaly está orientado a la contextualización del registro polínico a partir del estudio de la lluvia polínica actual en relación con la distribución de la vegetación. Dicho en otros términos: antes de poder interpretar correctamente el significado de las variaciones en el tiempo de los espectros polínicos procedentes de depósitos naturales o arqueológicos, debemos comprender el de sus variaciones sincrónicas en el espacio.

La figura 4 esquematiza este planteamiento.La morfología del paisaje, es decir, la disposición en el espacio de sus componentes, determina la distribución de la lluvia polínica en un territorio. La hipótesis metodológica general de la palinología es que a esta relación de determinación corresponde una función simétrica de representación, de tal modo que la observación de la última puede condu-

T. P., 57, n. $^{\circ} 1,2000$ 


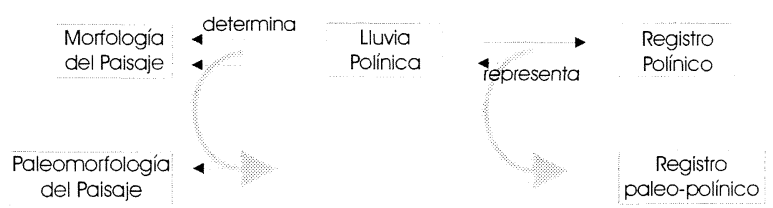

Fig. 4. Diagrama del diseño general de la investigación del Proyecto Kargaly.

cir a la reconstrucción de la primera. Con este fin, la variabilidad de la lluvia polínica es sistemáticamente registrada, según criterios metodológicos explícitos, para dar lugar al registro polínico, que mantiene con la lluvia polínica similares relaciones de determinación / representación a las que esta mantiene con la morfología del paisaje.

El proceso de conocimiento en Palinología se estructura por lo tanto en dos etapas que la investigación recorre en dirección inversa a la de las determinaciones naturales, en primera instancia, y observacionales, en segunda. En el paisaje actual tenemos acceso a todas las instancias de la secuencia, por lo que el proceso retroductivo se puede apoyar en criterios de interpretación externos al mismo.

La palinología arqueológica, tal como la entendemos aquí, asume que, conocidas las relaciones de determinación / representación para el paisaje actual, podemos acceder a la paleomorfología del paisaje a partir del registro paleopolínico, que suponemos representativo de la lluvia polínica en momentos del pasado. Para ello se acepta, como hipótesis básica que las funciones de determinación / representación observadas en el paisaje actual son extrapolables al pasado. El proceso de conocimiento se puede presentar metafóricamente entonces como la resolución de un sistema de ecuaciones, en el que tratamos de despejar la incógnita "paleomorfología del paisaje" a partir de los términos conocidos (règistros polínico y paleopolínico, morfología del paisaje actual) y un modelo general de las funciones que intervienen. De hecho el proceso consiste en aplicar estas funciones de representación, cuya forma y parámetros obtenemos de la relación entre la morfología actual del paisaje y el registro polínico actual, a la estimación de esas mismas funciones para el caso del registro paleopolínico.

Ahora bien, en este sistema de ecuaciones intervienen variables ocultas que complican el proceso. Cada una de las etapas en las funciones de determinación / representación se ve mediatizada por un conjunto de factores modificadores (Fig. 5). Así las

\section{Morfología} del Paisaje

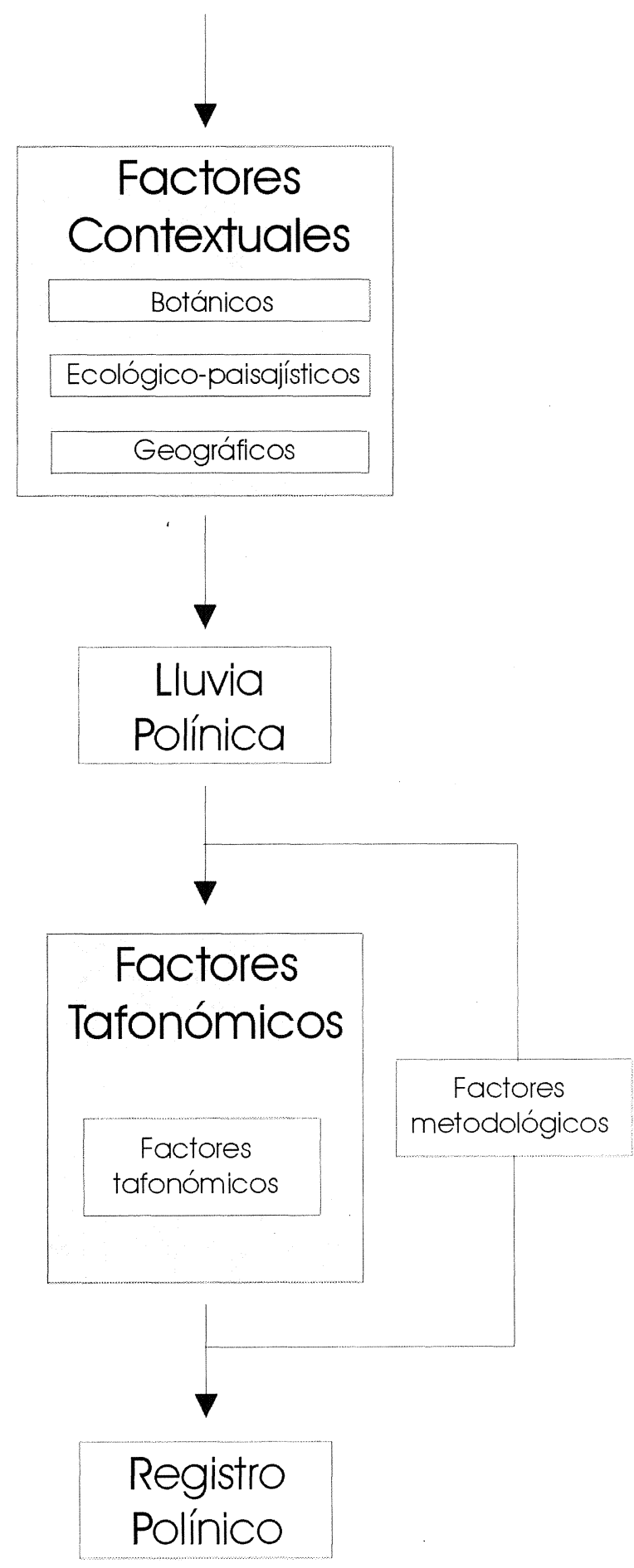

Fig. 5. Diseño ampliado de investigación del Proyecto Kargaly, incluyendo los factores modificadores. 
relaciones entre la morfología del paisaje y la variabilidad de la lluvia polínica dependen de la mediación de un conjunto de factores "contextuales", y operan a escalas espacio-temporales diferentes en una misma región. En un primer análisis podemos distinguir factores contextuales:

- Botánicos: morfología de los palinomorfos, mecanismos de dispersión específicos.

- Ecológico-paisajísticos: determinan la distribución en el espacio de las especies productoras y la intensidad de la polinización, efectos de interacción en las comunidades vegetales, acción antrópica, ciclos climatológicos, etc.

- Geográficos: mediatizan los procesos de dispersión y deposición de lalluvia polínica como altitud, régimen de vientos, morfología de la topografía, etc.

En segundo lugar, en la constitución del registro polínico intervienen dos tipos principales de factores modificadores:

- Tafonómicos: factores específicos que mediatizan la formación del registro polínico en los sedimentos, como la naturaleza de los suelos, su humedad, así como las condiciones específicas de formación de cada depósito.

- Metodológicos: la relación de representación entre el registro y la lluvia polínica está obviamente mediatizada por los criterios de observación y representación. Así el número de puntos de observación y la posición de los mismos influyen en la representación de la lluvia polínica que podemos esperar de un determinado registro.

Considerando todos estos factores, la distribución en un territorio concreto de una especie vegetal puede ser teóricamente estimada a partir del registro polínico si tenemos en cuenta las siguientes cuestiones, entre otras, recorriendo la figura 5 de abajo arriba: a) la cantidad y distribución espacial de las muestras de lluvia polínica obtenidas en dicho territorio; b) la variabilidad espacial de las propiedades específicas de los captadores del polen utilizados (por ejemplo, suelos); c) el mecanismo dispersor propio de la especie en cuestión, las condiciones de operación de ese mecanismo (como el régimen local de vientos) y su variabilidad espacial (por ejemplo la diferente exposición al viento de los puntos de observación); d) el régimen de polinización de la especie y su variabilidad temporal (debida, por ejemplo, a la variabilidad climatológica) y espacial (barreras a la dispersión como masas arbóreas interpuestas entre el foco emisor y los puntos de observación).
En este sentido, la distribución de la especie en el paisaje es el factor último que da cuenta de la representación en el registro polínico de su polen, pero la forma específica en la que ésta representa efectivamente a aquélla, lo que hemos llamado "función de representación", depende de un conjunto de factores contextuales y tafonómicos que determinan sus parámetros, y son específicos de cada especie vegetal y de cada contexto paisajístico.

Al trasladar estos supuestos al registro paleopolínico, encontramos que nuestra capacidad para interpretarlo en términos de paleo-morfología del paisaje depende de nuestra capacidad para estimar dichos parámetros y sus condiciones de aplicación a la retroducción de la paleomorfología del paisaje. Es un problema en el que interviene un número tan elevado de variables, muchas de ellas de difícil control, que no se puede formalizar en un contexto convencional de aplicación de la palinología arqueológica, pero sí es susceptible de una cierta formalización matemática, que permita su tratamiento en una investigación.

Volviendo al caso de una sola especie vegetal, entendemos que el hecho observable que conecta su presencia en el registro polínico con su distribución espacial es la variabilidad de su cantidad en distintos puntos del espacio, es decir, la varianza de su distribución espacial. Ahora bien, como hemos visto, ésta además depende de la influencia de varios factores que consideramos como fuentes de la varianza de la distribución. Las técnicas de análisis de la varianza permiten descomponerla, asignando a cada factor la cantidad que le corresponde.De este modo podemos tomar el resto, es decir, la varianza no asignada, como representación de la variabilidad espacial de la especie emisora más la debida al azar. Este esquema puede ser generalizado a todos los palinomorfos identificados, dando lugar a un modelo general de la lluvia polínica.

Nuestro objetivo general es informar este modelo para la región de estudio. La figura 6 esboza este diseño. Su primer estrato representa el sustrato real de la investigación, es decir, el paisaje actual, dentro del cual distinguimos esquemáticamente dos campos de observación: la morfología de la vegetación y la lluvia polínica. La observación de estos dos componentes del paisaje actual da lugar a las correspondientes formalizaciones o segunda instancia del proceso:

1) registro polínico: representa la variabilidad espacial de la lluvia polínica actual en la forma de

T. P., 57, n. $^{\circ} 1,2000$ 
PAISAJE ACTUAL

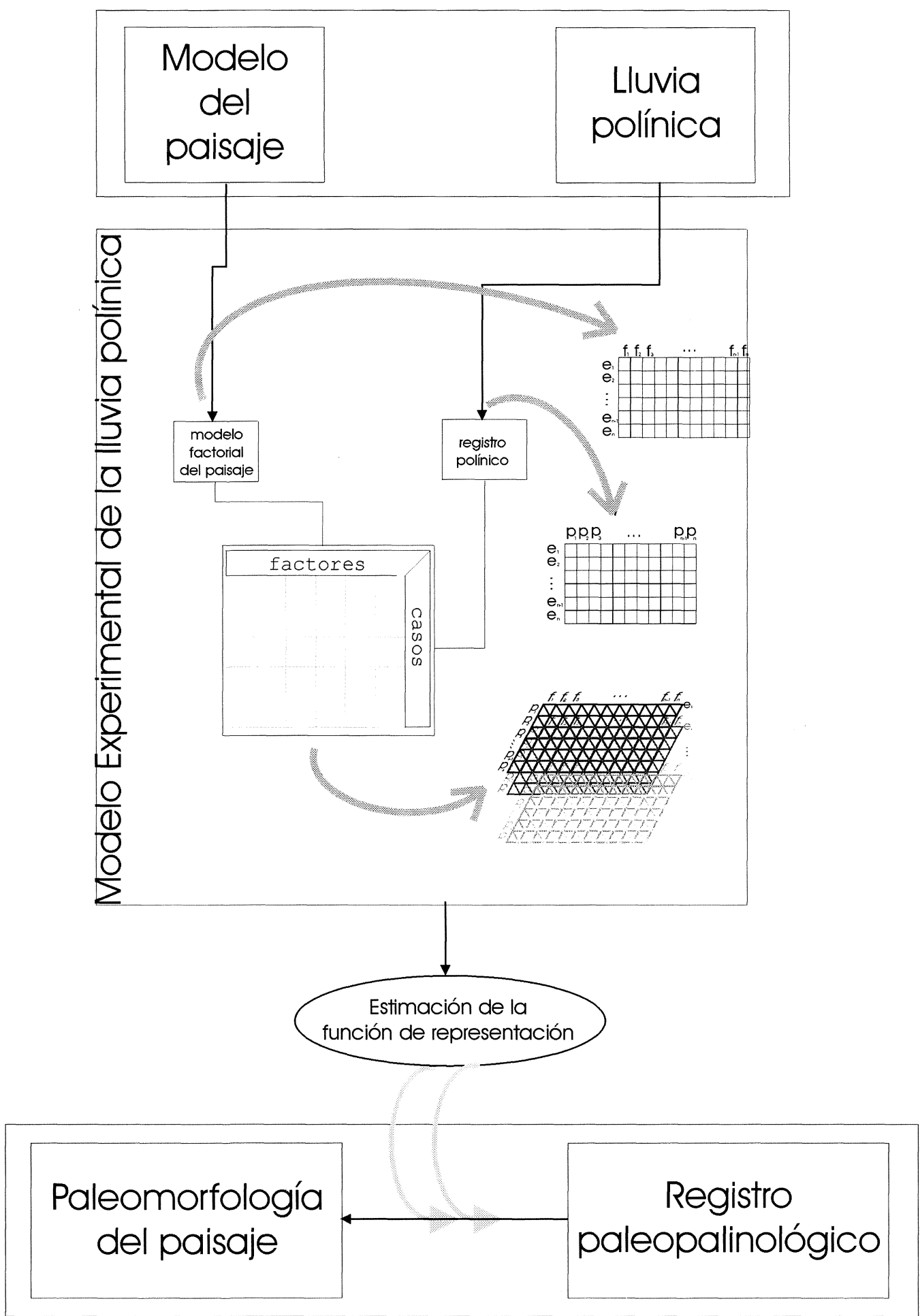

\section{PALEOPAISAJE}

Fig. 6. Diagrama del proceso de modelización de la investigación del Proyecto Kargaly. 
un número suficiente de espectros polínicos obtenidos en distintos puntos del territorio.

2) Modelo del paisaje: representa la variabilidad espacial de los distintos factores considerados en el modelo.

La siguiente instancia del proceso consiste en la consideración conjunta del registro polínico y el modelo del paisaje para constituir el modelo de la lluvia polínica, que contiene los espectros polínicos observados junto con los valores de cada factor contextual en cada punto de observación. El análisis de la covarianza entre los componentes de los espectros polínicos (clases de palinomorfos) y los factores contextuales conduce a la formulación de un modelo predictivo de lo que hemos llamado "función de representación".

El modelo de la lluvia polínica puede ser aplicado al registro paleopolínico para estimar su significado en términos de paleomorfología de la vegetación. Esto último requiere una discusión previa del grado en el que pueden ser extrapoladas al pasado las relaciones significativas de asignación de varianza identificadas en el modelo, i.e. el grado de dependencia de cada factor con respecto a las condiciones actuales. Así podemos suponer que la influencia de la altitud, o de los propios mecanismos de dispersión de cada especie son permanentes, mientras que no lo es la incidencia de la antropización.

Plasmar este diseño general en un programa viable de investigación requiere lograr una suficiente formalización del mismo a través de una metodología de modelización. La hipótesis de trabajo fundamental es que una parte muy relevante de los componentes que se citan, empezando por la morfología del paisaje y la variabilidad polínica y continuando por los factores contextuales y tafonómicos, es susceptible de cuantificación lo cual implica que es modelizable estadísticamente.Muchos de los factores citados pueden representarse como variables aleatorias, al adoptar su influencia valores mensurables en diferentes escalas (nominales, ordinales o de intervalo) y especificables para cada punto del territorio. Por otra parte, los propios registros polínicos son resultado de un muestreo estadístico, y se representan en forma de distribuciones de frecuencias.Son, pues, intrínsecamente modelizables: un espectro polínico es sólo el resultado de un experimento aleatorio que consiste en establecer la frecuencia de ocurrencia de los valores de una escala nominal (lista de taxones) en una muestra representativa extraida de una población constituida por la totalidad de los granos de polen contenidos en un sedimento.

Esas condiciones sugieren la posibilidad de afrontar la modelización del proceso de representación en términos matemáticos. En la etapa de modelización los distintos elementos representados en la figura 6 aparecen como matrices de datos. Así el registro polínico queda formalizado como una tabla cuyas filas corresponden a los distintos espectros polínicos $\left(\mathrm{e}_{1}, \mathrm{e}_{2}, \ldots \mathrm{e}_{\mathrm{n}}\right)$ y cuyas columnas a los distintos palinomorfos identificados $\left(\mathrm{p}_{1}, \mathrm{p}_{2} \ldots \mathrm{p}_{\mathrm{n}}\right)$, figurando en cada celdilla la frecuencia del palinomorfo $\mathrm{p}_{\mathrm{x}}$ en el espectro polínico $\mathrm{e}_{\mathrm{y}}$.

Por su parte el modelo del paisaje consiste en una matriz cuyas filas representan los distintos puntos de la matriz topológica general del territorio $\left(\mathrm{xy}_{1}, \mathrm{xy}_{2} \ldots \mathrm{xy}_{\mathrm{n}}\right) \mathrm{y}$ cuyas columnas son los distintos factores $\left(f_{1}, f_{2} \ldots f_{n}\right)$, teniendo cada celdilla el valor que toma el factor $f_{x}$ en el punto topográfico $x y$ Esta matriz incluye otra más restringida, cuyas filas corresponden a los distintos puntos del territorio en los que han sido obtenidos espectros polínicos. Al superponer esta última matriz con la que contiene el registro polínico obtenemos la matriz del modelo experimental de la lluvia polínica, que aparece en el diagrama como una superposición de matrices, cada una de las cuales corresponde a un espectro polínico localizado $\left(\mathrm{e}_{1}, \mathrm{e}_{2}, \ldots \mathrm{e}_{\mathrm{n}}\right)$. Cada matriz es una tabla de doble entrada que combina los valores locales de cada palinomorfo con los de cada factor, recogiendo cada celdilla la contingencia del factor $\mathrm{f}_{\mathrm{x}}$ sobre la frecuencia del palinomorfo $\mathrm{p}_{\mathrm{y}}$.

El término "experimental" alude aquí al contexto metodológico de la estadística inferencial. Una vez formalizado el problema en términos de un modelo estadístico, podemos afrontar la investigación como un proceso de contrastación experimental de hipótesis acerca de la estructura del modelo. Estas hipótesis hacen referencia a la existencia o no de relaciones significativas de asociación o correlación entre variables contextuales y distribución de palinomorfos o grupos de palinomorfos, y en conjunto definen un modelo teórico del proceso de formación del registro polínico a partir de las condiciones específicas del paisaje actual. En la última sección del artículo se ofrecen algunos ejemplos de este tipo de experimentos estadísticos y su inserción en las argumentaciones interpretativas de nivel más alto, relativas a los fenómenos investigados.

La articulación de estas propuestas metodológicas en un programa de investigación requiere,

T. P., 57, n. $^{\circ} 1,2000$ 
como se ve en la figura 6 , la formalización de tres campos de observación: el paisaje actual, la lluvia polínica actual y el registro paleopalinológico. La información de los correspondientes modelos de datos determina una investigación en tres etapas paralelas:

1) Investigación paleobotánica convencional, destinada a la formación de un cuerpo de datos sobre la variabilidad diacrónica del registro polínico.

2) Modelización del paisaje actual de Kargaly, cuyo objetivo es obtener una representación de la variabilidad actual de los factores considerados relevantes en la investigación.

3) Estudio sistemático de la lluvia polínica actual para crear un cuerpo de espectros polínicos localizados que pueda ser objeto de un análisis cruzado con las variables que intervienen en el modelo del paisaje.

La primera de las etapas de investigación no es objeto del presente trabajo, aunque sus resultados se dan aquí por supuestos. Como ya indicamos (apdo. 1.3.), incluyó flotaciones sistemáticas de sedimentos, obtención de restos antracológicos y secuencias paleopalinológicas en la excavación del poblado Gorny 1 (López García et alii, 1996), así como un intenso estudio arqueozoológico (Antipina, 1999). Los datos paleobotánicos se enriquecieron con secuencias polínicas apoyadas en dataciones de $\mathrm{C} 14$ en otros contextos arqueológicos (poblados Gorny 2 y Novenki) dentro del área de estudio, y secuencias de control en depósitos naturales dentro y fuera de la misma, hasta reunir un total de 11 secuencias.

El principal objetivo del programa de investigaciones paleobotánicas fue potenciar al máximo la variabilidad de las secuencias paleopalinológicas disponibles, tanto en lo que se refiere a la localización de emplazamientos como a las condiciones específicas de formación del registro, combinando por ejemplo depósitos naturales y arqueológicos. No es menos importante el esfuerzo por controlar las condiciones de comparación entre secuencias mediante dataciones radiocarbónicas y control estratigráfico, y entre datos actuales y paleopalinológicos mediante criterios explícitos de muestreo y control de las condiciones tafonómicas. En las dos secciones siguientes se desarrollan los planteamientos de las etapas segunda y tercera de la investigación, en cuanto propuesta integral de aplicación de varias metodologías de modelización numérica a problemas de Arqueología del Paisaje.

\section{UN MODELO FACTORIAL DEL PAISAJE DE KARGALY}

\subsection{Metodología y técnicas}

Como se ha dicho, el objetivo de la etapa de modelización del paisaje actual es doble: por un lado, describir la morfología actual de la vegetación; por otro proveer de datos sobre la variabilidad de parte de los factores contextuales relevantes en la formación del registro polínico. Se trata de los que dependen de características específicas del territorio, como los que hemos denominado geográficos, ecológico-paisajísticos y una parte de los tafonómicos (por ejemplo, la variabilidad edafológica).

En este contexto, y ateniéndonos a una elaboración prematemática del concepto, entendemos por "modelización del paisaje" su representación a partir de una serie limitada de magnitudes y variables que dan cuenta de aquella parte de su complejidad real que es relevante para un propósito concreto (en este caso los objetivos enunciados en el párrafo anterior). El fundamento metodológico de este enfoque y de su elaboración matemática está en el concepto de modelo factorial del paisaje, propuesto por J. Díaz Álvarez (1984) y desarrollado para el contexto de la Arqueología del Paisaje por uno de nosotros (Vicent, 1991: 41). Este concepto distingue dos categorías de componentes en los paisajes:

a) elementos: "componentes externos de un paisaje (...), es decir, aquellos rasgos directamente observables que permiten describirlo" (Díaz Álvarez, 1984: 19). La especificidad de los elementos como sustrato "descriptible" de un paisaje se expresa normalmente por la posibilidad de cartografiarlos.

b) factores: "componentes explicativos (...): cada una de las circunstancias o condiciones que determinan la configuración concreta de los elementos de un paisaje (...) [sus] determinantes estructurales" (Vicent, 1991: 42). En general, lo que identifica a los componentes factoriales del paisaje es que pueden ser medidos y tabulados, es decir, expresados como variables aleatorias.

Llamamos modelo factorial del paisaje a la representación de sus componentes morfológicos (elementos) en función de sus componentes genéticos (factores) (Díaz Álvarez, 1984: 106 y ss.). Cuando esta representación se construye a partir de la expresión de los factores como variables aleatorias tenemos finalmente un modelo probabilístico 
o experimental de los elementos considerados: "un paisaje (...) puede expresarse como un modelo matemático definido por la combinación lineal resultante de la combinación de todos sus elementos siendo dado cada elemento como un vector de factores" (Díaz Álvarez, 1984: 108).

Aquí no nos proponemos modelizar la totalidad del paisaje, sino sólo aquellos de sus componentes que suponemos relevantes en la determinación de la variabilidad de la lluvia polínica y su fosilización. Son, en términos generales, tres: la distribución de la vegetación, la distribución de los suelos y la morfología topográfica del terreno. Cada uno de ellos puede ser cartografiado. Modelizarlos significa encontrar combinaciones de magnitudes mensurables que permitan dar cuenta del contenido de los mapas correspondientes como una matriz de datos según el modelo de la figura 6.

En la topografía este paso resulta trivial: un mapa topográfico no es más que la representación gráfica de la combinación geométrica de tres variables (latitud, longitud y altitud). Su expresión factorial es un modelo digital del terreno (en adelante MDT) o matriz coordenada de los valores de estas tres dimensiones para todos los puntos de un territorio determinado. La vegetación o la edafología, sin embargo, no tienen una solución intuitivamente tan accesible. Aparentemente, la cartografía de la vegetación sólo es posible mediante la observación pormenorizada del terreno y el registro descriptivo de la localización de las distintas poblaciones y asociaciones vegetales. En realidad, sí existen factores mensurables comunes a todas las cubiertas vegetales, y que dependen de su naturaleza física. Como veremos con mayor detalle, todas las plantas fotosintéticas exhiben patrones característicos y específicos de absorción y reflexión de la radiación solar. Por lo tanto, bajo ciertas condiciones, la medición sistemática de la reflectancia de la superficie del terreno para determinadas regiones del espectro electromagnético, si fuera posible con el adecuado nivel de precisión, permitiría dar cuenta de la variabilidad específica de las cubiertas vegetales mediante una sola variable, o una combinación de un número limitado de éllas. Bajo esas condiciones, una matriz numérica de datos radiométricos de un territorio puede constituir una expresión factorial de la variabilidad de las cubiertas vegetales, representable analógicamente como un mapa de la vegetación.

El enfoque es aplicable igualmente a la variabilidad edáfica, puesto que varios de los componen- tes genéticos de la misma (naturaleza físico-química, humedad) se manifiestan también en forma de modificaciones observables en la respuesta espectral de los suelos.

En resumen: es posible construir modelos radiométricos que expresen factorialmente tanto la variabilidad de las cubiertas vegetales como la de las características edáficas. Queda por ver cómo es posible informar empíricamente estos modelos y operar con éllos con objeto de extraer datos sobre los factores determinantes de la variabilidad de la lluvia polínica.

El extraordinario desarrollo en los últimos años de métodos y tecnologías aplicables a la modelización del paisaje hace posible la puesta en práctica de este enfoque. La investigación que se presenta implica un uso intensivo de este tipo de tecnologías, particularmente de tres de ellas: la Teledetección espacial (desde ahora TD), los Sistemas de Información Geográfica (SIG) y el Sistema de Posicionamiento Global (GPS).

La TD nos da acceso a datos primarios sobre la variabilidad radiométrica del terreno a partir de las mediciones remitidas por sensores multiespectrales alojados en plataformas orbitales. Estos datos permiten la modelización de numerosas características relevantes de la superficie terrestre en forma tanto de variables numéricas como de representaciones analógicas (imágenes), cuya síntesis constituye lo que llamaremos un modelo radiométrico del paisaje. Como se sabe, en la actualidad la TD se aplica masivamente a una multitud de propósitos científicos, económicos, administrativos, etc. que tienen como rasgo común la necesidad de cartografiar con precisión características concretas y radiométricamente observables de la superficie terrestre, o medir su variabilidad espacio temporal. Entre estos propósitos destacan, por la cantidad de aplicaciones propuestas, los que tienen que ver con la vegetación y los suelos. El proyecto Kargaly propone un campo de aplicación concreto de la TD en problemas de Arqueología del Paisaje, mediante técnicas de modelización radiométrica de la vegetación y los suelos.

Las tecnologías SIG son una herramienta insustituible en un proyecto de este tipo, al permitir la integración de numerosos factores geográficos expresados en modelos matemáticos, incluyendo, por supuesto, los citados modelos radiométricos. Desde este punto de vista, y en cierto sentido, el trabajo de investigación se orienta a la creación de una representación SIG del problema. Este objetivo exige

T. P., 57, n. $^{\circ} 1,2000$ 


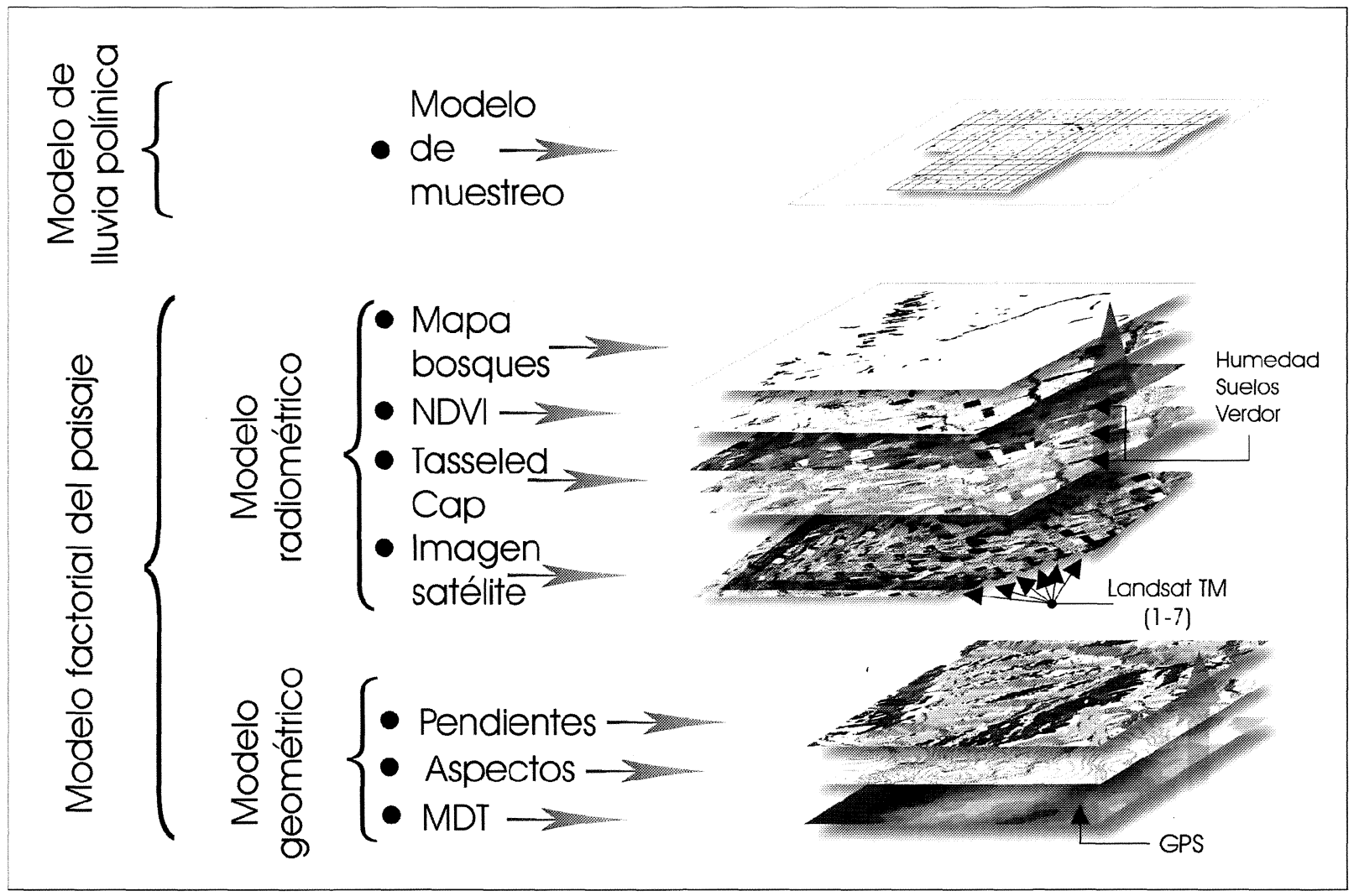

Fig. 7. Representación esquemática del modelo experimental del paisaje del Proyecto Kargaly.

que tanto la información que se refiere a los factores geográficos y contextuales cuanto los datos botánicos propiamente dichos (una y otros procedentes en gran parte de observaciones sobre el terreno), esté espacialmente referenciada y sea integrable en lo que llamaremos un modelo geométrico o cartográfico del paisaje. La tecnología GPS ofrece la posibilidad de verificar estos objetivos y ha sido aplicada sistemáticamente en todas las fases de la investigación: generación de datos para el MDT, georreferenciación de imágenes de satélite, elaboración de los modelos de muestreo, localización y control espacial del muestreo palinológico, trabajo de evaluación de la verdad terreno, y en general, control cartográfico de las observaciones de campo.

La aplicación de la tecnología SIG a la modelización del paisaje no sólo tiene ventajas operativas, sino heurísticas, al permitir visualizar fácilmente la estructura del modelo (Fig. 7). La representación de un elemento del paisaje en función de uno o varios factores consiste en la construcción de matrices de datos como se ve en la figura 6. Cada una de estas matrices puede ser analógicamente figurada igual que un mapa, y corresponde a una capa temática del SIG. El modelo factorial del paisaje, como totalidad, consiste pues en un conjunto coherente de mapas temáticos ajustados a un mismo espacio referencial que simboliza la matriz topológica, o modelo geométrico, del terreno en estudio. Este conjunto de mapas expresa gráficamente el modelo numérico, consistente en una matriz de tantas dimensiones como factores (capas).

Como se ve en la figura 7, el modelo de Kargaly, en su estado actual de elaboración, se compone del citadomodelo geométrico, y unmodelo radiométrico constituido a su vez por una serie de capas. Cada una se refiere a una matriz de datos radiométricos para todos los puntos de la superficie modelizada. Estas matrices resultan del procesamiento de datos obtenidos por el sensor TM del satélite Landsat 5, y corresponden a las distintas variables que dan cuenta del continuo vegetación-suelos (cft. infra).

La matriz de datos del modelo representa el paisaje como una distribución multivariable de valores para cada punto del terreno modelizado. Cada uno de esos "puntos" corresponde a una celdilla de 
la matriz de datos, cuya combinación de valores define la especificidad de un espacio real del terreno en relación con las características modelizadas. Por ejemplo: "los valores específicos del modelo espectral en un punto de coordenadas $\mathrm{x}$ e y denotan que el terreno está ocupado por un cultivo de cereales sobre un suelo de tipo chernozem con un determinado grado de humedad; los valores del MDT para ese mismo punto denotan que está situado a $\mathrm{z} \mathrm{m}$ de altitud, sobre una ladera de pendiente $\mathrm{p}$ y orientación de a grados".

La forma como se verifica en la práctica esta función de representación depende de tres decisiones metodológicas: la delimitación del terreno que es el sustrato real de la representación, el tipo y número de variables seleccionadas y la escala del modelo. La primera de estas cuestiones depende de decisiones externas al propio proceso de modelización conectadas con la delimitación teórica de los objetivos de investigación. En el presente caso, investigamos fenómenos que sólo son perceptibles a escala regional.

En las secciones siguientes presentaremos las soluciones adoptadas en el Proyecto Kargaly y argumentaremos acerca de su adecuación al problema de referencia: la modelización estadística de los factores determinantes de la variabilidad de la lluvia polínica.

\subsection{Escala del modelo: resolución espacial y delimitación del territorio}

La escala de un modelo es el grado de simplificación existente entre éste y su referente real. En primera instancia, el término alude a las dimensiones espaciales, pero aquí se amplía a otras dimensiones de información (espectrales, botánicas, topográficas...). La escala, en los dos sentidos que acaban de apuntarse (espacial e informacional) depende de dos factores: la resolución o precisión y el tamaño o complejidad del referente.

La resolución espacial es el tamaño de la porción de la superficie real modelizada que corresponde a la unidad mínima de información del modelo. Como se ha dicho, nuestro modelo numérico del paisaje es una matriz de datos que contiene los valores de determinadas variables para cada punto de una superficie real de terreno. En términos geométricos, cualquier superficie comprende infinitos puntos, lo cual resulta contradictorio con el objetivo de la modelización, que es representar de modo simplificado la realidad. Los "puntos" del modelo serán por lo tanto extensos, conformando áreas para las que los valores de las variables se consideran únicos.

En Kargaly, dado que una de las principales fuentes de información manejadas es una imagen Landsat $5 T M$, se ha ajustado la resolución de la totalidad del modelo a la suya $(30 \mathrm{~m})$. Así, la unidad mínima de información se corresponde con las superficies de $30 \times 30 \mathrm{~m}$ de las celdillas de la matriz numérica y/o a los pixels de las imágenes digitales que constituyen su representación analógica.

La definición de la resolución, junto con la delimitación de la superficie de terreno modelizada, determinan la escala, el tamaño de la matriz de datos y la precisión con la que es necesario pautar las escalas de medida específicas de cada variable considerada.

La precisión, o resolución informativa, de cada variable es la cantidad mínima de variación en el valor del factor al que corresponde que es consignable en el modelo. Sus parámetros vienen en gran parte dados por las soluciones técnicas adoptadas para los procesos de observación, y se discutirán más adelante.

Las decisiones metodológicas relativas a la delimitación del territorio modelizado dependen de los objetivos teóricos de la investigación y, en gran parte, también de los medios disponibles para llevarla a cabo. En consideración a unos y otros, el proyecto limitó su área de estudio a una parte del complejo arqueológico de Kargaly, suficientemente extensa como para recoger unidades geográficos coherentes a escala regional y suficientemente reducida como para resultar abordable en las condiciones de trabajo del proyecto.

Se ha trabajado a dos escalas: un área general de $774 \mathrm{~km}^{2}$, rectangular sobre un eje N-S, y un área de trabajo menor $\left(145 \mathrm{~km}^{2}\right)$, definida en su interior, donde se ha concentrado el trabajo analítico (Fig. 1C). El modelo se ha elaborado en su totalidad sólo para esta última, mientras que la primera informa sobre el contexto regional necesario para la correcta referenciación e interpretación de los datos radiométricos. Esa delimitación espacial pretende:

1) contextualizar el registro arqueológico: el área general, atendiendo a criterios de coherencia geográfica, toma como centro geométrico el poblado minero de la Edad del Bronce de Gorny 1 (apdo. 1.3.1), centro aproximado, además, del área que ha focalizado las excavaciones y prospecciones arqueológicas del proyecto. 
2) Obtener una representación significativa de la variabilidad regional del paisaje constituida por unidades completas y coherentes en su significado geográfico.

El área general incluye cinco distritos mineros (de los 11 distinguidos por Chernykh, 1994: fig. 2) del cuadrante suroccidental del complejo de Kargaly, y es una representación significativa del paisaje regional (Fig. 1C). Este está constituido básicamente por valles poco profundos excavados en la llanura por los ríos Kargalka, Ianguiz y Salmisch que corren en dirección NO-SE para desembocar, en cotas de unos $100 \mathrm{msnm}$, en el Sakmara que, a su vez, lo hace en el Ural. Este sistema de drenaje está limitado hacia el Oeste por una dorsal de máximas elevaciones (>300 msnm) que recorre la región en dirección $\mathrm{N}-\mathrm{S}$, con un trazado ligeramente sinuoso, separando la cuenca del Ural, al Este de la del Volga al Oeste. El sistema de drenaje se articula a partir de esta divisoria de aguas como un conjunto de barrancos transversales que cortan los páramos interfluviales y desembocan en los cursos principales mencionados. Así pues, el conjunto del paisaje está definido por la alternancia de páramos interfluviales, barrancos y valles fluviales que descienden escalonadamente desde los $300 \mathrm{msnm}$ a poco más de $100 \mathrm{msn}$ en dirección O-E.

El área de trabajo ha sido delimitada para captar la integridad del drenaje del río Usolka. Los elementos del sistema se pueden distinguir claramente: la mitad meridional del área está ocupada por la cuenca de recepción del Usolka, que se apoya al Oeste y Sur directamente sobre la divisoria (Fig. 1, Lam. I). Luego toma dirección Norte para trazar una amplia curva hacia el Este, al encuentro del más caudaloso Kargalka, con el que confluye en el cuadrante NE del área. La divisoria de aguas recorre en dirección N-S su tercio occidental, por lo que todo el tercio central está ocupado por su ladera oriental, en la que se abren varios barrancos de dirección $\mathrm{O}-\mathrm{E}$ que desaguan en el Usolka. Por último, el cuadrante SE está ocupado por la llanura sobreelevada (sirt) que el Usolka rodea al describir su curva. Esta llanura, ligeramente basculada hacia el Oriente, no presenta barrancos sobre el Usolka, sino que desagua en dirección Este, directamente en el Kargalka, cuyo valle corre paralelo al primero en dirección Sur, ya fuera del área de trabajo. Por su variedad topográfica interna contiene la totalidad de las unidades de paisaje que caracterizan a Kargaly en su conjunto.

\subsection{Modelo geométrico o topográfico}

El modelo geométrico de Kargaly es la definición del área de estudio en cuanto espacio físico coordenado, en relación tanto a su posición global en la Tierra (georreferencia) como a la estructura interna de su matriz topográfica. El proceso de georreferenciación es fundamental, por cuanto establece las dimensiones básicas de la matriz de datos y permite coordenar todas las variables en un espacio homogéneo. En Kargaly, dicho proceso se vio afectado por las condiciones de trabajo (8).

Como base cartográfica se utilizaron las series de mapas topográficos (9), de la región de Kargaly 1: $25.000,1: 50.000$ (escala de referencia) y 1: 100.000, así como otros materiales cartográficos a escalas mayores de la región de Orenburg y la RF de Bashkiria.

Desde 1942 la Unión Soviética estableció como elipsoide de referencia el de Krasovsky, condatum Púlkovo, y como sistema de coordenadas planas rectangulares el de Gauss-Krüger (proyección conforme). Al sistema se le denomina Sistema de Coordenadas 1942, tal y como aparece en la cartografía soviética. La transformación a este sistema desde WGS-84 no ofrece grandes complicaciones ya que los propios programas de cálculo incorporan los parámetros para realizarlo. Pero el problema fundamental proviene del hecho de que, como herencia de la "Guerra Fría", la cartografía militar soviética introdujo un sistema de distorsiones en la proyección que hacen imposible su uso en el proceso de georreferencia. Esto nos obligó a apoyar todo el proceso en observaciones GPS sobre el propio terreno en los puntos elegidos y, posteriormente, recurrir a una transformación plana por mínimos cuadrados entre las coordenadas obtenidas y las coordenadas mapa para poder superponer aquéllas sobre éstas. Para alcanzar el grado de precisión determinado por la escala elegida $(<30 \mathrm{~m})$ se empleó la técnica diferencial lo que, en las condiciones del área, planteó importantes problemas logísticos. En efecto, la inexistencia de bases comunitarias de GPS en la región requirió la instalación de una estación GPS permanente, generadora de las correcciones diferenciales necesarias para los receptores móviles. Como estación de referencia se empleó un receptor de 12 canales en L1 y código C/A alimentado por

(8) Muchos desplazamientos debieron hacerse a pie y sin poder acceder, en principio, a la cartografía que todavía allí se mantiene secreta.

(9) Glavnoie Upravleniie Geodezii i Kartografii GGK SSSR. 
baterías y con apoyo fotovoltaico a base de paneles solares portátiles. Como receptores móviles se usaron receptores de código C/A y L1 de 6 canales. El uso de sistemas portátiles de alimentación fotovoltaica, determinado por la imposibilidad de acceder a otras fuentes de energía (red eléctrica), constituyó una interesante y positiva experiencia técnica (Lám. IIA).

La mayor parte de los datos para la georreferencia del modelo se obtuvieron durante la campaña de 1997. La estación base de GPS se situó en el campamento de la expedición a unos $6.5 \mathrm{~km}$ al NO de Gorny 1. En este área se referenciaron mediante observaciones GPS 195 puntos, topográficamente identificables en la imagen Landsat TM y/o en la cartografía, incluyendo los vértices de la red geodésica rusa. La corrección geométrica de la imagen Landsat TM se hizo a partir de 45 de esos puntos.
El conjunto de los datos permitió informar los algoritmos de transformación entre sistemas de coordenadas y corregir las distorsiones cartográficas para el área de trabajo. El ajuste de la corrección de la imagen Landsat TM fue evaluado mediante observaciones GPS y puede estimarse en $<10 \mathrm{~m}$. Una vez georreferenciada, el área general queda orientada sobre un eje NE/SO, como consecuencia de la inclinación de la órbita que describe el satélite Landsat 5 (Fig. 1B,C).

Una vez georreferenciada el área general se generó el MDT del área de trabajo a partir de la información altimétrica de la cartografía 1: 50.000 (curvas de nivel y puntos acotados) (Fig. 8). Se procesaron algo más de 14000 geodatos para crear una malla tridimensional de $30 \mathrm{~m}$ de paso. A partir de esta malla se calcularon las matrices de pendientes y aspectos (orientación de las pendientes).

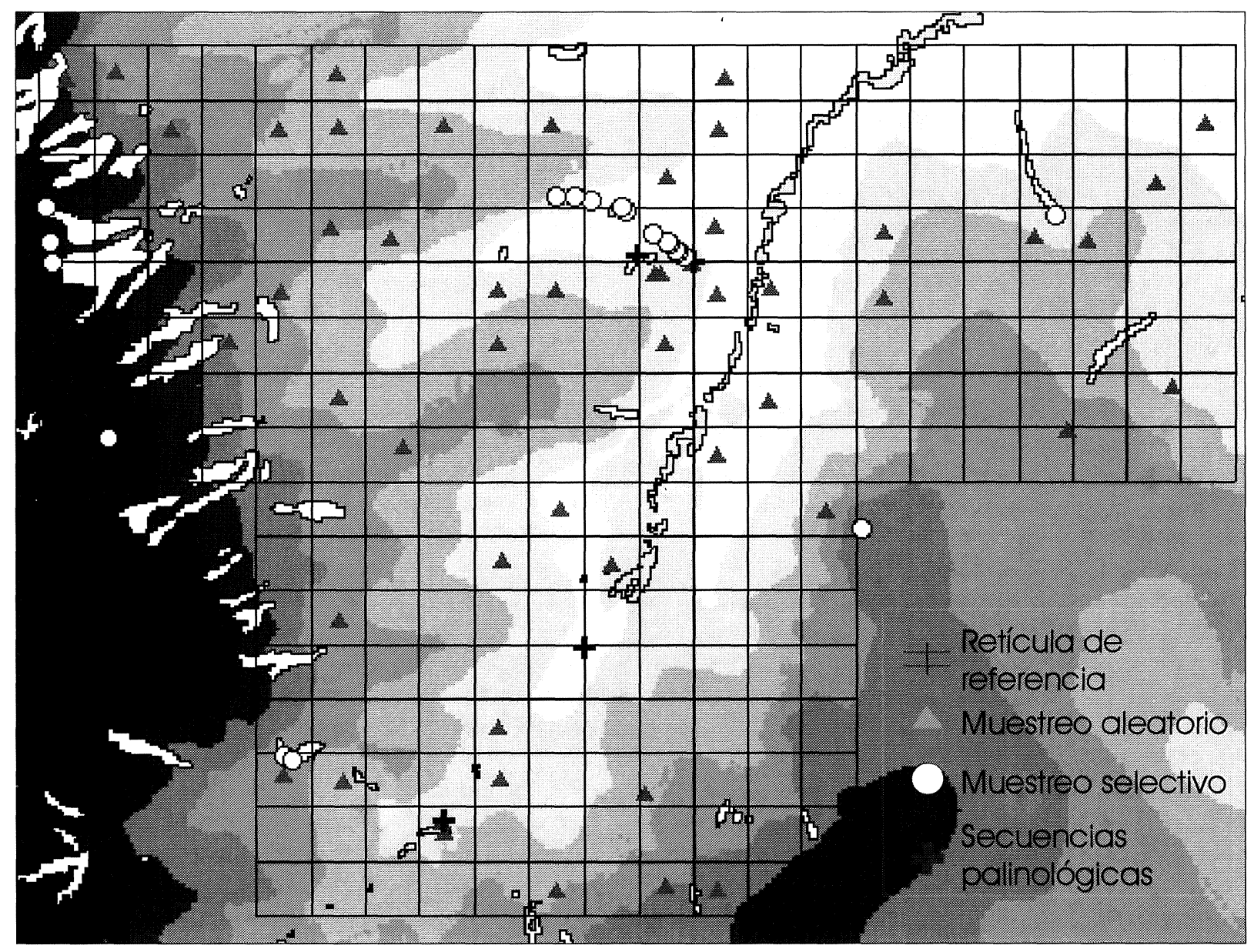

Fig. 8. Retícula de referencia para el muestreo palinológico en las dos zonas incluidas en el área de trabajo (Fig. 1): Gorny (al norte) y Novenki. Sobre el mapa de alturas (MDT) se representa también el mapa forestal. 


\subsection{Modelo radiométrico}

\subsubsection{Introducción}

La teledetección espacial ha permitido el uso de imágenes de satélite como soporte básico de un SIG en contexto arqueológico (Chapa et alii, 1998) y generar cartografías temáticas precisas a un coste relativamente bajo, a partir de los datos captados por sensores remotos desde plataformas orbitales. Esta posibilidad se fundamenta en la respuesta diferencial de las distintas coberturas de la superficie terrestre ante la radiación electromagnética procedente de la iluminación solar, que es absorbida o reflejada en función de la naturaleza físico-química y estado de las mismas. Cada tipo de cubierta presenta una respuesta espectral específica en cada una de las regiones del espectro electromagnético que puede ser registrada por los sensores remotos. Las imágenes de satélite contienen pues información sobre la distribución y variabilidad de todos aquellos factores geográficos que determinen pautas diferenciales en la reflectancia de la corteza terrestre. Llamamos modelo radiométrico de un paisaje a la estimación de la variabilidad espacial de un conjunto de factores geográficos establecida a partir del análisis de la variabilidad espectral del terreno.

La cubierta vegetal, objetivo de nuestra investigación, representa además un caso típico de aplicación de la TD. Todos los organismos fotosintéticos contienen uno o más pigmentos capaces de absorber radiación en aquella parte del espectro visible responsable de las reacciones físico-químicas de la fotosíntesis. Así mientras la mayor parte de la energía recibida por las plantas fotosintéticas en las regiones del Rojo $(0.63-0.69 \mu \mathrm{m}) \mathrm{y}$ del Azul (0.45-0.52 $\mu \mathrm{m})$ es absorbida, por el contrario la radiación infrarroja próxima (0.76-0.90 $\mu \mathrm{m})$ es reflejada en su mayor parte. Estas propiedades de reflexión y absorción dependen de dos factores básicos: la naturaleza de la planta (es decir, su identidad taxonómica) y su estado en cada momento del tiempo. Su absorción del rojo y azul, y la fuerte reflexión de infrarrojo próximo conforman, pues, la diferencia espectral de la respuesta de toda la vegetación y pueden usarse para la modelización de su distribución, características y estado.

D'Antoni y Spanner (1993) usaron modelos radiométricos de la vegetación actual para la calibración de datos paleopalinológicos mediante un Índi- ce Normalizado de Vegetación (desde ahora NDVI según sus siglas en inglés) calculado a partir de datos del satélite NOAA. Su fin era explicar la composición cualitativo/cuantitativa de espectros polínicos de la región de estudio. Aquí tratamos de desarrollar esta idea, intensificando la resolución tanto de los datos radiométricos cuanto de los datos botánicos incorporados al modelo.

Las imágenes de satélite y los datos derivados de su procesamiento proporcionan una representación sintética de algunos factores físicos relevantes subyacentes en la variabilidad de la vegetación. Esa representación es susceptible de ser cuantificada y espacialmente referenciada en la forma de variables aleatorias que pueden usarse para caracterizar su naturaleza (composición) y estado (momento del ciclo vegetativo, densidad, vigor, etc.).

Ese principio tiene dos posibles implicaciones para nuestros objetivos. Primero podemos suponer que la configuración del espectro polínico en un punto se relaciona con la naturaleza y estado de la vegetación de su entorno y, por lo tanto, con parte de las variables que los describen. De aquí se deriva la posibilidad de analizar las representaciones radiométricas de las cubiertas vegetales en términos de registro polínico. Así cabe pensar que la presencia de pólenes arbóreos depende no sólo de que haya formaciones forestales, sino de su densidad y extensión. Por lo tanto, en ausencia de otros factores debería guardar algún tipo de correlación con valores radiométricos específicos de las variaciones de verdor y humedad, dentro del rango espectral característico de las superficies arboladas. Esta posible relación puede ser investigada estadísticamente. En segundo lugar el análisis de las caracterizaciones espectrales de las cubiertas vegetales puede permitirnos cartografiar las formaciones que ocupan el paisaje y, por consiguiente, identificar en el espacio las fuentes emisoras de polen.De acuerdo con esto, las estrategias de explotación de los datos radiométricos en el proyecto Kargaly han sido, hasta el momento, dos:

1) generación y análisis de índices de vegetación:

2) aplicación de métodos de clasificación supervisada a la cartografía de asociaciones vegetales.

La calidad del modelo y el planteamiento de los métodos de análisis dependen en gran parte de la selección de los datos, es decir, del tipo de imagen y la fecha de adquisición de la misma. Nos detendremos en ello antes de exponer estas estrategias. 


\subsubsection{Selección de imágenes}

El trabajo se basa en una imagen Landsat 5 TM, adquirida el 26 de septiembre de 1994. Se seleccionó atendiendo a las habituales precauciones técnicas respecto a la calidad de la imagen y la ausencia de coberturas nubosas y para:

1) maximizar la resolución espectral: la imagen del sensor TM (Tematic Mapper) consta de 7 bandas, tres en la región visible del espectro (Rojo, Verde, Azul) y cuatro en la infrarroja (IR próximo, dos en IR medio e IR térmico) (10). Es, pues, la mejor opción para la investigación sobre cubiertas vegetales;

2) ajustar la resolución espacial a una escala regional de trabajo: la imagen Landsat presenta, en principio, una relativamente pobre definición espacial (30 m). Sin embargo esta resolución se adapta perfectamente a las determinaciones de escala, dada la extensión del área de trabajo, la escala de referencia (1: 50.000) y la irrelevancia de los factores morfológicos a escalas menores. En cualquier caso estos se han caracterizado sobre el terreno durante la toma de muestras botánicas;

3) maximizar la posibilidad de aplicar herramientas normalizadas y comparar resultados: la ingente cantidad de trabajo científico sobre cubiertas vegetales desarrollada desde 1984 para los estándares de Landsat TM ofrece amplias posibilidades comparativas y acceso a una gran cantidad de datos de referencia, técnicas de análisis y herramientas normalizadas. Esto facilita notablemente la tarea de interpretación.

La selección de un fecha de adquisición correspondiente a una imagen otoñal se apoya en las observaciones preliminares sobre el terreno (campaña de 1994) buscaba:

1) optimizar las diferencias entre las firmas espectrales características de las distintas especies vegetales. En el comienzo del otoño las cubiertas forestales y formaciones esteparias presentan su máxima variedad cromática, debido tanto a las diferencias entre sus ciclos vegetativos como a su máxima sensibilidad a las condiciones ambientales en el final del mismo;

2) maximizar el acceso a la observación de los suelos: la región de Kargaly tiene grandes extensio-

(10) Los rangos de frecuencias son la Roja (R) o Banda 3 (0.63-0.69 $\mu \mathrm{m})$, la Verde (V) o Banda $2(0.52-0.60 \mu \mathrm{m})$, la Azul (A) o Banda 1 (0.45-0.52 $\mu \mathrm{m})$, el Infrarrojo (IR) Próximo o Banda 4 (Irp) $(0.76-0.90 \mu \mathrm{m})$, el Infrarrojo medio (IRm) o Banda 5 (1.55-1.75 $\mu \mathrm{m}$ ), el Infrarrojo lejano (IRI) o Banda 7 (2.08-2.35 $\mu \mathrm{m})$ y el Infrarrojo (IRt) térmico o Banda $6(10.40-12.50 \mu \mathrm{m})$. nes de suelo cultivado. En la época de adquisición de la imagen, la mayoría están prácticamente desnudas, como consecuencia de los ritmos del ciclo agrícola. Después de la última recolección, la mayor parte de los campos están siendo arados o están en barbecho. Ello ofrece la máxima diferencia posible entre suelos cultivados y formaciones de pradera y estepa (difíciles de distinguir en las épocas de crecimiento de los cultivos) y una extensa "ventana" de acceso a la distribución regional de las características edafológicas;

3) maximizar la cercanía entre la fecha de adquisición de los datos y la de las observaciones sistemáticas sobre el terreno, con objeto de facilitar el reconocimiento de cubiertas sensibles a la variación interanual.

Obviamente, el manejo de una sola imagen (dictado por las reducidas posibilidades económicas del proyecto) plantea severas limitaciones a la investigación. La naturaleza y estado de las cubiertas vegetales varía a lo largo del ciclo anual, pero también se ve muy afectada por la variación interanual que, tal como hemos podido comprobar directamente, es intensa en una zona extremadamente continental, con grandes diferencias entre años secos y húmedos. Las sucesivas campañas de campo (1994, 1995, $1997,1998)$, en las que se controlaron parcelas testigo, nos permiten evaluar preliminarmente la amplitud de estas variaciones. Sin embargo para diseñar criterios de calibración más precisos, tanto de la variación interanual como de la anual, actualmente está en desarrollo la adquisición y análisis de una serie temporal amplia (series multiestacionales de varios años) de imágenes NOAA. Pese a su limitada resolución espacial $(1 \mathrm{~km})$ sus características espectrales permitirán comparaciones controladas con los datos TM para evaluar los cambios en los índices de vegetación dependientes de los ciclos de variación en las condiciones climáticas. El coste de adquisición de la imagen $N O A A$ es, por otra parte, muy reducido. Este proyecto de desarrollo de un método de calibración constituye en si mismo una línea de investigación abrierta, cuyos resultados se comunicarán en el futuro.

\subsubsection{Indices de vegetación}

Tratan de reducir a una sola dimensión la multidimensionalidad propia de las medidas multiespectrales. Básicamente, son combinaciones de bandas espectrales que, a partir de la respuesta espectral

T. P., 57, n. ${ }^{\circ} 1,2000$ 
de una superficie, realzan la contribución de la vegetación y atenúan la de otros factores como el suelo, la iluminación, la atmósfera, etc. Se obtienen a partir de transformaciones ortogonales o se basan en cocientes de bandas. En el proyecto incorporamos índices de los dos tipos, puesto que la evaluación de las posibilidades de la TD es una de sus prioridades metodológicas. Además de explorar algunos otros, hemos trabajado con un índice de tipo cociente, el NDVI (Normalized Differencie Vegetation Index) y otro de tipo ortogonal, la transformación 'Tasseled Cap'(TC).

\subsubsection{Cocientes de bandas: el NDVI}

El uso de estos índices ofrece varias ventajas en nuestras condiciones de trabajo. Primero, son una buena ayuda para elaborar criterios de separación entre cubiertas vegetales lo que es necesario en Kargaly, donde la uniformidad de algunas de ellas proporciona valores de los niveles digitales (ND) muy similares en varias de las bandas.

En segundo lugar, la topografía (en concreto las variables pendiente y orientación) produce gradientes de luminancia que son independientes de las cubiertas, al tiempo que este efecto de umbría afecta a todas las bandas del mismo modo. La ventaja considerable de los cocientes es que el resultado es independiente de la irradiancia incidente de modo que sólo la reflectancia de la cubierta concreta se verá representada en el índice.

Desde un punto de vista riguroso, estos cocientes deberían calcularse a partir de las reflectancias y no desde los niveles digitales, básicamente porque la dispersión atmosférica tiene un comportamiento diferencial en los distintos canales. En nuestro caso consideramos perfectamente válido nuestro modo de proceder porque no necesitamos interpretar físicamente los resultados, sino compararlos de forma relativa.

Hemos manejado algunos índices de vegetación basados en la combinación de bandas del visible y del IRp que, por otra parte, también son los más usados. Finalmente, siguiendo las propuestas citadas de D'Antoni y Spanner (1993) nos decantamos por utilizar como herramienta principal el cálculo del $N D V I$ (Fig. 9) que permite una buena comparación e interpretación de los resultados, al tiempo que está bastante extendido tanto en términos generales, como en investigaciones similares a la que llevamos a cabo.
La curva de reflectancia de las hojas de todas las plantas es muy parecida en las regiones del visible y el Irp. En el visible $(0.4-0.7 \mu \mathrm{m})$ la reflectancia es pequeña (alrededor del 10\%). Los pigmentos absorben la mayor parte de la radiación. Son mayoría las clorofilas a y b que tienen dos bandas de absorción, una en elAzul y otra en el Rojo. El máximo en 0.55 $\mu \mathrm{m}$ en esta región explica el color verde de las hojas (Ormeño, 1993: 89).

Como los pigmentos y la celulosa de las hojas son transparentes a la radiación en el IRp (0.7-1.3 $\mu \mathrm{m})$, la absortancia de la hoja es muy baja y prácticamente toda la radiación es reflejada o transmitida: la reflectancia alcanza valores que rondan el $50 \%$. Esta magnitud depende en su mayor parte de la estructura de la hoja y del estado fenológico de la misma. Fuera de los estados extremos, juventud y senescencia, las propiedades de las hojas de plantas anuales permanecen constantes.

A su vez, la presencia de agua tiene su mejor indicador en la banda del Infrarrojo medio (IRm), donde se localizan bandas de absorción importantes pero también se manifiesta en el visible y el Irp. Así, una disminución del contenido de agua produce un incremento en su reflectancia. En definitiva, cualquier cambio en las condiciones de las plantas lleva a cambios detectables en las diferentes longitudes de onda.

Por lo tanto, el NDVI da cuenta de la situación de la cubierta terrestre respecto a la localización y situación de la vegetación. Así sólo los valores positivos del intervalo de existencia del índice se corresponden con zonas de vegetación. Los valores negativos, generados por la mayor reflectancia en el visible que en el IRp, pertenecerán a zonas de suelo desnudo, superficies rocosas o agua, siempre desprovistas de cobertura vegetal.Al mismo tiempo el índice, a partir de las características que hemos visto anteriormente, proporciona una clave de la estructura y situación de la vegetación.

\subsubsection{2. Índices ortogonales: transformación Tasseled Cap}

Este tipo de índices se calcula mediante giros del espacio bidimensional que forman las bandas del IRp y el R. Se persigue que uno de los ejes se oriente con referencia a la línea de suelos (la más próxima al eje R) quedando el otro perpendicular al anterior. Entre ellos están el PerpendicularVegetation Index (PVI) (Richardson y Wiegand, 1977) y su 


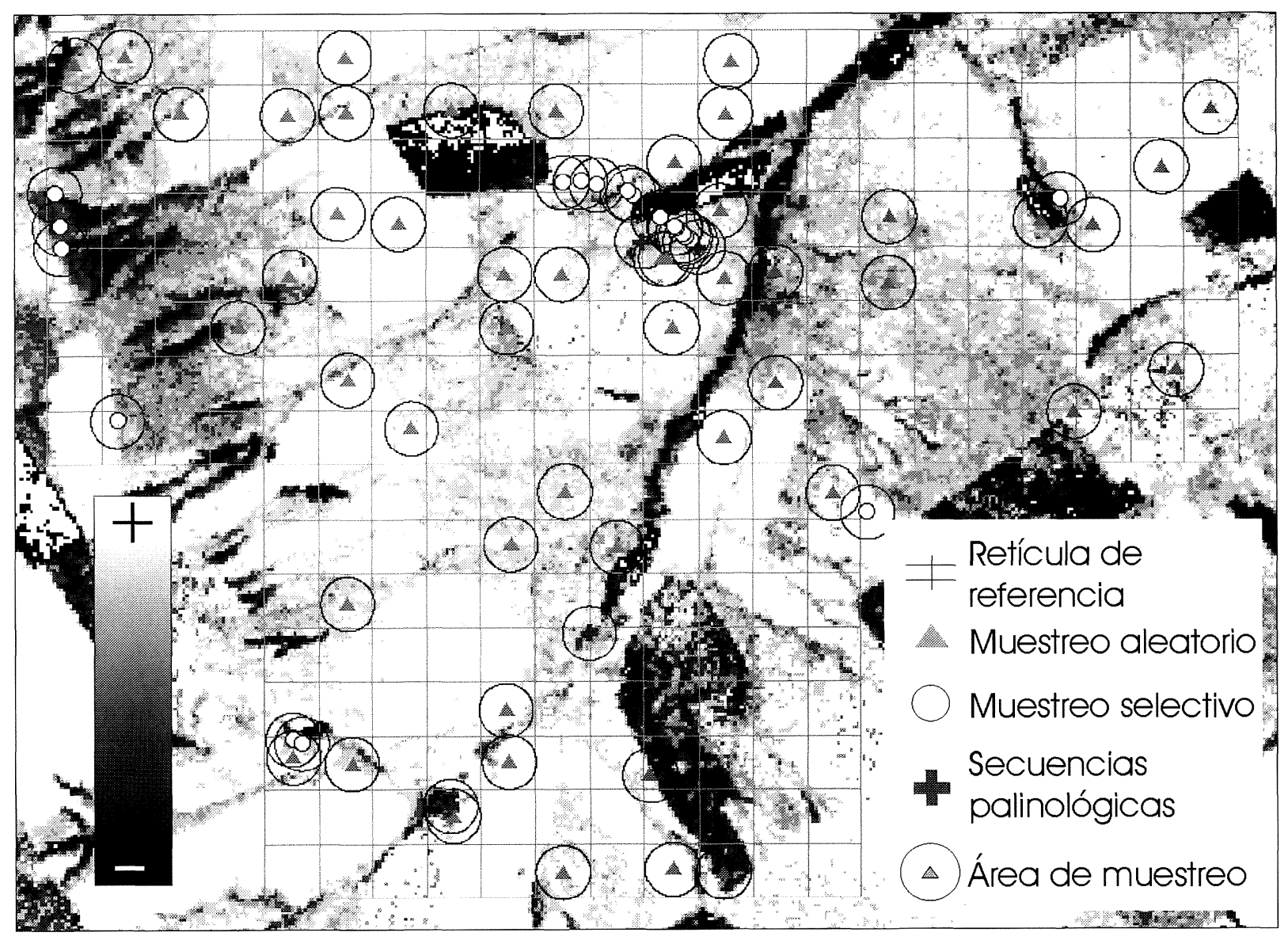

Fig. 9. NDVI del área de trabajo con representación de las áreas de muestreo de $250 \mathrm{~m}$ de radio. Se han invertido los valores de gris en la imagen para facilitar su reproducción. Los tonos mas oscuros expresan los valores mas altos del NDVI correspondientes a vegetación mas húmeda y densa.

extensión a un espacio multidimensional o GreenVegetation Index, cuyo ejemplo es la citada transformación Tasseled Cap.

La TC, desarrollada por R.J. Kauth y G. Thomas (1976), es una transformación global del mismo tipo que los Componentes Principales pero con un carácter más general. Su principal ventaja sobre el resto de los índices es que proporciona unos resultados con significación física precisa.

Su procedimiento de obtención se basa en la evolución espectral de los cultivos durante su desarrollo vegetativo. Debe su nombre a la forma en gorrito con borla (tasseled cap) que adquiere la representación en un espacio tridimensional de la nube de puntos expresiva de los diferentes estadios de los cultivos.

En esencia lo que los autores de la $T C$ pretendían era buscar unos ejes de variación que maximizaran el comportamiento de los cultivos para distinguir- los mejor del suelo desnudo. Esto se realizaba mediante la combinación lineal de las bandas del sensor MSS que, de ese modo, definía cuatro nuevos ejes muy correlacionados con las variables que formaba la nube de puntos del desarrollo vegetativo. Las cuatro bandas que se conseguían eran brillo, verdor, amarillez y no-tal (non-such). Este último eje daba cuenta de la varianza en los niveles del brillo no atribuible ni a los suelos ni a la vegetación.

En nuestro caso hemos realizado esta transformación a partir de la matriz de coeficientes adaptada a las bandas del sensor TM. Esta variación permite la definición de tres bandas nuevas: brillo, verdor y humedad. En este nuevo espacio vectorial se pueden distinguir ya tres planos: a) el de la vegetación: formado por el eje brillo y el eje verdor, b) el de los suelos: formado por brillo y humedad y c) un plano de transición: formado por el verdor y la humedad. 
2.4.4. Clasificación supervisada: el 'mapa forestal de Kargaly' (Fig. 8)

La clasificación de la imagen ha ido dirigida, hasta el momento, casi en su totalidad a explorar la posibilidad de separar la clase formación forestal por su importancia esencial en toda la investigación. De los dos métodos que existen en clasificación digital de imágenes nos hemos decantado por el supervisado. Este método ha orientado un intensivo trabajo de campo para definir claramente las clases a evaluar en el apartado forestal. Como resultado provisional de este proceso se presenta un mapa forestal simplificado cuya leyenda consta de dos categorías: bosques con y sin presencia de abedules (cft.p. 63).Antes de la clasificación se estudió la capacidad de discriminación de las categorías que aventuramos como clases espectrales. El método elegido, básico enTD, consiste en la representación gráfica de los niveles digitales de las categorías de la leyenda para cada banda espectral. Estos gráficos se conocen como diagramas de firmas espectrales y dan una idea de si las clases están bien definidas o hacen necesaria una generalización debido a la mala discriminación de cubiertas.

El trabajo propio de clasificación se inicia fijando en la escena TM una serie de áreas de entrenamiento cuya adscripción a una de las clases de la leyenda (en nuestro caso bosques con y sin abedules) se conoce. De este modo se precisan las variables que conforman matemáticamente la clase (11), las cuales serán utilizadas en la fase de asignación de cada píxel a su correspondiente clase (12). La etapa de definición de las áreas de entrenamiento ha sido la más delicada. Primero se necesita que los píxeles sean homogéneos, esto es, no haya píxeles correspondientes a más de una clase. Esta tarea es complicada en la zona de estudio por las propias características de las formaciones boscosas, bosques riparios, muy estrechos y formados por gran variedad de especies. En segundo lugar, la variabilidad en el interior de las clases hizo necesaria más de un área de entrenamiento. En cualquier caso, como la clasificación exigía gran precisión se tomaron entre 10 y 100 píxeles por clase y banda.

En definitiva, las cubiertas a clasificar impusieron la elección de áreas de entrenamiento de pequeño tamaño pero distribuidas por toda la zona, lo que a la postre resulta ser teóricamente más provecho-

(11) El vector de medias y la matriz de covarianzas de cada una de las áreas.

(12) Evidentemente se supone normalidad para las clases. so. Finalmente, ya clasificada la cubierta forestal, se digitalizó vectorialmente para que su manejo fuera más sencillo y rápido.

\subsection{El modelo factorial de Kargaly}

Recapitulando esta sección, tenemos que el modelo radiométrico de las cubiertas vegetales de Kargaly está constituído primariamente por dos matrices de datos derivados del procesamiento de 6 de las bandas de una imagen Landsat 5 TM. Estas dos matrices (NDVI y Tasseled Cap) consisten en datos coordenados sobre el valor correspondiente de cada índice de vegetación para cada unidad de información de la imagen (pixel), es decir, para cada unidad de $30 \times 30 \mathrm{~m}$ de la superficie del área de trabajo. Las matrices de datos constituyen en si mismas el registro de variables aleatorias medidas a nivel de intervalo, pero pueden ser representadas de forma analógica como imágenes (de tipo raster) integrables como "capas" del SIG. Esta técnica permite su análisis mediante técnicas SIG, con objeto de establecer las diferencias estadísticas entre las distribuciones de sus valores en áreas específicas del terreno.

El NDVI es una sóla banda, correspondiente a una matriz de dos dimensiones que puede ser tratada como una única variable (Fig. 9). Por su parte, la transformación $T C$ consta de tres bandas que pueden tratarse independientemente. Es una matriz de 5 dimensiones que da lugar a tres imágenes diferentes. El modelo radiométrico analógico de Kargaly consta pues de cuatro capas (Fig. 7).A éllas hay que añadir las capas resultantes de procesos de clasificación, como el que da lugar al "mapa forestal". Ya adelantamos la doble estrategia de análisis de esta masa de datos: 1) Análisis estadístico: las distintas bandas se tratan como variables aleatorias, relacionando los parámetros de su distribución en diferentes áreas, delimitadas por criterios que se exponen más abajo, con las magnitudes de los diferentes componentes del registro polínico.

2) Clasificación: la elaboración de mapas de las formaciones vegetales a partir de la clasificación de los índices y su corrección con observaciones directas de la verdad terreno da lugar a nuevas variables de análisis. Un ejemplo típico son los mapas de distancias creados a partir del mapa forestal para investigar la influencia de los factores de dispersión del polen arbóreo en la formación de los registros polínicos (Fig. 10). 
En cualquier caso, este modelo contiene datos de gran riqueza y accesibilidad operativa sobre la caracterización de las cubiertas vegetales de Kargaly. $\mathrm{Su}$ superposición al modelo geométrico permite analizar conjuntamente la variabilidad de la vegetación con los factores topográficos ya citados.

Nuestro modelo consiste, finalmente, en una matriz de 9 dimensiones ( 7 variables mas latitud y longitud), cada uno de cuyos elementos representa una superficie física de $30 \times 30 \mathrm{~m}$, de la que conocemos:

1) la altitud (en msnm Báltico),

2) la pendiente (en grados en sentido vertical),

3) el aspecto u orientación de la pendiente (en grados en sentido horizontal),

4) el valor del $N D V I$ (en niveles digitales),

5) el valor del índice de humedad de la transformación $T C$ (en niveles digitales),

6) el valor del índice de verdor de la transformación $T C$ (en niveles digitales),

7) el valor del índice de suelos de la transformación $T C$ (en niveles digitales).

En principio, cada una de estas matrices representa un factor estructural del paisaje. Su consideración conjunta nos proporciona una imagen analítica de la variación en el espacio de las cubiertas vegetales a partir tanto de la localización de sus distintas formaciones cuanto de la relación entre sus características físicas más relevantes y los factores topográficos. Así pues, en primera instancia, el modelo es útil para comprender la estructura de relaciones de estos factores en la configuración de la distribución de la vegetación a escala regional.

\section{MODELO DE LA LLUVIA POLÍNICA DE KARGALY}

\subsection{Introducción}

El objeto de la modelización no son, en primera instancia, los espectros polínicos en si mismos, sino sus condiciones de formación. El término "lluvia polínica" designa, pues, el registro polínico de un punto dado y los valores de un conjunto de variables en torno a ese punto en una fracción de territorio definida como "unidad de muestreo" (desde ahora UM). La selección de un número representativo y probabilísticamente significativo de UMs distribuidas por el área de trabajo va acompañada de su caracterización palinológica y contextual. Esta caracterización incluye:
1) obtención de, al menos, un espectro polínico a partir de sedimentos superficiales en un punto situado aproximadamente en el centro de la UM, determinado por el modelo de muestreo;

2) toma, en su caso, de muestras palinológicas adicionales en puntos distintos al centro de cada UM donde se localicen formaciones vegetales con potencial interés botánico e incidencia en la formación del registro polínico;

3) inventario florístico de parcelas testigo en torno a los puntos de muestreo;

4) información de variables de contextualización para cada punto de muestreo referidas a sus condiciones topográficas y sedimentológicas;

5) descripción de la verdad terreno de cada UM en relación con la interpretación de la variables radiométricas.

Este proceso de investigación da lugar, por una parte a una interpretación empírica del modelo del paisaje en términos de verdad terreno, y por otra a un conjunto ordenado y contextualizado de registros polínicos. Estos, una vez integrados con los datos paleopalinológicos y con secuencias de control obtenidas dentro del área de trabajo y en su exterior, constituyen la tabla de datos palinológicos que será el objeto principal de análisis.

El modelo de la lluvia polínica queda definido, pues, como una matriz de datos en la que cada UM aparece caracterizada por su espectro polínico, representado por la distribución de frecuencias de los distintos palinomorfos identificados en el sedimento, y un conjunto de variables de contextualización. Esta matriz se integra con el modelo factorial del paisaje, mediante su incorporación al SIG como una nube de puntos con atributos. De esta manera es posible calcular los valores de las variables del modelo factorial para cada punto del muestreo palinológico. La tabla de datos resultante constituye el modelo experimental del problema, susceptible de ser analizado como una matriz de covarianzas entre las distribuciones de los datos palinológicos referenciados espacial y cronológicamente y las de las variables topográficas, radiométricas y contextuales.

El alcance de estos datos en relación con la formación del registro polínico a escala local que se trata de investigar depende de decisiones metodológicas en tres planos:

1) definición de las UM;

2) tamaño de la muestra y selección de las localizaciones de las UM muestreadas;

3) criterios específicos del muestreo palinológico.

T. P., 57, n. ${ }^{\circ} 1,2000$ 
Las dos primeras cuestiones atañen al modelo de muestreo adoptado. El tamaño y forma de las UM determina, en cierto modo la "resolución" del modelo. La decisión a ese respecto está en función de criterios palinológicos que se discuten en la sección 3.2.1.

Una vez definidas las UM queda por decidir cuántas y cuáles son necesarias para representar adecuadamente la variabilidad regional lo que, en los términos en los que se plantea la investigación, es un problema estadístico.

La tercera cuestión se refiere tanto a los criterios técnicos de obtención de los registros polínicos como a los criterios botánicos de organización e interpretación de los datos palinológicos y contextuales. El principal problema es la homogeneidad de los datos botánicos actuales y los procedentes de secuencias paleopalinológicas.

\subsection{Modelo de muestreo}

\subsubsection{Definición de las unidades de muestreo}

El principal factor que determina la formación de los registros polínicos es la distribución de la vegetación en torno al punto en el que esta es observada. Este factor se puede descomponer a su vez en otros dos: los mecanismos específicos de dispersión polínica de cada tipo de planta y su localización en el espacio. El criterio para la definición de UM debe atender, en nuestro caso, a facilitar el control de este último factor.

Los estudios de lluvia polínica nos permiten concebir el tipo y rango de dispersión de cada palinomorfo a partir, fundamentalmente, de la presencia actual de ciertos taxones en una determinada zona, así como de sus porcentajes en los diagramas polínicos'correspondientes.

A tales efectos, Janssen (1966) estableció cuatro categorías de palinomorfos en función de la distancia de procedencia de su polen o espora respecto al punto de muestreo:

1) extra-local: palinomorfos procedentes de taxones in situ sobre el propio punto de muestreo y que, por lo tanto, suelen aparecer sobrerrepresentados en los espectros polínicos. Se tiende a excluirlos de la suma base polínica.

2) local: palinomorfos cuyo emisor dista $10-20$ $\mathrm{m}$ del punto de muestreo. Por regla general formarán parte de las formaciones vegetales propias de la zona muestreada, sin tener por ello que estar sobre- rrepresentados. Sin embargo son igualmente excluibles de la suma base polínica.

3) regional: palinomorfos procedentes de taxones cuyo rango de implantación dista mas de $20 \mathrm{~m}$. Los palinomorfos "regionales" podrían formar parte del paisaje de la zona de muestreo o no, pero en cualquier caso sí se encontrarían en la región estudiada.

4) extra-regional: palinomorfos cuyo aporte esporo-polínico es totalmente alóctono. Se encuentran incluso en hábitats diferentes a los de la región estudiada, localizados a varios kilómetros de distancia. En Kargaly, serían extra-regionales los palinomorfos procedentes de los pinares del Sur de los Urales o Kazajstán, hábitats completamente diferentes del estepario, distantes entre 200 y $300 \mathrm{~km}$.

Esta categorización permite definir un modelo geométrico sencillo de zonas concéntricas a partir del cual puede racionalizarse tanto el trabajo de campo como la interpretación de los datos palinológicos y los índices de vegetación. Con objeto de articularlo se definieron las UM como cuadrados de $500 \mathrm{~m}$ de lado dentro de una retícula que cubre toda el área de trabajo (Figs. 8 y 9). Esta división del territorio en unidades regulares tiene importantes consecuencias metodológicas. Permite normalizar la observación de los efectos de extra-localidad y localidad mediante la realización de inventarios florísticos en áreas circulares de 250 y $10 \mathrm{~m}$ de radio inscritas en cada UM. Por su parte, gracias a la regularidad del esquema de muestreo, se podrá generalizar estas observaciones al nivel de los efectos local-regional-extrarregional, así como incorporar muestras adicionales, con objeto de controlar la influencia de formaciones singulares de vegetación, o discontinuidades relevantes en la configuración paisajística de la UM.

La población objeto de muestreo queda definida como un conjunto de 546 UMs. Esto predetermina a su vez los puntos del territorio que pueden ser objeto de muestreo palinológico que, en teoría, se reducirían a los centros geométricos de las unidades (sin tener en cuenta las muestras selectivas). La localización efectiva de cada uno de estos puntos depende de los criterios de construcción del sistema de referencias. En Kargaly, la retícula se definió tomando como centro Gorny 1, de forma que la delimitación de unidades resulta totalmente independiente de la distribución de las características observadas. El conjunto de los centros de sus 546 celdillas constituye en si mismo un modelo de 
muestreo sistemático del territorio. Este tipo de muestreo es idóneo para la distribución de características naturales en el espacio (Cochran, 1978: 284 y ss.). Sin embargo las limitaciones presupuestarias del proyecto hacían imposible adoptar esta estrategia, por lo que se optó por el modelo de muestreo aleatorio, que se presenta en la siguiente sección.

\subsubsection{Diseño muestral}

Una vez definida la UM como unidad de información, la estrategia de muestreo debe resolver cuántas y cuáles de ellas deben ser seleccionadas para obtener una aproximación razonable a la "variabilidad natural" de la población. Subrayamos que, en las condiciones normales de una investigación real, las decisiones sobre el modelo de muestreo deben contar siempre con los medios materiales disponibles y tratar de distribuir las opciones de forma óptima de acuerdo a los objetivos de la investigación. De hecho, las decisiones sobre el tamaño de la muestra están dadas como un factor más del problema y configuran un caso típico de "asignación óptima para un tamaño de muestra fijo" (Cochran, 1978: 138). En el proyecto Kargaly pudimos asumir la toma de unas 50 muestras palinológicas dentro de este experimento.

La "variabilidad natural" de la población investigada está definida en nuestro modelo por un conjunto de variables que miden la distribución de aquellas características del territorio relevantes para el problema de referencia. El criterio fundamental de muestreo es que represente adecuadamente la distribución de estas variables en el conjunto del territorio. En principio este criterio puede satisfacerse por medio de un muestreo aleatorio simple. Sin embargo, dado que debemos contar con un tamaño muestral fijo, predeterminado por el coste de las observaciones y los recursos disponibles, y conocemos la distribución de estas características en la población estudiada, optamos por un modelo de muestreo aleatorio estratificado (Cochran, 1978: 127 y ss.) para aumentar la precisión relativa y, por lo tanto, el rendimiento global del muestreo. En efecto, "la estratificación puede dar lugar a una ganancia en precisión de los estimadores de las características de toda la población. Es posible subdividir una población heterogénea en subpoblaciones, cada una de las cuáles es internamente homogénea de tal modo que se puede obtener un estimador muy preciso de cualquiera de las medias de los estratos derivadas de una muestra pequeña en ese estrato" (Cochran, 1978: 128).

En nuestro caso, y gracias al modelo factorial del paisaje, podemos establecer un criterio de estratificación basado en la coherencia geográfica, tomando como base las distintas unidades de paisaje visibles en el área, y como criterio complementario maximizar la contextualización del registro paleopalinológico. Con este fin se definieron dos zonas de muestreo, correspondientes a dos de los distritos incluídos en elárea de trabajo, para los cuales disponemos de información paleopalinológica: Gorny y Novenki. Con objeto de adecuar el modelo al marco regular de definición de las UM las unidades de paisaje elegidas quedaron totalmente inscritas en la retícula de referencia. El resultado se presenta en la figura 8.

El área de Gorny incluye 176 UMs. Forman un transecto de $11 \times 4 \mathrm{~km}$ en dirección E-O, en cuyo centro se situa la colina de Gorny (Lám. II) de la que proceden tres de las secuencias paleopalinológicas en contextos arqueológicos: Gorny 1 y 2 y "Casa Rusa". Contiene la secuencia ordenada de todas las unidades de paisaje presentes en el área de trabajo: ladera oriental de la divisoria de aguas, barrancos e interfluvios, valle del Usolka y sirt. El transecto recoge la articulación de estas unidades, al incluir el desarrollo completo del Barranco de Mijailovsky, desde su cabecera a su desembocadura en el Usolka. Este barranco presenta una fuerte impronta de las labores mineras modernas, al igual que parte de la vertiente occidental del sirt.

Inmediatamente al Sur, el área de Novenki comprende $88 \mathrm{UM}$. Es un rectángulo de $5.5 \times 4 \mathrm{~km}$, centrado en el poblado de la Edad del Bronce de Novenki, donde efectuamos una secuencia paleopalinológica en contexto arqueológico. A pocos metros del mismo se encuentra el depósito higroturboso del que procede una de las secuencias tomadas en depósitos naturales ("Turbera de Novenki"). Otra segunda ("Terraza de Novenki") se obtuvo en un punto del área situado a unos $2 \mathrm{~km}$ al NO del mismo. Esta zona de muestreo ocupa la casi totalidad de la cuenca de recepción del Usolka y su curso alto, con sus distintas unidades interiores. $\mathrm{Al}$ contrario que el área de Gorny carece prácticamente de indicios de actividad minera reciente.

Estas áreas se muestrearon independientemente, con objeto de retener en la medida de lo posible sus especificidades, como la ausencia o presencia de actividad minera, diferencias de altitud media, orientación, etc. El tamaño de muestra óptimo para 
cada estrato se determinó por el método de "asignación proporcional del tamaño de las muestras" (Cochran, 1978: 129 y ss.) con el objetivo de alcanzar fracciones muestrales del $20 \%$ para cada estrato.

Finalmente se seleccionaron al azar $36 \mathrm{UM}$ en el área de Gorny y 19 en la de Novenki. El total de 55 unidades resultante supone una fracción muestral del $10 \%$ para el caso de un muestreo en una sola etapa.

La precisión ganada al estratificar la muestra puede evaluarse comparando sus resultados con los de un muestreo aleatorio simple de toda el área de trabajo, lo que se realiza fácilmente simulando sobre el SIG las distintas hipótesis de muestreo. Así, podemos comparar la precisión de los modelos de muestreo tomando una variable, por ejemplo, la altitud, y comparando los errores típicos de su media para las distintas hipótesis:

- Muestreo sistemático $(n=546)=2.607$

- Muestreo aleatorio simple $(n=55)=5.555$

- Muestreo aleatorio estratificado $(n=55)=3.931$

El modelo elegido representa un término intermedio entre el caso óptimo (e inviable) de un muestreo sistemático con una fracción muestral del $100 \%$ y un muestreo aleatorio en una etapa con el tamaño muestral predeterminado por el coste. Este efecto se debe al hecho de que los criterios de estratificación han minimizado la varianza interna de los estratos. Podemos decir por lo tanto que, consideradas las limitaciones externas fijadas por el coste, el modelo adoptado resulta el más eficiente posible.

\subsubsection{Realización}

Con objeto de transformar el modelo de muestreo escogido en un plan de trabajo de campo se generaron varias muestras aleatorias (probabilísticamente equivalentes) para cada área de muestreo y se compararon entre si atendiendo a dos criterios:

1) representación ponderada de todas las unidades de paisaje: se escogen los muestreos con menor índice de concentración de puntos, es decir, los más homogéneamente distribuídos dentro de cada zona;

2) minimizar el coste de obtención de muestras: se opta por muestreos que permitan recorridos de campo más fáciles y programables en función del número de jornadas y de su articulación con los escasos medios de transporte disponibles.

Las dos series de UM escogidas finalmente representan un compromiso entre estos dos criterios.
Después se calcularon las coordenadas precisas de sus centros, definidos como punto óptimo de muestreo. Estos datos permitieron su localización sobre el campo aplicando técnicas de navegación con GPS. Sin embargo la localización final de los puntos efectivamente muestreados fue modificada en ocasiones por criterios de coherencia botánica (apdo. 3.3.2.1.). Estas modificaciones no sobrepasan el ámbito de error medio de la determinación por GPS, que puede aproximarse a unos $100 \mathrm{~m}$ antes de la corrección diferencial (13). Este error se asume en el trabajo de campo ante la imposibilidad de aplicar tecnologías de corrección en tiempo real a la navegación. Ahora bien, una vez elegido el punto efectivo de muestreo su posición fue determinada con corrección diferencial, con objeto de reajustar el modelo espacial de muestreo. Una vez ajustado se pudo comprobar que la desviación media entre puntos programados y efectivos no excede de los $20 \mathrm{~m}$ para el conjunto del área (excluidos los desplazados atendiendo a criterios de coherencia palinológica).

Tras situar cada "punto efectivo de muestreo" se tomaron muestras palinológicas y realizaron inventarios florísticos, documentación fotográfica y descripción de la correspondiente UM. Como ya se ha dicho, este proceso aconsejó en determinadas ocasiones la obtención de muestras palinológicas adicionales, con el fin de controlar el efecto palinológico de singularidades del paisaje. Estas muestras se documentaron de la misma forma que las incluidas en el muestreo aleatorio, pero se consideran una serie diferente (muestras selectivas).

Todos estos trabajos se llevaron a cabo en la campaña de campo de agosto de 1998. Se documentaron un total de $60 \mathrm{UM}$, de las cuales 55 corresponden al muestreo regular (36 del área de Gorny y 19 de la de Novenki), 4 a muestras de polen selectivas adicionales en dos de las UM de dicho muestreo y 5 al muestreo selectivo al margen de aquel. Esto supone un total de 64 puntos de muestreo palinológico.

\subsection{Los datos palinológicos}

\subsubsection{Introducción}

Una vez discutidos los criterios de muestreo y caracterización de las UMs, así como las líneas

(13) El sistema de distorsión conocido como "disponibilidad selectiva", responsable de este error, fue suprimido por el gobierno de los Estados Unidos de América en 1-V-2000. 
generales de su aplicación, hay que dar cuenta de los criterios específicamente palinológicos. Como se sabe, el núcleo del experimento es la constitución de una tabla de datos palinológicos representativos de la lluvia polínica actual, que serán comparados con el cuerpo de datos paleopalinológicos generados en las intervenciones arqueológicas realizadas dentro del proyecto. Algunos problemas metodológicos e interpretativos a ese respecto proceden de las probables diferencias tafonómicas sistemáticas entre muestras superficiales y paleopalinológicas (apdo. 3.1.).

La hipótesis metodológica general es que la comparación entre datos palinológicos actuales y arqueológicos requiere que tanto los métodos de obtención de las muestras como los de su procesamiento para extraer el registro polínico sean homogéneos. Esta homogeneidad metodológica permite controlar la variabilidad tafonómica e incorporarla al modelo, separándola de la variabilidad específicamente producida por los factores paisajísticos. En esta sección se discuten los criterios a los que ha dado lugar esta hipótesis y su aplicación a la obtención de los 64 espectros polínicos que, junto con el resto de los datos que caracterizan a las UMs, constituyen el modelo de la lluvia polínica actual de Kargaly. Estos criterios se refieren al método de extracción de los sedimentos superficiales, a la localización exacta del punto en la que se practicó en cada caso y al registro de sus condiciones contextuales específicas de relevancia tafonómica.

\subsubsection{Metodología de obtención de los espectros polínicos}

Los estudios de lluvia polínica actual se suelen basar en dos tipos principales de recolección: mediante captadores especiales o mediante la toma de muestras de musgos.

En el primer caso, se obtiene una medida de la lluvia polínica del año en curso. La necesidad de comparar nuestros datos palinológicos actuales con muestras procedentes de sedimentos arqueológicos excluye esta opción por dos razones:

1) las muestras paleopalinológicas de sedimentos representan el resultado acumulado de periodos de tiempo indeterminados, aunque en cualquier caso prolongados;

2) no es posible comparar muestras de polen fósil y actual sin asumir fuertes sesgos en varios aspectos relevantes de la comparación, tanto tafo- nómicos (por ejemplo, conservación diferencial del polen) como taxonómicos (criterios de identificación).

Los musgos, como captadores naturales, serían más adecuados para nuestro marco comparativo. Retienen el polen acumulado en los últimos 20-30 años, periodo que puede acotarse con precisión datándolos, por ejemplo, por el análisis de su contenido en cadmio. Sin embargo la práctica ausencia de musgos en la mayor parte de las unidades de paisaje de Kargaly hacen igualmente inviable esta opción.

En consecuencia se optó por reproducir el método que se emplea en la extracción de sedimentos en posición estratigráfica, tomando como objeto de muestreo el horizonte superficial del suelo actual considerado en su conjunto como una unidad estratigráfica. Siguiendo ese criterio se recogieron $50 \mathrm{gr}$ de los $10 \mathrm{~cm}$ superficiales del suelo. Suponemos que estas muestras, al igual que las procedentes de contextos arqueológicos, representan una muestra aleatoria del contenido en polen de una unidad estratigráfica, y que este contenido es representativo de las condiciones de lluvia polínica durante su periodo de formación.

Esto último plantea el problema del referente cronológico de los espectros polínicos recuperados. Las fechas de $\mathrm{C} 14$ disponibles para niveles arqueológicos y de depósitos naturales de la zona permiten aproximar provisionalmente una curva de sedimentación media para la región, a partir de la cual podemos estimar el periodo de formación de la capa superficial del terreno entre 50 y 30 años. Disponemos de información documental sobre el paisaje de Kargaly para todo este periodo, lo que facilita considerablemente la interpretación. Ahora bien, estas estimaciones se ven en la práctica muy afectadas por la variabilidad de las condiciones locales de formación de suelos, que dependen de diversos factores, ambientales y antrópicos. Resulta imposible fijar una "cronología fina" para los procesos de formación de suelo. Pero esta situación es en todo análoga a la que plantean los registros paleopalinológicos. Al conceptualizar el marco comparativo a partir de unidades estratigráficas introducimos en el registro polínico actual la misma indeterminación cronológica que se asume en el paleopalinológico. Pero a la vez esto nos permite fijar criterios de control para los efectos tafonómicos de esta indeterminación, al desplazarse el problema a la naturaleza edafológica de los sedimentos. Así, tanto la velocidad relativa de formación de un horizonte estrati- 
gráfico, como sus cualidades en la captación de polen y sus efectos en la conservación del mismo, pueden considerarse homogéneas para cada tipo de suelo presente en el área de trabajo. Por lo tanto pueden controlarse los sesgos producidos por la naturaleza de los sedimentos mediante algunas variables clasificatorias, no necesariamente muy complejas.

Ahora bien, todas estas reflexiones resultan pertinentes sólo si podemos asumir que tomamos muestras de suelos naturales formados a lo largo de un proceso continuo y no alterados por remociones profundas que hayan modificado su estructura. Esto no puede suponerse para los terrenos cultivados recientemente que tienen un peso abrumador en el paisaje actual de Kargaly.

Por lo tanto, el control de los sesgos tafonómicos en la muestra debe considerar dos posibles fuentes de variabilidad: la dicotomía suelos naturales / suelos cultivados y la variabilidad edafológica. Los problemas que ambas plantean han sido resueltos mediante criterios de decisión específicos durante el proceso de muestreo y la creación de variables de contextualización, tal como se discute a continuación.

\subsubsection{Tratamiento de la dicotomía suelos naturales /suelos cultivados}

El paisaje actual de Kargaly está profundamente modificado por las condiciones creadas por la colonización agrícola soviética de la zona, que sustituye con un paisaje agrario socialista el anterior paisaje minero resultante de la explotación de los recursos cupríferos entre mediados del siglo XVIII AC y principios del siglo XXAC. Este proceso de sustitución se consolida a principios de los años 50: las ediciones cartográficas de 1957 muestran el mismo sistema actual de parcelación y la red de caminos y asentamientos.

La agricultura en la región está ampliamente mecanizada. Esto significa que los terrenos de cultivo son la mezcla de un amplio paquete estratigráfico que en ocasiones puede involucrar a toda la serie edafológica desde la roca de base. Esta situación afecta a casi un $60 \%$ de la superficie total del área de trabajo. Por lo tanto, es inevitable que una proporción similar de los puntos de muestreo programados estén situados en este tipo de terrenos. Efectivamente, 33 de los 55 puntos lo están, lo que supone exactamente un $60 \%$ de la muestra.
Aceptar las condiciones del muestreo en lo que se refiere al peso relativo de los suelos alterados implica una pérdida de información. Sin embargo, desde la lógica de los objetivos del experimento, la comparación entre muestras procedentes de campos de cultivo y de suelos naturales retiene información de gran interés, al permitir identificar pautas de formación del registro polínico diferenciadas en los suelos cultivados y naturales. Estos patrones pueden tener valor prospectivo en la identificación de las condiciones tafonómicas de muestras paleopalinológicas.

Ahora bien, atendiendo al significado propiamente paisajístico de los datos palinológicos, y dada la limitación del tamaño de la muestra, el número de observaciones en terreno cultivado representa efectivamente una pérdida de información, en la medida en que supone escindir la muestra en dos series de datos tafonómicamente incompatibles.

Las decisiones adoptadas en el curso de la investigación trataron de (1) minimizar el efecto de esta contradicción, planteando un compromiso equilibrado entre los distintos objetivos del experimento y sin alterar las condiciones del muestreo (básicamente el carácter aleatorio de la selección de puntos) y (2) controlar los sesgos tafonómicos mediante su incorporación al modelo en la forma de una variable de control.

Esta última se informó atendiendo a los distintos contextos posibles de muestreo, que se agruparon de acuerdo al grado de alteración de las condiciones naturales de formación de suelo. Se consideraron "suelos naturales" aquellos sin trazas de alteración. Dentro de ellos se distinguieron dos variedades contextuales: praderas naturales (incluyendo todas las variedades esteparias) y bosques (incluyendo las formaciones riparias).

Los "suelos alterados" se agruparon en dos categorías. Por un lado aquellos terrenos en los que los usos del suelo no implican remociones profundas que puedan haber alterado la estructura sedimentaria: pastos y zonas de paso de ganado, áreas mineras, áreas de ocupación humana y bordes de cultivo (se sobreentiende que en estas zonas se seleccionaron emplazamientos de muestreo que ofrecieran garantías de estabilidad edafológica). Por otro, se clasificaron como "cultivos" los emplazamientos con evidencias de remociones profundas del terreno por uso de máquinas agrícolas, tanto en el presente como en los últimos 50 años. Esto incluye, por lo tanto, los campos labrados en la actuali- 
dad, pero también los barbechos y las parcelas abandonadas, aunque hayan sido ocupadas por vegetación esteparia "natural".

La categorización de los contextos de muestreo permitió analizar el modelo muestral y ajustar las decisiones a los objetivos sin alterar las condiciones generales del muestreo. Para ello se utilizaron dos sistemas: ajustes a pequeña escala en la localización de los puntos efectivos de muestreo y obtención de muestras selectivas. En el primer caso el objetivo era doble: por un lado, evitar la sobrerrepresentación de los terrenos removidos; por otro obtener un perfil, tafonómicamente compatible con la serie principal de datos, de la formación de registro polínico en el interior de las unidades de cultivo.

En efecto, debe tenerse en cuenta que los campos de cultivo, en cuanto unidades de paisaje, contienen otros elementos además de las superficies labradas: lindes, caminos y áreas de reserva. En Kargaly estas últimas están frecuentemente en conexión con la presencia de labores mineras que hacen imposible el uso de máquinas agrícolas pesadas. En cierto sentido, la caracterización palinológica de los campos cultivados como unidad de paisaje requeriría el análisis de esta variabilidad interna. De cualquier modo, ni siquiera en el interior de las UM cultivadas en su totalidad (un 36\% para el conjunto de las dos áreas de muestreo) todos los puntos posibles de muestreo corresponden a suelo efectivamente cultivado, aunque la probabilidad de que así sea es abrumadoramente más alta que cualquier otra opción.

Como se ha dicho, 33 de las 55 muestras programadas $(60 \%)$ se localizaban directamente sobre terreno cultivado. Sin embargo, en 11 ocasiones, pequeños desplazamientos, en todo caso inferiores al error medio de navegación asumido en el proceso de localización, permitían elegir emplazamientos sobre suelos estables dentro de unidades totalmente cultivadas. En tales casos se decidió descartar el punto programado, reduciendo así el peso global de los suelos de cultivo en el muestreo, sin alterar sus condiciones generales de representación global en cuanto unidades de paisaje. Esta representación queda desdoblada en dos series de muestras independientes y con condiciones tafonómicas diferentes. Las 11 muestras "desplazadas" se integran por su parte en las categorías correspondientes, particularmente "borde de cultivo" y "áreas mineras".

Por último, 4 de las 9 muestras selectivas se obtuvieron en suelos en el interior de formaciones forestales. Estos puntos faltaban en el muestreo programado, si bien 6 de ellos (10.9\%) se localizaban a menos de $100 \mathrm{~m}$ de un bosque.

\subsubsection{Tratamiento de la variabilidad edafológica}

La variabilidad específicamente edafológica de los sedimentos, en cuanto factor determinante de la formación del registro polínico, es en parte independiente de la dicotomía examinada en la sección anterior. Si bien los cultivos tienden a localizarse en suelos especialmente aptos, el carácter extensivo y mecanizado de la agricultura moderna de Kargaly y la relativa homogeneidad de los suelos de la región, hacen irrelevante esta tendencia. A efectos del control de este factor en el modelo consideraremos dos dimensiones básicas de varialidad en la naturaleza de los suelos, sean estos cultivados o no: la clasificación edafológica general y el grado de humedad edáfica.

La distribución de los suelos en la región de Kargaly es muy homogénea, como corresponde en general a las estepas euroasiáticas, con un predominio absoluto de los suelos tipo chernozem, sólo alterado por los escasos afloramientos de sustratos arcillosos y de descomposición de las areniscas de base. A partir de las observaciones in situ se pudo establecer que la totalidad de las muestras superficiales se distribuye en dos categorías edáficas: chernozem $(86 \%)$ y suelos subarcillosos (14\%).

La humedad edáfica es un factor adicional relevante, que puede determinar variaciones en el comportamiento de cada tipo de suelo en relación con la captación y conservación de polen. La humedad edáfica puede ser controlada también a partir de las observaciones in situ y el análisis de los propios espectros polínicos, evaluando la presencia de hidro-higrófitos en los mismos. Atendiendo a este último criterio se construyó una escala de 4 grados: alta, media, baja y nula. Su combinación con la que recoge los tipos de suelo da lugar a 8 variantes edáficas, de las cuales sólo 7 están representadas en el muestreo superficial.

Ahora bien, dado el intenso grado de antropización del paisaje kargaliense, la naturaleza del suelo no es el único factor que debe ser considerado. Además de la destrucción de la estructura natural de los suelos ocasionada por su remoción (cft. sección anterior), ahora tendremos en cuenta los efectos de la acción humana en relación con la composición

T. P., 57, n. ${ }^{\circ} 1,2000$ 
química del suelo. Las actividades ganaderas o, en general, la presencia humana intensa (por ejemplo en áreas de ocupación antigua o reciente) puede alterar drásticamente la composición de los suelos naturales (por ejemplo mediante amplios aportes de nitrógeno). Estas posibles fuentes de variación se pueden recoger igualmente mediante combinaciones de variables ordinales establecidas a partir de los inventarios florísticos, atendiendo a la proporción del recubrimiento de nitrófilas (indicativas en general de actividades antrópicas) y de ruderales y otros indicadores de actividad ganadera. De esta manera se construyeron dos escalas de cuatro niveles (alto, medio, bajo y nulo) para el grado de antropización y los indicios de actividad ganadera.

\subsubsection{Composición general de la tabla de datos palinológicos}

Las 64 muestras de sedimentos superficiales extraidas en Kargaly (campaña de 1998) se procesaron y analizaron bajo los mismos criterios de identificación y recuento que las 11 secuencias paleopalinológicas y las 14 muestras selectivas (campaña de 1997), que constituyen el resto del corpus de datos palinológicos del proyecto. Los datos resultantes, como es usual, registran para cada caso la frecuencia de los distintos tipos de palinomorfos (pólenes, microfósiles y esporas) identificados en cada muestra. En el conjunto del corpus ha sido posible identificar 137 palinomorfos, de los cuáles sólo 111 están presentes en las muestras superficiales.

La formalización estadística de estos datos plantea algunas cuestiones previas acerca de las estrategias de modelización y la conceptualización de los distintos elementos del problema, que se discutirán en la sección siguiente. Por otra parte, la extensión del inventario de palinomorfos identificados implica serias dificultades para el análisis: muchos de ellos son tremendamente minoritarios, mientras que otros presentan siempre altas proporciones. Además, el significado en términos de paisaje vegetal no viene dado por palinomorfos aislados, sino por asociaciones. Todo ello exige adoptar estrategias de reducción de los datos, creando variables agregadas.

Con este fin, todos los palinomorfos identificados se ordenaron en diversos grupos ecológicos, de acuerdo al catálogo florístico de la zona de estudio. Su elaboración atiende a la presencia recurrente de las especies inventariadas en las unidades de paisaje identificadas, combinada con criterios morfológicos. Los grupos quedaron definidos como sigue:

A. árboles y arbustos de la ripisilva local, incluyendo los pozos mineros

B. árboles y arbustos alóctonos con carácter regional o extra-regional

C. cultivos

D. herbáceas exclusivas de la ripisilva o de los pozos mineros

E. arbustos y herbáceas típicamente esteparios

F. especies indicativas de actividad antrópica (salvo cultivos)

G. hidro-higrófitos y pteridófitos

H. arbustos y herbáceas de amplio espectro ecológico

M. microfósiles no polínicos.

Estos agrupamientos tienen un valor fundamentalmente prospectivo, por cuanto permiten simplificar el análisis exploratorio del modelo.

Finalmente, y con objeto de completar la representación de los factores contextuales de origen botánico, entre todos los palinomorfos identificados, se llevó a cabo una selección de acuerdo al modo de dispersión de su polen. Las dos categorías establecidas fueron las siguientes: anemófilos, si dispersan su polen por el viento; y entomófilos, si lo hacen con la intervención de insectos. Entre los anemófilos se seleccionaron Alnus, Betula, Populus, Quercus robur t., Abies, Picea, Pinus sylvestris t., Cerealia, Gramineae, Ephedra distachya t., Sanguisorba officinalis, Rumex acetosa t., Rumex acetosella t. y Chenopodiaceae/Amaranthus. Los entomófilos incluyen a Rosaceae indif., Boraginaceae, Helianthemum t., Leguminosae, Cichorioideae, Labiatae, Polygonum aviculare t., Resedaceae y Urticaceae. El palinomorfo Artemisia se consideró dentro de ambas categorías.

\subsubsection{Criterios de modelización y estrategias de análisis}

Desde un punto de vista estrictamente probabilístico cada espectro polínico es la representación de la distribución de una única variable (cuyos valores corresponden al inventario de clases taxonómicas) en una muestra (constituida por el total de palinomorfos identificados) extraída de una población (consistente en el total de palinomorfos existentes en el sedimento procesado). Asumimos que estas "poblaciones" son, a su vez, muestras de una 
única población hipotética constituida por todos los palinomorfos potencialmente susceptibles de figurar en la muestra en la totalidad del área investigada. Esta hipótesis da coherencia a la comparación a escala regional entre espectros polínicos, que quedaría estructurada como la comparación entre distribuciones de frecuencias de una única variable nominal en muestras independientes. Este enfoque, que podemos llamar holístico, impone una estrategia de análisis basada en la comparación de puntos de muestreo entre sí, en función de la similitud de la composición cuantitativa de su inventario de palinomorfos. Un ejemplo típico es el análisis de conglomerados, frecuentemente utilizado en palinología.

El enfoque anterior se contrapone con la práctica de lo que podemos llamar enfoque analítico, muy frecuente en la bibliografía sobre modelización estadística de datos palinológicos que se basa en la consideración de cada clase taxonómica como una variable independiente, medida a nivel de intervalo. Sobre este supuesto podemos aspirar a investigar, por ejemplo, la correlación entre distintos palinomorfos, asumiendo que sus frecuencias en cada caso son medidas independientes de la cantidad de cada palinomorfo referidas a una escala continua e independiente. Tendría sentido, por lo tanto, hablar de la media o la desviación típica de tal palinomorfo en tales grupos de casos.

Esto plantea algunos problemas metodológicos de fondo. Los datos de frecuencias de clases taxonómicas sobre muestras independientes determinan que la probabilidad de cada taxón en cada caso dependa de la del resto y del tamaño de la muestra. Esta última dificultad se suele obviar recurriendo a los porcentajes, pero eso no elimina la autocorrelación de la matriz de datos. La consideración de las clases taxonómicas como variables aleatorias independientes parece, cuando menos, forzar las implicaciones estadísticas del tipo de observación empírica que constituye un análisis polínico en realidad: una clasificación, no una operación de medida. La revisión crítica de la práctica estadística en palinología que ello sugiere, en cualquier caso, cae fuera del propósito de este trabajo. Por otra parte, el núcleo significativo de esta práctica parece plausible: las probabilidades observadas de cada clase taxonómica individualmente considerada pueden aceptarse razonablemente como estimaciones de la presencia del correspondiente palinomorfo en un sedimento. Así, la serie de valores de dicho palinomorfo en el conjunto de los casos constituiría una distribución muestral, cuyos parámetros pueden considerarse estimadores de los de la distribución de dicho palinomorfo en el área investigada. Sobre este supuesto se puede orquestar una estrategia de análisis basada en la comparación paramétrica del comportamiento de las distintas clases taxonómicas en relación con otras variables del modelo, topográficas, radiométricas o contextuales.

Estas dos estrategias de análisis pueden desarrollarse complementariamente a partir de una única matriz de datos, que recoge las frecuencias absolutas de cada palinomorfo en cada punto de muestreo, conceptualizado como "caso". Eventualmente se deberán discutir las transformaciones de los datos necesarias para dar coherencia a cada análisis.

Por ejemplo: a la hora de definir cada clase taxonómica como variable continua, puede proceder su transformación a una escala que elimine la influencia dẹl tamaño de la muestra: proporciones, porcentajes o algún proceso de normalización. En este último caso debería decidirse si la base de la transformación debe ser el total de cada palinomorfo o el de cada muestra.

\section{EXPLOTACIÓN DÉ MODELO EXPERIMENTAL: ALGUNOS EJEMPLOS}

\subsection{Introducción}

El modelo experimental resultante de la secuencia de procesos de modelización e información que se han descrito en las secciones anteriores es una matriz estructurada de datos que contiene una representación significativa tanto de la variabilidad de la lluvia polínica en la actualidad, cuanto de una serie de factores geográficos relevantes en la explicación de dicha variabilidad, según el modelo teórico expuesto.

En su estado actual de elaboración, la matriz general consta de dos partes que recogen los datos de los espectros polínicos (A) y paleopolínicos (B). La matriz A tiene 76 filas por 157 columnas. Las filas corresponden al total de espectros polínicos, considerados como casos de la tabla. Las columnas contienen las variables del modelo.

La matriz B recoge los 90 espectros paleopolínicos, agrupados en 11 secuencias. En ocasiones los espectros de sus niveles superficiales se han considerado parte de ambas matrices y se han calculado los valores de todas las variables para ellos. 
En cuanto a las variables, 137 columnas corresponden a las frecuencias de cada palinomorfo identificado en cada espectro. Una columna más presenta el total de palinomorfos identificados en cada muestra, y sirve de base para el cálculo de proporciones.

El resto de las variables contienen datos calculados a partir del modelo factorial del paisaje o derivados de la observación directa del terreno. Los primeros son las 5 variables topográficas (latitud, longitud, altitud, pendiente y aspecto) y los datos radiométricos que proceden de las 4 variables primarias del modelo del paisaje (NDVI, índices de humedad, suelos y vegetación). Los datos incorporados a la matriz son la media y desviación típica de la distribución de cada una de estas variables en áreas de $250 \mathrm{~m}$ de radio en torno a cada punto de muestreo, según el modelo que se presenta en la figura 9 y se ha discutido en la sección 3.2. Por lo tanto, la matriz contiene 8 columnas de datos radiométricos.
Además de las radiométricas, el modelo factorial del paisaje incluye variables de segundo orden, derivadas de la clasificación de aquellas. A partir del mapa forestal de Kargaly, ya disponible, se han calculado 3 variables más para la matriz. Recogen la distancia lineal de cada punto de muestreo a la masa forestal más cercana: dos de ellas en cada una de las categorías de la leyenda del mapa (bosques con y sin abedules) y la tercera independientemente de la composición de la masa forestal (Fig. 10).

La matriz se completa con un conjunto de variables nominales $u$ ordinales, que caracterizan diversos aspectos del contexto de cada punto de muestreo palinológico. La forma en la que se han definido estas variables se ha discutido anteriormente (sección 3.3.2.). Tres de ellas (grado de antropización, intensidad de la actividad ganadera y grado de humedad edáfica) se han definido a partir de sus indicadores palinológicos sobre una escala ordinal de 4 'valores (de máximo a mínimo). La

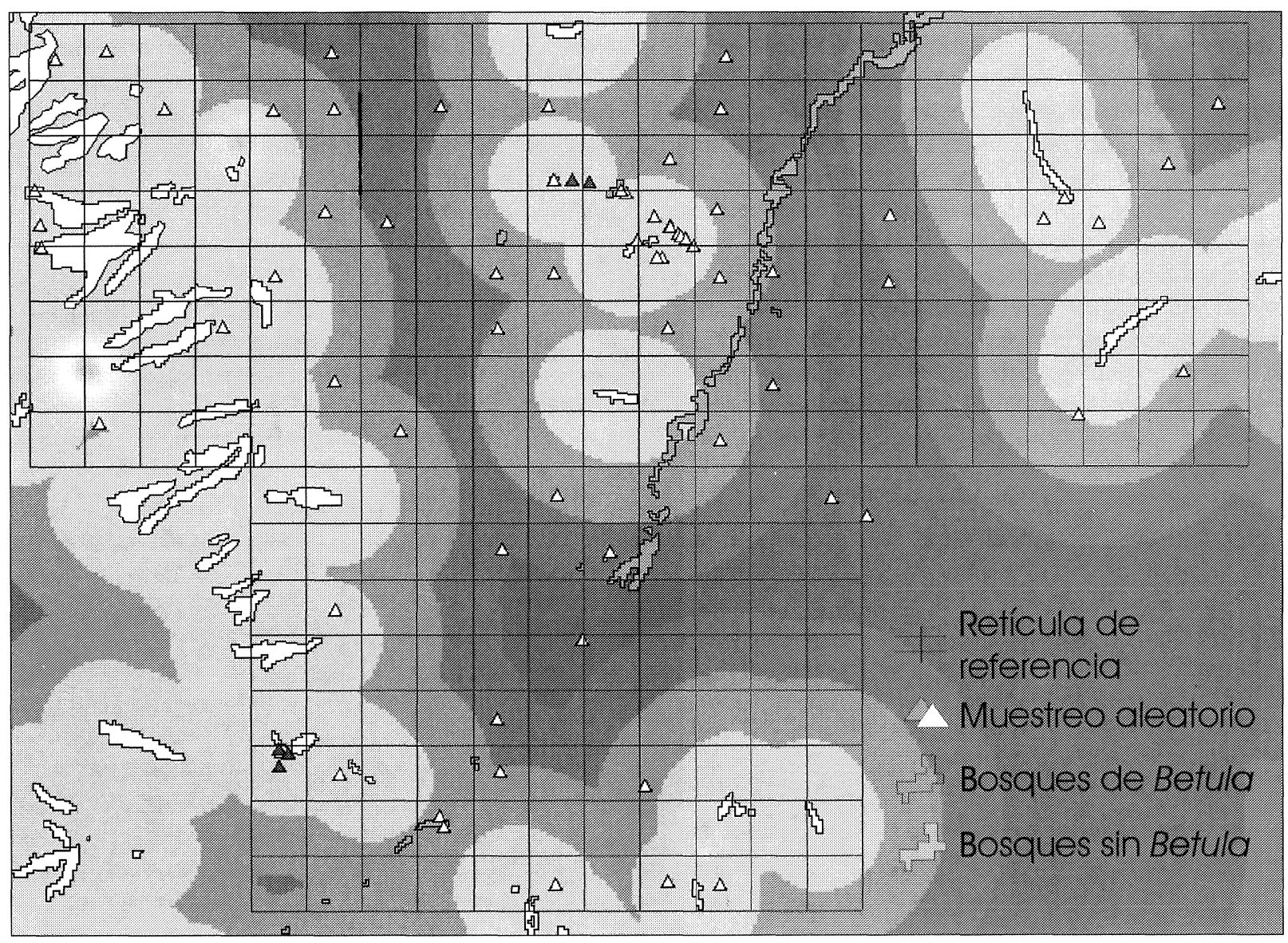

Fig. 10. Mapa de distancias a "bosques con abedules". Los triángulos oscuros representan las muestras cuyos residuos del modelo de distancias son menores de -4 desviaciones típicas. 
variable "contexto" consiste en una escala nominal con 9 valores, correspondientes a los distintas unidades de terreno presentes en el área. En la misma línea, una variable recoge el tipo de formación vegetal en la que se encuentra cada punto, según una escala nominal de 11 categorías, establecidas a partir de los inventarios florísticos. El tipo de suelo da lugar a una variable dicotómica (chernozem o subarcilloso). Por último, una variable ordinal de 4 niveles da cuenta del grado de cobertura de las tierras cultivadas en la UM en la que está situado cada punto muestreado.

Según el diseño general de la investigación, este conjunto de datos debe ser útil para explicar los procesos de formación del registro polínico en relación con la morfología del paisaje. Como se ha dicho, el término experimental hace referencia a la forma en la que se debe afrontar esta investigación, mediante la formulación y contrastación de hipótesis estadísticas. El trabajo con el modelo requiere, por lo tanto, la formulación de las cuestiones interpretativas en los términos de experimentos estadísticos.

La primera fase de exploración de los datos calibra el propio modelo. Se trata de establecer la cantidad de información retenida por el modelo, y en qué medida es significativa en relación con el diseño teórico de la investigación, permitiendo contrastar sus hipótesis básicas. El modelo debe contener pues información suficiente como para caracterizar los factores contextuales y tafonómicos y evaluar su efecto sobre la variabilidad de los datos palinológicos. Si ese efecto es significativo, entonces determinará patrones observables de variabilidad espacial de la lluvia polínica. El conjunto de la investigación tiene por objetivo su identificación y análisis.

La segunda fase caracteriza y analiza esos patrones en relación con la morfología del paisaje. Esto significa analizarlos a partir de los datos del modelo radiométrico del paisaje. Ello requiere múltiples enfoques metodológicos, tanto analíticos como clasificatorios, cuyo objetivo es establecer un modelo de representación entre el registro polínico y la distribución de la vegetación.

Por último se comparan las secuencias paleopalinológicas a partir de la aplicación de los modelos predictivos derivados del trabajo con el modelo experimental. A partir de este análisis, el conjunto de los registros palinológico y paleopalinológico se transforma en un campo de contrastación de hipótesis interpretativas.
Esta sección presenta algunos ejemplos de la calibración y exploración del modelo.Estos ejemplos aunque utilizan sus datos, no pretenden ofrecer resultados finales, sino, en todo caso, indicaciones de las tendencias y mostrar el manejo del modelo y su posible utilidad.

\subsection{Análisis de la distribución de Betula}

La caracterización y calibración de las variables del modelo consiste en el análisis individualizado de la covarianza de cada tipo de palinomorfo identificado (o asociaciones relevantes de los mismos) con el resto de las variables del modelo, de acuerdo con las hipótesis básicas. La forma general de estas hipótesis es: "el factor $f$ covaría significativamente con el palinomorfo $p$ ". Esto significa que conocido el valor de dicho factor en un punto dado, podemos hacer predicciones razonables sobre el valor del palinomorfo, dentro de un determinado intervalo de confianza. Este trabajo nos permite establecer en qué medida los factores contextuales y tafonómicos influyen por si mismos, o en combinación con otros, en la varibilidad espacial de la lluvia polínica y establecer un modelo predictivo.

Esta etapa de análisis individualizado de las variables tiene por objeto localizar efectos significativos de estas sobre la varibilidad de cada palinomorfo. Resulta imposible, dado el carácter de este artículo, su desarrollo sistemático. Cada elemento de la lista de palinomorfos identificados requiere sus propios contextos botánicos y biogeográficos de interpretación, y se verá afectado por los factores contextuales y tafonómicos de distintas formas, que es necesario identificar y caracterizar durante la investigación. Por otra parte, cada uno de estos taxones tiene un significado específico en relación con las hipótesis interpretativas de referencia.

Utilizaremos en los ejemplos un taxon arbóreo, conectado con el principal problema interpretativo: la evaluación de los recursos forestales en relación con la discordancia entre la disponibilidad actual de recursos forestales y las expectativas creadas por las hipótesis interpretativas derivadas del registro arqueológico. Si consideramos las cifras de producción metalúrgica deducidas por Chernyj para la Edad del Bronce, debemos suponer que las masas forestales de Kargaly fueron mucho más extensas entonces que en la actualidad (del orden de tres veces más).

El enfoque más simple posible consiste en usar 
la distribución actual de los palinomorfos de las especies forestales autóctonas como referencia comparativa para la interpretación de los datos paleopalinológicos. Así, por ejemplo, tomamos la especie local de máximo valor energético, Betula, y comparamos los valores de su distribución actual y en las muestras paleopalinológicas correspondientes a niveles de la Edad del Bronce. El promedio de la proporción es superior en las muestras de la Edad del Bronce (9.1046) que en las actuales (5.3612), y esa diferencia (3.7434) no es significativa $(\mathrm{T}=1.719, \mathrm{gl}=122$, sig. $=0.088)$.

Aunque las diferencias de medias son muy acusadas, este resultado no corrobora la hipótesis de una fuerte pérdida de recursos forestales en la región. Pero una comparación como esta, basada en la tendencia central de las distribuciones, sólo puede mantenerse sobre el supuesto de que la distribución de los palinomorfos sea aleatoria con respecto al espacio. En tal caso las diferencias entre las muestras individuales se pueden atribuir al azar, y la media de la distribución regional puede tomarse como una medida comparable de la extensión de la cobertura de esa especie. Esta hipótesis se basa, a su vez, en el supuesto de la correlación positiva y significativa entre el peso de los palinomorfos en el registro y la superficie de cobertura de las correspondientes especies productoras. Esta última hipótesis no se somete ahora a contraste, aunque la discutiremos más adelante.

Sin embargo (cft. sección 1.3.), para Betula, factores locales como la cercanía a una fuente emisora de polen pueden influir fuertemente en su representación en el registro polínico. Si esto es así en un grado significativo, entonces la comparación directa de tendencias centrales entre los datos prehistóricos y actuales pierde parte de su significado.

Este problema se explora mediante experimentos a partir de los datos del modelo: identificación de las fuentes de varianza de la distribución de los datos polínicos.

En la actualidad el abedul es la especie predominante en los bosques galería que flanquean los cursos de los barrancos (Lám. I), con especiales concentraciones en sus cabeceras sobre la divisoria de aguas (Fig. 8), mientras que está prácticamente ausente de las formaciones riparias en los cursos fluviales permanentes, donde predominan Salix y Populus. En los bosques de barranco, el abedul se combina en distintas proporciones con especies como Alnus, Populus tremula, etc. que carecen, en principio, de valor en la producción de carbón ve- getal apto para las labores metalúrgicas. Los problemas que nos ocupan tienen por lo tanto una singular relación con la distribución de Betula. Interesa determinar si su localización en contextos topográficos muy determinados y discontinua en el espacio, es residual, resultado de la sobreexplotación de los bosques, o por el contrario es extrapolable al pasado. Para ello es necesario establecer de qué forma el registro polínico actual refleja dicho patrón espacial.

En primer lugar, de acuerdo la comparación de las secuencias paleopolínicas de la colina de Gorny (sección 1.3.), asumimos que hay una fuerte correlación entre la distancia del punto de observación y las fuentes emisoras de polen y el peso de este en el registro polínico.A partir de este supuesto formulamos la hipótesis básica de un modelo predictivo: existe una relación significativa entre la distancia a la fuente emisora y la proporción de Betula en cáda muestra. Esta relación puede ser caracterizada para las condiciones actuales investigando la correlación entre la cantidad de polen y la distancia de cada punto a la formación forestal más próxima a partir de los datos del modelo (Fig. 10).

En este análisis exploratorio tiene sentido considerar conjuntamente todas las muestras que figuran en la matriz de datos del modelo: los dos muestreos aleatorios (series MA/Gorny y MA/Novenki) $\mathrm{y}$.las muestras selectivas tomadas en las campañas de 1997 (T1) y 1998 (MO). Sin embargo la composición de la matriz debe ser tenida en cuenta, y un análisis confirmatorio posterior debe proceder a partir de la comparación entre estas series.

La figura 11 A representa el modelo geométrico de la hipótesis general o "modelo de distancias": la distribución de la proporción de Betula aparece sobre el eje de ordenadas y la distancia a la formación de abedules más próxima sobre las abscisas. En él están la totalidad de las muestras de superficie disponibles, tanto los muestreos aleatorios como los selectivos. Finalmente se ha incluido la recta de regresión, que es la representación geométrica de la solución más simple al problema.

Un primer examen del gráfico sugiere dos observaciones. En primer lugar ilustra una cierta regularidad en el comportamiento espacial de Betula: la curva descrita por los valores máximos, que decrecen a medida que aumenta la distancia. Sin embargo, por debajo de esta curva de máximos, no parece haber un orden perceptible en los datos, lo que indica la actuación de factores restrictivos diferentes a la distancia. Por otra parte, el ajuste del modelo 

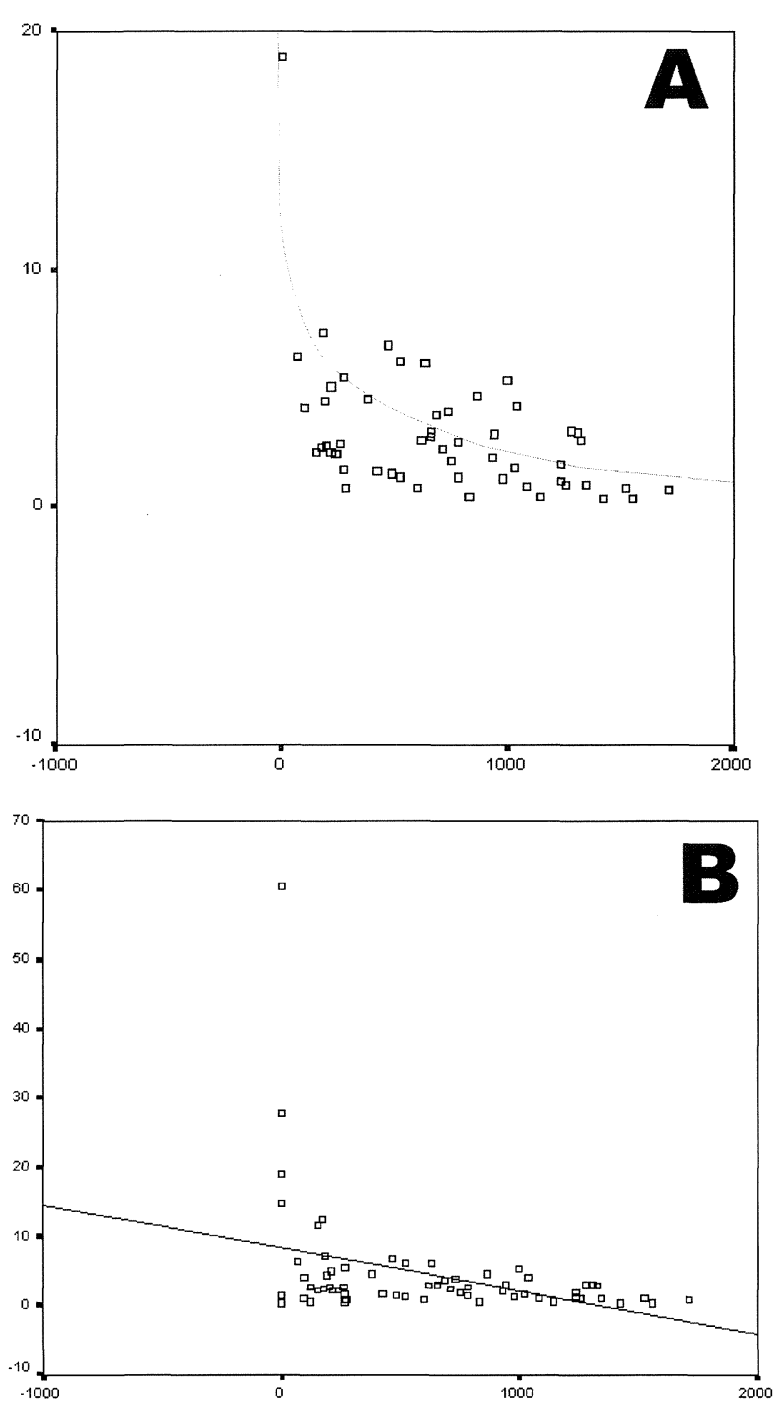

Fig. 11. Modelo geométrico del modelo de distancias. En ordenadas la distribución de la proporción de Betula y, sobre las abscisas, la distancia a la formación de abedules mas próxima. A. Curva de ajuste del modelo. B. Recta de regresión.

lineal es muy pobre $\left(\mathrm{R}=0.355 ; \mathrm{R}^{2}\right.$ corregido= $0.112)$, aunque significativo $(\mathrm{F}=8.965 ; \mathrm{gl}=64$; prob=0.004). Sólo explica una pequeña cantidad de varianza (algo más del $11 \%$ del total) lo que, unido al diagnóstico anterior sobre factores restrictivos adicionales, descarta la utilidad de un modelo predictivo lineal. Podemos mejorar la hipótesis tratando de ajustar a los datos modelos no lineales: utilizando un modelo logarítmico se consiguen resultados mucho mejores: $\mathrm{R}$ múltiple $=0.602$; $\mathrm{R}^{2}$ ajustado $=0.352(\mathrm{~F}=35.302 ; \mathrm{gl}=63 ; \mathrm{prob}=$ 0.000) (Fig. 11 B).
Si aceptamos este modelo estadístico como expresión de la hipótesis general sobre la correlación entre distancia y peso de Betula en el registro, podemos atribuir los errores de predicción (o residuos del modelo) a la influencia de factores, en principio independientes de la distancia. Es decir, la ecuación del modelo logarítmico nos permite predecir el valor de Betula en un punto dado si este dependiera exclusivamente de la distancia. La diferencia entre esta predicción y el valor realmente observado en cada caso de la tabla se debe a la actuación de otros factores, sean topográficos o contextuales. Podemos analizar la distribución de estos errores en relación con otras variables con objeto de mejor nuestras predicciones.

La distribución tipificada de los residuos fundamentará una segunda etapa de análisis, donde intentaremos localizar las fuentes de la porción de varianza de Betula no explicada por el modelo de distancia. Como primer paso, cruzamos la distribución con todas las variables contextuales para establecer cuáles explican por si mismas porciones significativas de varianza.A continuación se presentan los casos en los que esto sucede, es decir, donde las distribuciones de valores de residuos generadas por las variables contextuales son significativamente distintas, según el modelo general de análisis de la varianza. Esto viene a significar que cada variable permite observar errores sistemáticos del modelo de distancias asociados con distintos tipos de contextos. Estos resultados, aunque preliminares como se ha subrayado y sujetos a un análisis confirmatorio posterior, constituyen en si mismos una evidencia de segundo orden sobre la complejidad de los patrones espaciales de variabilidad del registro polínico, y requerirán una discusión interpretativa específica.

Las variables que modifican significativamente la distribución de los residuos del modelo de distancias son las siguientes:

-ZONA: zonas de muestreo a las que se asignan los casos, concretamente Gorny y Novenki.

- OR4: orientación de la pendiente agrupada en cuadrantes (N, S, E y O) más un valor "llano" para aquellos puntos situados sobre una pendiente de cero grados.

- CULTIVOS: grado de cobertura de los terrenos cultivados en la UM en la que se sitúa cada punto, estimada a partir de las variables radiométricas. Es una escala ordinal de cuatro valores: total $(100 \%$ de cobertura), alto (más del 50\%), medio (entre 50 y $25 \%$ ) y bajo (inferior al $25 \%$ ). 
-ANTROP: grado de antropización del entorno inmediato de cada punto de muestreo, evaluado a partir del peso de taxones nitrófilos en el inventario florístico, validado por la evaluación de otros indicadores sobre el terreno. Se expresa en cuatro valores ordinales: alto (recubrimiento de nitrófilas superior al 50\%), medio (entre 50 y $25 \%$ ), bajo (inferior al 25\%) y nulo (ausencia de nitrófilas).

- HUMEDAD: grado de humedad edáfica en el punto de muestreo, estimado a partir del peso de taxones hidro-igrófitos en los inventarios polínicos. Escala ordinal de cuatro valores: alta (recubrimiento de hidro-igrófitos superior al 50\%), medio (entre 50 y $25 \%$ ) y nulo (sin representación de hidroigrófitos en el inventario florístico).

- GANAD: grado de incidencia de prácticas ganaderas, evaluado en términos de cobertura de ruderales y otros taxones indicativos. Es una escala ordinal de cuatro valores: alta (recubrimiento superior al 50\%), media (de 25 a 50\%), baja (inferior a $25 \%$ ) y nula (ausencia de indicadores).

Estas variables están construidas a diferentes escalas, en función del procedimiento de observación mediante el que se han informado. La primera se refiere a la localización de las muestras en el espacio regional y en el modelo de muestreo. Las dos siguientes, OR4 y CULTIVOS, han sido calculadas a partir del modelo factorial del paisaje, y su límite de resolución espacial es la de éste $(30 \mathrm{~m})$. Así la clase "cobertura total" de CULTIVOS no excluye la existencia de espacios no cultivados, en todo caso de dimensiones inferiores a las de un píxel de la imagen Landsat TM. Los datos de OR4 se refieren al paso de malla del MDT, que es, igualmente, de $30 \mathrm{~m}$. El resto de las variables de la lista aluden, por el contrario, a las condiciones específicas de cada punto de muestreo evaluadas en su contexto inmediato (un radio de $10 \mathrm{~m}$ ). En resumen, la lista de variables nos remite a factores que operan a las tres escalas de análisis: regional, local y extralocal. A continuación comentaremos brevemente los resultados, poniendo entre paréntesis los datos más significativos de las tablas de análisis de la varianza (los valores de $\mathrm{F}$ y $\mathrm{R}^{2}$ refieren al modelo en su conjunto, incluyendo la intersección y el efecto del factor analizado).

La asignación de los casos a las dos zonas de muestreo, ZONA ( $\mathrm{F}=7.314 ; \mathrm{gl}=1 ; \mathrm{prob}=0.009 ; \mathrm{R}^{2}$ ajustado $=0.091 ;$ Fig. 12 ) es responsable de casi un $10 \%$ de la varianza. En relación con el modelo de distancias, esta asignación se refleja en que el promedio de los errores es positivo y del orden de una

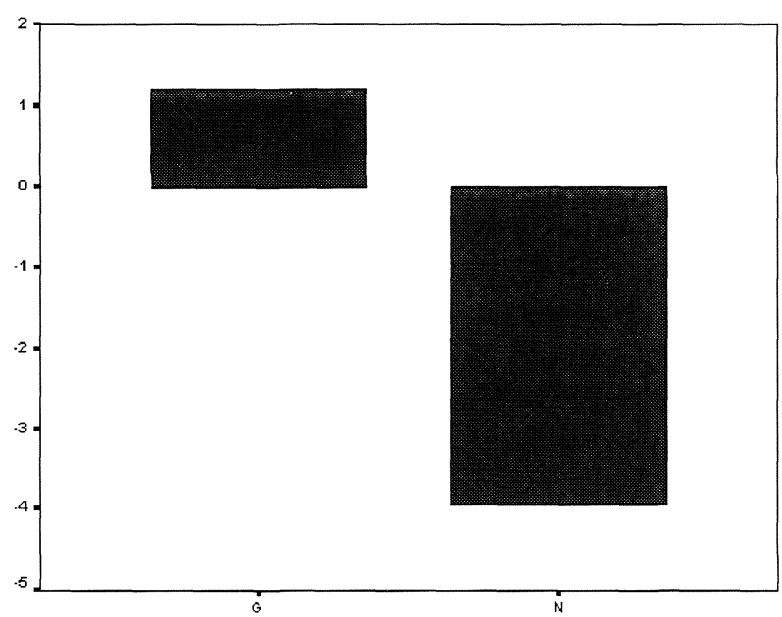

Fig. 12. Residuos del modelo de distancias de las formaciones forestales en el área de Gorny (G) y Novenki (N).

desviación típica para Gorny, y negativo del orden de 4 desviaciones típicas en Novenki. Este resultado expresa la desigual distribución de las formaciones forestales en ambas áreas: en Gorny, la categoría "bosques con abedules" representa un 3.98\% de la superficie total, mientras que en Novenki se reduce al $1.35 \%$. En el registro polínico, esto se expresa como una significativa diferencia de medias en las distribuciones de la proporción de polen de Betula: $5.33 \%$ en Gorny y $1.37 \%$ en Novenki ( $\mathrm{T}=$ $1.920, \mathrm{gl}=71$, prob.=0.003). Sin embargo, los resultados no muestran esta diferencia cuantitativa, sino más bien un diferente patrón espacial en la variabilidad de Betula en el registro. En efecto, la diferencia de medias en la proporción de Betula es significativa, pero la de distancias entre puntos de muestreo y bosques con abedules no lo es (Gorny= $617 \mathrm{~m}$; Novenki $=767.37 ; \mathrm{T}=0.993 ; \mathrm{gl}=65$, prob. $=$ 0.324). La distribución de los residuos del modelo de distancias debería, por lo tanto, ser semejante en ambos distritos, independientemente de las diferencias cuantitativas entre ellos.

Efectivamente, al analizar por separado el modelo de distancias para ambas zonas se observa que el ajuste del modelo logarítmico mejora apreciablemente para Gorny $\left(\mathrm{R}\right.$ múltiple $=0.774, \mathrm{R}^{2}$ ajustado $=$ 0.59 ), mientras que prácticamente desaparece para Novenki (R múltiple $=0.269, \mathrm{R}^{2}$ ajustado $\left.=0.001\right)$. El examen de los casos anómalos para encontrar sus rasgos comunes se aborda como una consulta al SIG. Los puntos con máximos errores positivos de predicción (aquellos en los que la proporción de Betula es significativamente superior a la predicha por el modelo de distancia) son los situados en el 
interior de formaciones boscosas. Los que tienen valores negativos extremos (mayores de 4 desviaciones típicas) son puntos localizados en condiciones muy específicas, como muestra la figura 10. Los dos más septentrionales (T1_10 y T1_11) están a menos de $250 \mathrm{~m}$ al SE de un pequeño abedular, pero también a menos de $300 \mathrm{~m}$ al NO de un bosquecillo de Acer negundus. Por su parte, los cuatro más meridionales (MO_7, MO_8, MA_42 y MA_43) se asocian con la única formación de Quercus detectada en el interior del área de trabajo.Así, pese a la corta distancia a una formación del tipo "bosque con abedules", la proporción de Betula en ambos grupos de puntos es mucho menor de lo esperable a tenor del modelo de distancias, como consecuencia de la sobrerrepresentación de Acery Quercus respectivamente.

Al eliminar de la tabla los casos extremos (mayores de 4 y menores de -4 desviaciones típicas) la mejora del ajuste del modelo logarítmico de distancias es sustancial. Para el área de Gorny tenemos un $\mathrm{R}$ múltiple de 0.791 y un $\mathrm{R}^{2}$ ajustado de 0.616 y para la de Novenki un R múltiple de 0.682 y un $\mathrm{R}^{2}$ ajustado de 0.406 . El modelo conjunto mejora también alcanzando un R múltiple de 0.765 y $\mathrm{R}^{2}$ ajustado de 0.577 .

Estos cambios no hacen desaparecer el efecto de ZONA sobre la distribución de los residuos del modelo de distancias depurado, que sigue siendo significativo $(\mathrm{F}=0.423$, prob. $=0.045)$, aunque retiene mucha menos varianza $\left(R^{2}\right.$ ajustado $\left.=0.058\right)$. La robustez de esta relación refuerza la hipótesis de que las dos zonas de muestreo presentan patrones espaciales distintos, como sugiere también que los datos de Novenki depurados admitan mejor un modelo de ajuste lineal $\left(\mathrm{R}\right.$ múltiple $=0.76276, \mathrm{R}^{2}$ ajustado $=0.53533$ ) que el logarítmico. Puede estar reflejándose un fenómeno real, asociado a una diferente morfología del terreno. De ser así, proporciona información valiosa para comprender cómo el registro polínico refleja las diferencias en la morfología del paisaje. Pero los resultados pueden deberse también a diferencias en la constitución de la tabla de datos, como las existentes entre los dos muestreos aleatorios que constituyen el núcleo de la tabla y a la influencia de las muestras selectivas, que pueden sobrerrepresentar categorías específicas de datos. Recordemos el caso de las tomadas en torno al núcleo de Quercus. Estos problemas requieren un análisis más detallado, que es imposible desarrollar aquí.

La variable $\mathrm{OR} 4(\mathrm{~F}=2.843 ; \mathrm{gl}=4 ; \mathrm{prob}=0.032$;
$\mathrm{R}^{2}$ ajustado $\left.=0.105\right)$ explica algo más de un $10 \%$ de la varianza de los residuos (expresada por el coeficiente $\mathrm{R}^{2}$ corregido). La figura $13 \mathrm{~A}$ permite interpretar preliminarmente el patrón responsable de este resultados: representa los valores promedios de los residuos del modelo de distancias para cada valor de la variable OR4.Así, podemos ver que sus predicciones son tremendamente ajustadas para los puntos situados en laderas orientadas al $\mathrm{N}$ y $\mathrm{O}$, así como en los situados en llano, mientras que presentan errores promedios negativos de más de dos desviaciones típicas para las laderas orientadas al E y positivos de más de 5 desviaciones típicas en los orientados al S. Es decir, el modelo de distancias "funciona" para todos los contextos, excepto los orientados al S y E. La hipótesis más sencilla es considerar la acción del viento en el transporte de polen. Como Betula es un taxón anemófilo, podemos suponer que el modelo de distancias operará de forma regular y constante en los puntos expuestos al viento dominante durante las etapas de polinización, y presentará anomalías en el resto de las orientaciones.

Esta explicación es una hipótesis contrastable, a la que se pueden oponer hipótesis alternativas. Por ejemplo, el efecto de la variable OR4 podría reflejar como ocurría con ZONA aspectos contextuales: la posible asociación entre localización de los bosques y orientación de las pendientes. De hecho, la mayor superficie de bosques con abedules está sobre la vertiente oriental de la divisoria de aguas Volga-Ural, en vertientes orientadas al E. En tal caso, el efecto significativo de la orientación sobre los residuos del modelo no se debería a la acción del viento en el transporte del polen, sino al propio patrón espacial de la especie investigada.

Las variables CULTIVOS $(\mathrm{F}=3.098 ; \mathrm{gl}=3$; prob $=0.033 ; R^{2}$ ajustado $=0.091 ;$ Fig. $\left.13 B\right), A N-$ TROP $\left(\mathrm{F}=5.064 ; \mathrm{gl}=3 ; \mathrm{prob}=0.003 ; \mathrm{R}^{2}\right.$ ajustado $=$ 0.162 ; Fig. $13 \mathrm{C})$ y $\operatorname{HUMEDAD}(\mathrm{F}=4.940 ; \mathrm{gl}=3$; prob $=0.004 ; R^{2}$ ajustado=0.158; Fig. 13D) explican pequeñas porciones de varianza $(9 \%, 15.8 \%$ y $16.2 \%$ respectivamente) y admiten también varias hipótesis interpretativas contrastables. Primero podemos suponer que su efecto sobre la distribución de residuos del modelo de distancias se debe a la actuación de filtros tafonómicos. Sería esperable que a menor presencia de rasgos de antropización, de alguna manera implícitos en las escalas de las dos primeras, correspondieran menores errores de predicción (positivos o negativos), en la medida en que el modelo de distancias representa la hipó-

T. P., 57, n. ${ }^{\circ} 1,2000$ 

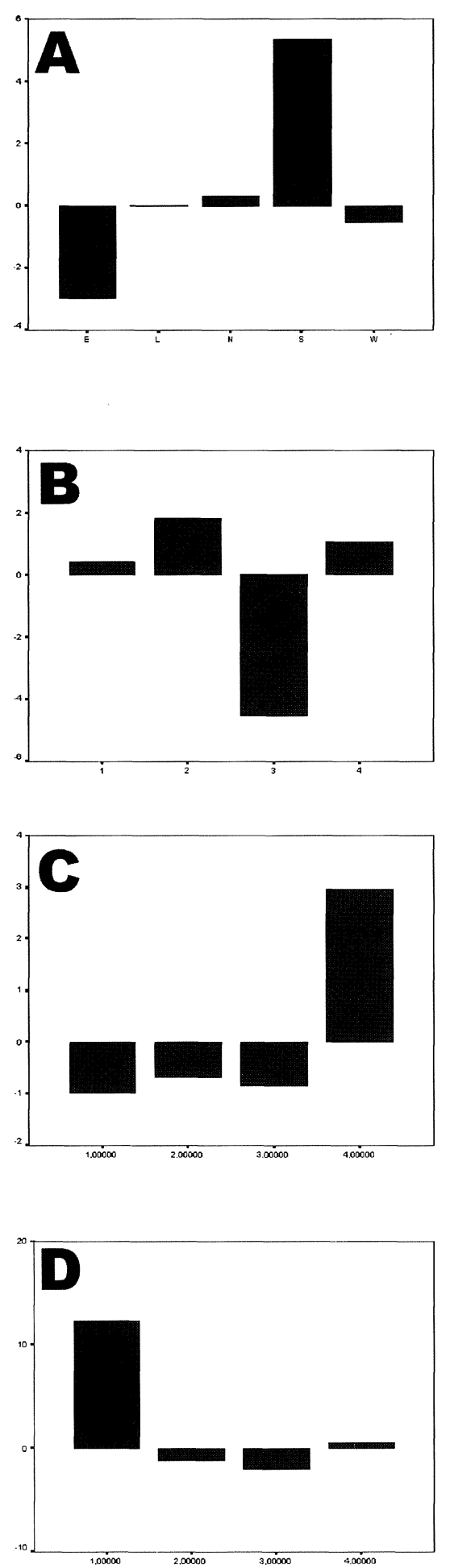

Fig. 13. Residuos del modelo de distancias explicados por las variables: A. OR4 (Orientación de la pendiente); B. CULTIV (cobertura de los terrenos cultivados); C.ANTRO (grado de antropización); D. Humedad (edáfica en el punto de muestreo). tesis más plausible en condiciones "naturales". Esto se cumple con la variable ANTROP, pero no con la de CULTIVOS cuyas mayores anomalías están en la categoría 3 (cobertura media: entre 50 y $25 \%$ ). Esto sugiere una posible hipótesis alternativa: el efecto de este factor puede deberse a la concomitancia entre la localización predominante de las formaciones con abedul y los tipos de contextos que denota CULTIVOS. Así, las UM con cobertura media de terreno cultivado tienen muchas posibilidades de albergar pequeñas formaciones arbóreas preservadas como lindes o cortavientos en los caminos de labor. De hecho, la distribución de las distancias covaría significativamente con la escala de cobertura de cultivos $(\mathrm{F}=3.46$; prob. $=0.022)$, siendo la media para la categoría $3(398.77 \mathrm{~m})$ apreciablemente inferior a la total $(630 \mathrm{~m})$.

La variable HUMEDAD $(\mathrm{F}=4.940 ; \mathrm{gl}=3$; prob $=; \mathrm{R}^{2}$ ajustado $\left.=0.158\right)$ cumple los patrones esperables: lás anomalías (positivas) se concentran en la categoría 1 (máxima humedad edáfica), asociada con las propias áreas boscosas y terrenos inmediatos. Así, la distancia media a formaciones con abedul es inferior a $10 \mathrm{~m}$ para el grupo de casos definido por este valor, y aumenta linealmente a medida que disminuye el grado de humedad edáfica. De nuevo, esta variable recoge un efecto locacional más que un fenómeno asociado a un filtro tafonómico. El gráfico advierte, no obstante, que la varianza del modelo es casi totalmente explicada por el contraste entre la categoría 1 (máxima humedad edáfica) y el resto, al igual que ocurría en ANTROP con la oposición entre el valor 4 y los restantes. En ambos casos el fenómeno reflejado por el efecto de los factores sobre los residuos es el mismo: el contraste entre las áreas boscosas y el resto del territorio. Esto indica la necesidad de algunos replanteamientos en el análisis posterior.

Para terminar, la variable GANAD $(\mathrm{F}=6.104$; $\mathrm{gl}=3 ; \mathrm{prob}=0.001 ; \mathrm{R}^{2}$ ajustado $=0.227 ;$ Fig. 14$)$, es la que más varianza retiene por si sola. El significado de la distribución de los errores del modelo de distancias no sugiere en esta ocasión explicaciones tan claras. El promedio de errores es significativamente mayor en la categoría 2, sin que esto pueda explicarse como covarianza con el propio modelo de distancias. Es necesario investigar el posible patrón espacial generado por este factor, o sus interacciones con otras variables del modelo.

Con este fin, el análisis separado de las variables contextuales debe completarse con la elaboración de modelos más complejos. Las proporciones de 


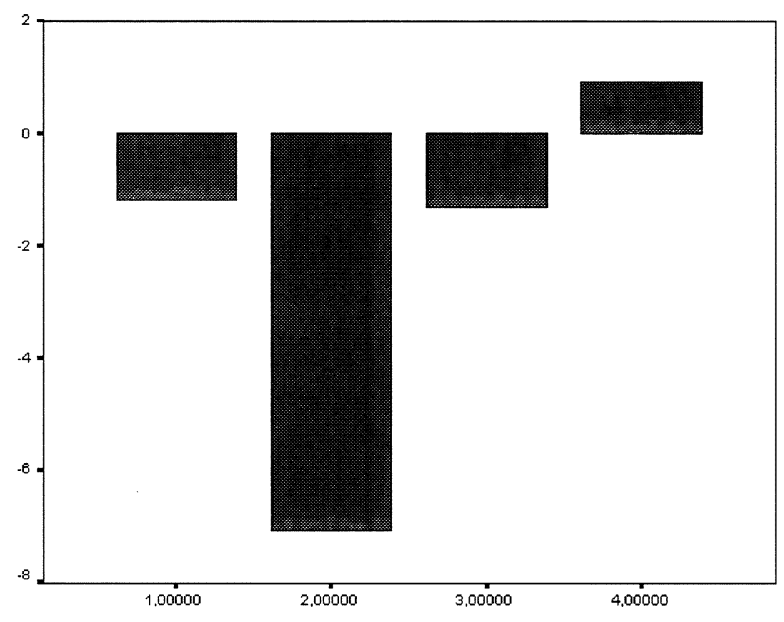

Fig. 14. Residuos del modelo de distancias explicados por la variable GANAD (incidencia de prácticas ganaderas).

varianza explicadas por los factores que hemos visto son pequeñas, pero significativas. En todos los casos, los resultados denotan una significativa dependencia de factores locacionales en la representación de Betula en el registro polínico. En varios, estos patrones de dependencia puede explicarse adecuadamente con hipótesis sencillas, lo que no ocurre en otros (por ejemplo GANAD).

El siguiente paso en el análisis exploratorio es evaluar las interacciones de esas variables entre si. Eventualmente, estas interacciones pueden definir patrones relevantes de variabilidad, o aclarar los problemas que afloran en la etapa anterior de análisis. Para ello podemos construir modelos multifactoriales de análisis de la varianza, tratando de combinar varias variables en un solo modelo. Ante la imposibilidad de desarrollar toda esta fase citaremos un solo ejemplo.
La tabla 1 muestra un modelo construido a partir de los residuos del modelo de distancias y cuatro factores explicativos. Tres de ellos son ordinales (CULTIVO, HUMEDAD e incidencia de prácticas ganaderas GANAD). Se ha añadido como covariante del modelo la altitud (Z_MDT), una variable continua. Sorprendentemente el ajuste del modelo es extraordinariamente bueno: da cuenta de casi un $86 \%$ de la varianza de los residuos. El examen de dicha tabla permite ver cómo las proporciones de varianza explicada por los factores principales (expresadas en los valores de la columna "suma de cuadrados") son proporcionales a las que hemos aislado en el análisis individualizado, mientras que las interacciones de segundo y tercer orden sólo son significativas en el caso de HUMEDAD por CULTIVOS. Aquí estamos ante un patrón espacial complejo, que debe ser investigado. El elevado ajuste de este modelo denota que las variables que figuran en él contienen información relevante sobre la variabilidad de la distribución de Betula en el registro polínico. Recapitulando, sabemos que esta distribución varía en función de la distancia a la fuente emisora de polen, pero que esta variación es distinta en función de la distribución zonal de la cobertura boscosa (ZONA) y la altitud (Z_MDT), del grado de alteración de la UM en la que está situado cada punto (CULTIVOS) y de su entorno inmediato (ANTROP, GANAD), así como de la distribución de la humedad edáfica en relación con las características de la UM (interacción CULTIVOS x HUMEDAD). Parte de estos efectos pueden interpretarse como consecuencias de la redundancia entre las distintas variables, extremo que debe ser aclarado por el posterior análisis confirmatorio. Pero, de ser correcta esta apreciación, esto no hace sino reforzar la hipótesis

\begin{tabular}{|c|c|c|c|c|c|}
\hline Fuente & \begin{tabular}{|c|}
$\begin{array}{c}\text { Suma de cuadrados } \\
\text { tipo III }\end{array}$ \\
\end{tabular} & gl & Media cuadrática & $\mathbf{F}$ & Sig \\
\hline $\begin{array}{l}\text { Modelo corregido } \\
\text { Intersección } \\
\text { Z_MDT } \\
\text { RCULTIV } \\
\text { RGANAD } \\
\text { RHUMED } \\
\text { RCULTIV } * \text { RGANAD } \\
\text { RCULTIV } * \text { RHUMED } \\
\text { RCULTIV } * \text { RHUMED } \\
\text { RCULTIV * RGANAD } * \\
\quad \text { RHUMED } \\
\text { Error } \\
\text { Total } \\
\text { Total corregido }\end{array}$ & $\begin{array}{r}951.078^{\mathrm{a}} \\
8.499 \\
19.347 \\
164.018 \\
305.657 \\
26.305 \\
11.233 \\
55.458 \\
12.612 \\
\\
.179 \\
66.682 \\
1047.083 \\
1017.760\end{array}$ & $\begin{array}{r}28 \\
1 \\
1 \\
3 \\
3 \\
3 \\
5 \\
5 \\
3 \\
\\
1 \\
24 \\
53 \\
52\end{array}$ & $\begin{array}{r}33.967 \\
8.499 \\
19.347 \\
54.673 \\
101.886 \\
8.768 \\
2.247 \\
11.092 \\
4.204 \\
\\
.179 \\
2.778\end{array}$ & $\begin{array}{r}12.225 \\
3.059 \\
6.963 \\
19.678 \\
36.670 \\
3.156 \\
.809 \\
3.992 \\
1.513 \\
.065\end{array}$ & $\begin{array}{l}.000 \\
.093 \\
.014 \\
.000 \\
.000 \\
.043 \\
.555 \\
.009 \\
.237 \\
.802\end{array}$ \\
\hline
\end{tabular}

${ }^{a} \mathrm{R}$ cuadrado $=.934$ ( $\mathrm{R}$ cuadrado corregido $=.858$ ).

Tab. 1. Tabla de ANOVA de residuos tipificados del modelo de distancias.

T. P., 57, n. $^{\circ} 1,2000$ 
básica del análisis, según la cual el principal factor explicativo de la variabilidad de Betula en el registro polínico es la proximidad a las áreas de implantación de esta especie.

Sin un análisis confirmatorio no estamos aún en condiciones de abordar la discusión de los datos paleopalinológicos. Pero en cualquier caso, estos resultados preliminares invalidan la hipótesis de que la comparación directa de las tendencias centrales en la dispersión de Betula en la actualidad y en las muestras de la Edad del Bronce pueda usarse como criterio estimativo de las transformaciones en el tiempo de la cobertura arbórea de Kargaly. Debemos, por el contrario, considerar en esta comparación otros aspectos contextuales que han sido puestos de manifiesto por el análisis.

\subsection{Reflexiones finales}

Era nuestro propósito presentar los aspectos metodológicos de una investigación aún en curso, más que sus resultados. En este sentido, el ejemplo discutido en la sección anterior se refiere más a la viabilidad y coherencia del enfoque propuesto que a los problemas específicos de interpretación que plantea el registro polínico de Betula.

El análisis de algunas variables del modelo experimental a partir de una hipótesis sencilla (modelo de distancias) ha puesto de manifiesto algunos patrones de regularidad espacial en la variabilidad del registro polínico, en relación con aspectos de la morfología del paisaje. Siempre se trata de indicaciones que deben ser investigadas más profundamente a partir del diseño de experimentos confirmatorios. Pero lo que importa ahora es subrayar la adecuación del enfoque metodológico al tipo de problemas planteados. Por una parte, las técnicas de modelización del paisaje aplicadas permiten representar con un grado suficiente de precisión los rasgos del mismo relevantes desde el punto de vista del modelo teórico. Por otra, la aplicación de un'enfoque estadístico combinado con técnicas SIG (es decir, la combinación de modelos matemáticos y cartográficos) ha demostrado su virtualidad en la formulación de hipótesis contrastables que pueden dirigir la investigación, complementando los enfoques convencionales de investigación paleoambiental.

Los elementos del diseño de investigación, tomados en conjunto o aisladamente, son susceptibles de adaptación a diferentes contextos de investiga- ción. Por ello, el experimento realizado dentro del proyecto Kargaly es una propuesta generalizable que permite materializar una demanda permanente de los arqueobotánicos a los arqueólogos: la necesidad de contextualizar el registro paleoambiental con estudios sistemáticos del paisaje actual.

En realidad todo el diseño del proyecto Kargaly desarrolla enfoques propios de la palinología arqueológica que, como se ha dicho, quedan excluidos de la práctica normal por las dificultades materiales y por la falta de comunicación entre arqueólogos y botánicos. Proponemos un posible marco de integración entre los objetivos arqueológicos y los enfoques específicamente arqueobotánicos que, al mismo tiempo, contiene elementos de una crítica constructiva a las limitaciones del enfoque tradicional de la colaboración entre arqueólogos y botánicos. También aflora algunos problemas básicos de la estadística de datos palinológicos como la modelización paramétrica de los datos polínicos, o las limitaciones de los métodos convencionales de muestreo y recuento.

El diseño de investigación pretende articular estas demandas de rigor palinológico con el marco de intereses más amplio de los objetivos, métodos y planteamientos teóricos de la Arqueología del Paisaje. Los problemas interpretativos demandados por el registro arqueológico de Kargaly sólo pueden ser resueltos en el contexto de una consideración global del paisaje como instancia determinante de los procesos históricos y determinada al mismo tiempo por ellos. Esta concepción exige la extensión de la noción de registro arqueológico a la totalidad del espacio regional y, en consecuencia, todo un diseño teórico y metodológico en el que técnicas adecuadas de investigación queden integradas en el marco de la argumentación arqueológica. El paisaje, a escala regional, no puede ser "excavado", pero si "modelizado", de forma que la construcción del registro arqueogeográfico esté dirigida por una comprensión global del mismo. La experiencia de Kargaly muestra cómo varias técnicas de modelización del paisaje, particularmente la Teledetección espacial, pueden convertirse en herramientas eficientes para la Arqueología.

Al mismo tiempo, los ejemplos desarrollados expresan los problemas de esta empresa de modelización del paisaje. Algunos, como la escasa resolución de las variables contextuales, que se traduce en redundancias o ambigüedades, proceden de las propias limitaciones en el contexto fáctico de la 
investigación. El proyecto Kargaly se ha desarrollado en condiciones extremadamente difíciles, especialmente desde el punto de vista logístico, lo que ha limitado la posibilidad de generar datos contextuales de alta resolución. Pensamos, por ejemplo, en la producción de datos analíticos complementarios que permitan analizar con mayor precisión los filtros tafonómicos que intervienen en la formación del registro. No obstante, como demuestra el ejemplo de Betula, incluso con variables de baja resolución es posible observar regularidades que pueden marcar nuevas vías de investigación.

El desarrollo posterior de la investigación debe completar esta propuesta metodológica y respaldarla en sus propios resultados. El modelo factorial del paisaje está aún en construcción: falta por culminar la compleja elaboración de una clasificación general de las cubiertas vegetales a partir de las variables radiométricas y las observaciones de la verdad terreno. La elaboración de esta clasificación, de la que el "mapa forestal de Kargaly" es sólo una parte, permitirá abordar la modelización estadística del amplio conjunto de palinomorfos identificados, y su análisis cruzado con el resto de las variables del modelo.

Finalmente un elemento generalizable del diseño de la investigación es su propio planteamiento y algunos de los rasgos característicos de su realización material. Primero subrayamos el papel básico del diseño teórico, que permite articular los diseños metodológicos e identificar y jerarquizar los objetivos empíricos. Segundo, es importante el papel desempeñado por la opción por una metodología experimental, es decir, la articulación de toda la investigación como un proceso de formulación y contrastación de hipótesis. Esta opción se articula a partir de la adopción de una metodología estadística que concibe la investigación, en su etapa observacional, como la construcción de un modelo matemático del problema de referencia. Por último, destacamos como se articula el diseño experimental con la observación sobre el terreno: al disponer de un modelo de datos estadísticamente coherente, los procesos de observación pueden sistematizarse y objetivarse al máximo.

En resumen, consideramos que, al margen de los problemas específicos de la investigación, el proyecto Kargaly ofrece elementos valiosos para afrontar el diseño de investigaciones a escala regional, integrando técnicas avanzadas de modelización del paisaje con objetivos y métodos arqueológicos y arqueobotánicos convencionales.

\section{AGRADECIMIENTOS}

Al Dr. E.N. Chernyj y los miembros de su equipo sin cuyo apoyo científico y personal esta investigación no habría sido posible. Gracias a Tamara $\mathrm{O}$. Teneishvili sentimos que todos hablábamos la misma lengua. Su ayuda ha ido siempre mucho mas allá de lo imaginable en lo profesional y lo personal. Sus traducciones han agilizado y animado nuestras reuniones y nos han permitido manejar información esencial para la investigación. En la traducción de los textos han participado también la Dra.V. Kozloskaya, M. Sánchez-Nieves, M. Cruz Berrocal y A. Jepure. El Dr. A.Gilman (Dept. of Anthropology, CSUN), además, tradujo al inglés los textos de este artículo y nos hizo comentarios muy pertinentes sobre su borrador sin que le quepa ninguna responsabilidad en el resultado final. La figura 1 modifica originales realizados por J. Sanchez García (cft. nota 5). En el trabajo de campo recordamos la colaboración de S. Bikov, D. Valkov y A. Karpujin. La dirección del Instituto de Arqueología de Moscú (Dr. R.M. Munchaev, G.E. Afanasiev y V.I. Guliaev) y la Subdirección de Relaciones Internacionales del CSIC (D. ${ }^{a}$ P. Goya y D. ${ }^{a}$ M. SánchezAyuso) sostuvieron en todo momento la política de intercambio científico entre nuestros dos países en momentos difíciles para laAcademia Rusa de Ciencias. En la preparación de la campaña de 1998 contamos, además, con la cooperación de la Subdirección de Relaciones Científicas Internacionales del Ministerio de Asuntos Exteriores y, en especial, de D. A. Spiegelberg. Agradecemos a R. Vidal Calero y E. López-Romero su ayuda en la estructuración de la base de datos. El Dr. F. Alonso Mathias gestionó varias dataciones en el Laboratorio de Geocronología del Instituto de Química Física Rocasolano, CSIC, Madrid y el Dr. Ph. Kohl (Dept. of Anthropology, Wellesley College, Massachussets) nos puso en contacto con el Laboratorio Austin Long (Dept. of Geosciences, University of Arizona, Tucson). Los Drs. V. Puchkov (Ufimian Scientific Center, Bashkiria, Rusia) y A. Pérez Estaún (Dpto. de Geofísica, Institut de Ciències de la Terra 'Jaume Almera', CSIC, Barcelona), miembros del 'EUROPROBE'S URALIDES Project' (ESF), nos ayudaron a comprender la geología de Kargaly y a obtener la inaccesible cartografía rusa. En esta última tarea la colaboración del Dr. Kohl fue también esencial. A los geólogos A.V. Nikiforov y G. Nikiforova y a la botánica A.Vasilievna debemos útiles orientaciones en el trabajo de campo y a 
C. Puch (Laboratorio de Teledetección INTA, Madrid) en la selección y adquisición de la imagen de satélite. El Exmo. y Mgfco. Rector de la Universidad Politécnica de Madrid, D. S. de la Plaza Pérez, autorizó la participación de I. de Zavala Morencos en el proyecto. E. Moreno García resolvió nuestro problema de alimentación de los aparatos electrónicos y de iluminación en el campo mediante un dispositivo de paneles solares de su invención.

\section{BIBLIOGRAFÍA}

AnTIPINA, Ye.Ye.(1999): “Kostnyie ostatki zhivotnyj s poselenia Gorny (biologuicheskie i arjeologuischeskie aspekty issledovania)". Rossiskaia Arjeologuiia, 1: 103-116.

BIRKS, H.J.B. (1987): "Multivariate analysis in geology and geochemistry: an introduction". Chemometrics and Intelligent Laboratory Systems, 2: 15-28.

BIRKs, H.J.B. y BIRKs, H.H. (1980): Quaternary Palaeoecology. Edward Arnold. London.

BIRKs, H.J.B. y GoRdon, A.D. (1985): Numerical Methods in Quaternary Pollen Analysis. Academic Press. London.

Cardelús, B. (1988): Páramos y estepas. Debate/Círculo. Barcelona.

Černych, E.N.; Antipina, E.E. y Lebedeva, E.Ju. (1998): "Produktionsformen der Urgesellschaft in den Steppen Osteuropas (Ackerbau, Viehzucht, Erzgewinnung und Verhüttung)". En Das Karptenbecken und die Osteuropäische Steppe. Nomadenbewegungen und Kulturaustausch in den vorchristlichen Metallzeiten (4000-500 v. Chr.). Herausgegeben von Bernhard Hänsel und Jan Machnik. München. Rahden/Westf.: 233-252.

Chapa, T.; Vicent, J.M.; Rodríguez, A.L. y Uriarte, A. (1998): "Métodos y técnicas para un enfoque regional integrado en arqueología: el proyecto sobre el poblamiento ibérico en el área del Guadiana Menor (Jaen)". Arqueología Espacial, 19-20: 105-120.

Chernit, E.N.; Avilova, L.I.; Bartseva, T.B.; Orlovskaia, L.B. y TeneISHVILI, T. (1990): "El Sistema de la Provincia Metalúrgica Circumpóntica”. Trabajos de Prehistoria, 47 : 63-101

CHERNYKH, E.N. (1992): Ancient metallurgy in the USSR. The Early Metal Age. Cambridge University Press. Cambridge.

- (1994): "L'ancienne production minière et métallurgique et les catastrophes écologiques anthropogènes: introduction au problème". Trabajos de Prehistoria, 51 (2): 55-68.

- (1996): "The Down of Mining and Metallurgy in Eastern Europe: the New Discoveries". En B. Bagolini y F. Lo Schiavo (eds.): XIII International Congress of Prehistoric and Protohistoric Sciences (Forli, Italia, 8-14
September 1996). Colloquia 10, The CopperAge in the Near East and Europe. Colloquium XIX: Metallurgy: Origins and Technology: 85-93. ABACO. Forlì.

ChernyJ, Ye.N. (1997): Kargaly. Zabity mir. Nox. Moskva.

Cherny, Ye.N.; Avilova, L.I.y OrlovsKaiA, L.B. (2000): Metallurgical Provinces and Radiocarbon Chronology. Rossiiskaia Akademiia Nauk. Institut Arjeologii. Moskva

Chernyu, Ye.N.; KuZminyu, S.V.; Lebedeva, Ye.Yu.; Agapov, S.; LunKov, V.Yu.; OrLovSKaIA, L.B.; TeneISHVILI, T. y VALKOV, D.V. (1999): “Arjeologuicheskie pamiatniki Epoji Bronzy na Kargaly (poselenie Gorny i druguie". Rossiskaia Arjeologuiia, 1: 77-101.

Chibilyov, A.A. (1966): Prirodnoie naslediie Orenburgskoi oblasti. Orenburgskoie knizhnoie izdatelctvo. Orenburg.

Cochran, W.G. (1978): Técnicas de muestreo. C.E.C.S.A. México.

D'Antoni, H. y Spanner, M.A. (1993): "Remote sensing and modern pollen dispersal in Southern Patagonia and Tierra del ' Fuego (Argentina): Models for Palaeoecology".Grana (32): 29-39.

Díaz Álvarez, J.R. (1984): Geografía y agricultura. Componentes de los espacios agrarios. Cincel. Madrid.

Gaillard, M.J.; Birks, H.J.B.; Emanuelsson, U. y BerGLUND, B.E. (1992): "Modern pollen/land-use relationships as an aid in the reconstruction of past land-uses and cultural landscapes: an example from south Sweden". Vegetation History and Archaebotany, 1: 3-17.

Gaillard, M.J.; Birks, H.J.B.; EMAnUelsson, U.; KarlsSon, S.; Lageras, P. y Olausson, D. (1994): “Application of modern pollen/land-use relationships to the interpretation of pollen diagrams -reconstructions of land-use history in south Sweden, 3000-0 BP". Review of Palaeobotany and Palynology, 82: 47-73.

HICKS, S. y BIRKS, H.J.B. (1996): "Numerical analysis of modern and fossil pollen spectra as a tool for elucidating the nature of fine-scale human activities in boreal areas". Vegetation History and Archaebotany, 5: 257 272.

JANSSEN, C.R. (1966): "Recent pollen spectra from the deciduous and coniferous-deciduous forests of northeastern Minnesota: a study in pollen dispersal". Ecology, 47: 804-825.

KaUth, R.J. y Thomas, G. (1976): “The tasselled cap: A graphical description of the spectral-temporal development of agricultural crops as seen by Landsat". Proceedings of the Symposium on Machine Processing of Remotely Sensed Data, (4B): 41-51.

López García, P.; Uzquiano, P.; López Sáez, A. y Gómez, C. (1996): "Primeros datos sobre la paleovegetación cuaternaria de la Gran Estepa Eurasiática (Los Urales, Rusia)". En B. Zapata (ed.): Estudios Palinológicos. Universidad deAlcalá de Henares.Alcalá de Henares: 75-8.

Martínez Navarrete, M. ${ }^{\text {II }}$. (coord.)(1993): Teoría y práctica de la Prehistoria: Perspectivas desde los Extremos 
de Europa/Theory and Practice of Prehistory: Views from the Edges of Europe. Universidad de Cantabria y CSIC. Santander.

Moore, P.D.; Webb, J.A. y Collinson, M.E. (1991): Pollen analysis. Blackwell Scientific Publications. Oxford.

Morales-MuñIz, A. y Antipina, E. (e.p.): "Srubnaya Faunas and Beyond: A critical Assesment of the Archaeozoological Information from the East European Steppe". En C. Renfrew y K. Boyle (eds.): Late Prehistoric Exploitation of the Eurasian Steppe. MacDonald Institute Monographs. Cambridge.

ORMEÑo, S. (1993): Teledetección fundamental. EUITT. UPM. Madrid.

PRESA, F. (coord.) (1997): Historia de las literaturas eslavas. Cátedra. Madrid.

Richardson, A.J. y Wiega, C.L. (1977): "Distinguishing Vegetation from Soil Background Information". Photogrammetric Engineering and Remote Sensing, (43): 1541-1552.
RoviRA LLORENS, S. (1999): “Una propuesta metodológica para el estudio de la metalurgia prehistórica: el caso de Gorny en la región de Kargaly (Orenburg, Rusia)". Trabajos de Prehistoria, 56(2): 85-113.

VICENT GARCía, J.M. (1991): "Fundamentos teórico-metodológicos para un programa de investigación arqueogeográfica". En P. López García (de.): El cambio cultural del IV al II milenios A.C. en la Comarca Noroeste de Murcia. CSIC. Madrid: 31-117.

- (1993a): "Departamento de Prehistoria del Centro de Estudios Históricos (CSIC)". En M. ${ }^{a}$ I. Martínez Navarrete (coord.): Teoría y práctica de la Prehistoria: Perspectivas desde los Extremos de Europa. Universidad de Cantabria y CSIC. Santander: 19-35.

- (1993b): "Recensión de E.N. Chernykh (1992)".Trabajos de Prehistoria, 50: 286-291.

VV.AA. (1994): 6 Coloquio Hispano-Ruso de Historia. Fundación Cultural Banesto. Madrid. 